\title{
Modeling Migration and Citizen-Science Data to Estimate Golden Eagle Abundance in Eastern North America
}

Andrew J. Dennhardt

West Virginia University

Follow this and additional works at: https://researchrepository.wvu.edu/etd

\section{Recommended Citation}

Dennhardt, Andrew J., "Modeling Migration and Citizen-Science Data to Estimate Golden Eagle Abundance in Eastern North America" (2014). Graduate Theses, Dissertations, and Problem Reports. 109. https://researchrepository.wvu.edu/etd/109

This Thesis is protected by copyright and/or related rights. It has been brought to you by the The Research Repository @ WVU with permission from the rights-holder(s). You are free to use this Thesis in any way that is permitted by the copyright and related rights legislation that applies to your use. For other uses you must obtain permission from the rights-holder(s) directly, unless additional rights are indicated by a Creative Commons license in the record and/ or on the work itself. This Thesis has been accepted for inclusion in WVU Graduate Theses, Dissertations, and Problem Reports collection by an authorized administrator of The Research Repository @ WVU. For more information, please contact researchrepository@mail.wvu.edu. 


\title{
Modeling Migration and Citizen-Science Data to Estimate Golden Eagle Abundance in Eastern North America
}

\author{
Andrew J. Dennhardt \\ Thesis submitted to the \\ Davis College of Agriculture, Natural Resources, and Design \\ at West Virginia University
}

in partial fulfillment of the requirements for the degree of

Master of Science in

Wildlife and Fisheries Resources

Todd E. Katzner, Ph.D., Chair

George T. Merovich, Jr., Ph.D.

Adam E. Duerr, Ph.D.

David C. Brandes, Ph.D.

Division of Forestry and Natural Resources

Morgantown, West Virginia

2014

KEYWORDS: Aquila chrysaetos, golden eagle, Hawk Migration Association of North America, mark-recapture, Pennsylvania, raptor migration model

Copyright 2014 Andrew J. Dennhardt 


\section{ABSTRACT \\ Modeling Migration and Citizen-Science Data to Estimate Golden Eagle Abundance in Eastern North America}

\section{Andrew J. Dennhardt}

Understanding animal movements is fundamental to ecology and conservation, yet direct measurement of movements of birds is both challenging and costly. Raptor populations are especially difficult to monitor, but movement models can provide information toward this goal. The golden eagle (Aquila chrysaetos canadensis) in eastern North America is a species of regional conservation concern, and little is known about its population ecology, movements, or behavior. Because of their rarity and role as apex predators, improving monitoring of this small population is of great importance. Similar to using movement models to help improve monitoring, developing new methods to estimate the size of wildlife populations is also important to ecology and conservation. In fact, building an understanding of population demography is often the primary goal of monitoring programs. However, the vagility of many organisms can have significant impacts on population-level monitoring by affecting survey methods and demographic estimates. Demographic analyses, which may require large amounts of data collected over time, are often expensive to collect and maintain. Citizen-science data often involve extensive effort but limited cash expenditures. In the case of hawk-counts in the USA, these data are both standardized and maintained by the Hawk Migration Association of North America. To date, hawk-count data have yet to be used to estimate species population size.

In my first chapter, I simulated autumn migration of golden eagles in Pennsylvania, USA based on regional topography, eagle flight behaviors, estimated uplift, and a principal axis of migration. In total, I modeled 6,094 flight routes, averaging $2,191( \pm 1,281 ; \pm \mathrm{SD}$; range: 3 $5,373)$ moves. I found that $71 \%$ of my simulations intersected the Ridge and Valley physiographic province of the central Appalachians. Simulations were spatially comparable to historic, flight route data collected via telemetry. In my model, orographic uplift was significantly stronger and more frequently occurring than thermal uplift (Welch's two-sample $t=$ $-560.13, \mathrm{df}=43,059,702, p<0.0001)$, and uplift values were not correlated with the number of simulated movements (orographic, Pearson's $r=-0.015$ and thermal, $r=0.003$ ). I used output from my simulations to select sites and collect field data in new areas concentrating golden eagles on migration. This not only preliminarily verified my modeled predictions, but it also allowed me to locate new, potential monitoring sites for migrant golden eagles. I also compared output from my migration model to that of another model, to evaluate the influence of topography, spatial relationships with hawk-count sites, and role of scale in modeling migration.

In my second chapter, I evaluated the utility of hawk-count data for population size estimation of golden eagles migrating in eastern North America. I used my computer model 
from the first chapter to simulate migratory flights of eagles to assess what proportion of the population is available to be counted at hawk-counts in Pennsylvania, USA. I then conducted a mark-recapture analysis to estimate mean detectability of migrating eagles and mean local abundance along an important migration corridor. Finally, I used estimates of availability and detectability to adjust data from hawk-count sites to derive regional estimates of population size. Mean $( \pm$ SD) availability of golden eagles to hawk-count sites was $0.240( \pm 0.140$; range: 0.040 $-0.440)$. I estimated mean detectability as 0.073 ( \pm 0.010 ; range: $0.048-0.109)$. Previous estimates of population size for golden eagles in eastern North America were $1000-5000$.

All of my population estimates far exceeded that of previous approximations. When using detection rates from recent literature, only then were my estimates $<5,000$ individuals. Using my estimates of availability and detectability, mean population size was more than five times larger than the maximum previous estimate. My smallest estimate was three times larger than the previous maximum estimate. Larger estimates were driven by the low availability and detectability of birds passing by hawk-counts. Overall, this work suggests that (a) detection estimates need to be improved, (b) the majority of migrating golden eagles in eastern North America are not counted at hawk-count sites, and (c) previous population estimates for this species are likely low-possibly, greatly so. This exercise demonstrates the utility of using citizen-science data in concert with movement models to address a pressing conservation goal: estimating population size for species of regional concern. My research contributes to current scientific knowledge through development of a novel, cost-effective method for modeling migration patterns and abundance of a rare, low-density raptor species. 


\section{DEDICATION}

This work is wholeheartedly dedicated to my father, mother, and brother. Growing up on a small farm in rural Illinois taught me the true meaning of passion, hard work, and determination. Every day, I saw my parents work diligently to take care of my brother and me, along with our 150+ year old family farm. Throughout childhood, our parents showed us what genuine landscape stewardship looks like. Because of Dad's passion for trees, my brother and I must have helped plant thousands of deciduous and coniferous species in the front yard and pasture. Thanks to Mom's love for gardening, we worked through the dirt and sweat in the summer months to grow our favorite fruits and vegetables. Come harvest time, we spent hours and hours, on weekends and even after school, hauling in the season's yield. Greatest of all, Dad taught us how to truly care for the land through rotating nutrient-rich and nutrient-needy crops, growing organic produce devoid of herbicides and pesticides, and selling our products (while simultaneously distributing honest family values) to the local community. From all of these experiences, I learned to value and cherish natural resources, especially the animals inhabiting our Midwestern ecosystem. Inspired, in the evenings after school, I would go find scientific books in our library, ones that would really pique my interest. In my early years, the majority would consist of paleontological history - every young boy's starting point, I think. As I entered primary school, the books that I chose began to involve recent ecology and natural history. It was here that my passion for raptor ecology was born. I reviewed account after account involving members of this unique avian group. These modern-day dinosaurs had my spirit locked in a captivating grip. Of all of the different kinds - eagles, hawks, harriers, falcons, and owls - one kind in particular had kept me especially fascinated. It was the golden eagle. Stories about the sheer size, beauty, power, and prowess of this eagle species had seized me for a long time, thereafter. After years of cultivating the determination and drive necessary, as a student in secondary school, I vowed to study these cunning eagles someday. Following my high school and undergraduate education, including memorable experiences researching peregrine falcons and barn owls in the Midwest and spotted owls in California, I looked eagerly for the perfectfitting Master's project. I found Dr. Todd Katzner at West Virginia University, an enthusiastic and successful researcher-but most importantly, a man dedicated to conservation research surrounding North America's golden eagles. Honestly, I was very fortunate to have found an advisor and friend in Todd Katzner. Despite offers to attend programs involving projects on other raptor species in different places, I knew exactly where I was called to go. It was to West Virginia University where I would get the chance to research golden eagles in eastern North America. For me, it was a dream realized to come here, and I am truly thankful to all who have made my tenure here exceptionally enjoyable, productive, and successful. Thank you to all of you who became my dearest friends, colleagues, and family away from home. In the end, I come back full-circle with a special thanks to my immediate family. Thank you, from the bottom of my heart, for supporting me throughout all of the many trials and uncertainties to reach this point in my career. As a first-generation college graduate, and with a humble heart, I look forward to keep paving the way for more friends, neighbors, and kin in the years to come. Dad, Mom, and Christian: This one is for you! 


\section{ACKNOWLEDGMENTS}

This thesis is written using the first plural pronoun "we" to recognize the individual, pertinent contributions of each coauthor. Research was conducted by A. Dennhardt, under the direction of T. Katzner. Graduate committee members D. Brandes, A. Duerr, and G. Merovich, Jr. provided advisement on the scientific methodology, content, writing, and Masters' examinations associated with the project. Sincerest gratitude goes to these gentlemen, first and foremost, for their leadership and guidance. Funding for this research was provided by the Hawk Migration Association of North America 2012 Research Award, Highlanders for Responsible Development, Inc., Virginia Society for Ornithology, and the Eastern Golden Eagle Working Group. Various hawk-count sites provided their data, which helped make this project a success. We sincerely thank the following individuals and organizations: B. Barnhurst and M. McIntosh (Eagle Crossing, Quebec, CAN), Bird Protection Quebec (Montreal, Quebec, CAN), the Ministere des Ressources naturelles et de la Faune, Gouvernement du Quebec (Quebec, CAN), and Cape May Observatory (New Jersey, USA). We also thank L. Goodrich at Hawk Mountain Sanctuary for her work in getting permissions from all of the hawk-count sites and the actual data to our research team for use. We thank K. Bildstein for his support of this work and for allowing our researchers to stay at the Acopian Center for Conservation Learning at Hawk Mountain Sanctuary during a busy field season, chock-full of hours traveled by automobile. We also give much gratitude to the many hawk-count sites in eastern North America recording migratory birds of prey, whose data we used in this research, especially all of the count sites in Pennsylvania, USA. We also thank the devoted observers at Allegheny Front Hawkwatch and Tussey Mountain who lent much of their golden eagle surveying expertise to our researchers. We also thank V. Maskey, S. Lamont, V. Talreja, G. Doretto, D. McLaughlin, M. Strager, and E. Iannello at West Virginia University whose tireless generosity in lending computer coding expertise and technological resources and support is sincerely appreciated. Without their kindness and guidance, this research could not have been completed successfully. We are thankful for generous assistance in the field from H. Clipp, N. Goodman, and L. Moon. We also thank the members of the Katzner Laboratory at West Virginia University: M. Wheeler, S. Behmke, C. Slover, J. Mallon, B. Drahota, C. Concepcion, M. Braham, T. Miller, J. Daniel, M. Paulson, and J. Hall whose valued suggestions for improving seminars, reports, and papers associated with this research is greatly respected and appreciated. 


\section{TABLE OF CONTENTS}

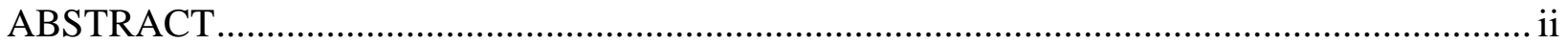

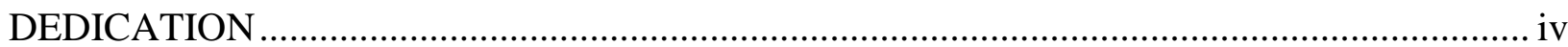

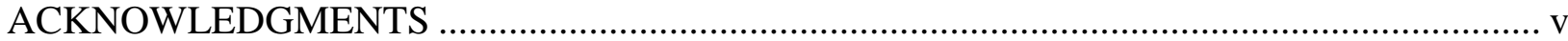

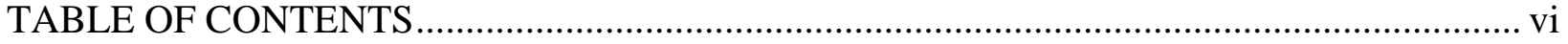

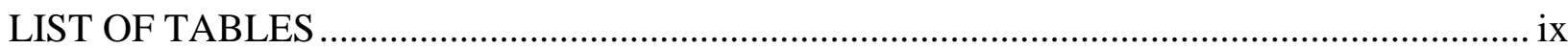

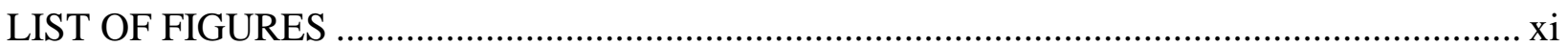

CHAPTER 1: MODELING AUTUMN MIGRATION IDENTIFIES NEW MOVEMENT CORRIDORS OF A RARE, SOARING RAPTOR IN CENTRAL APPALACHIA ................. 15

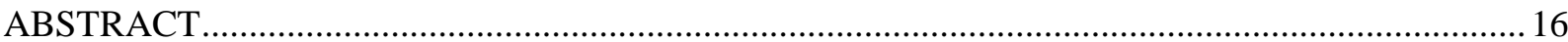

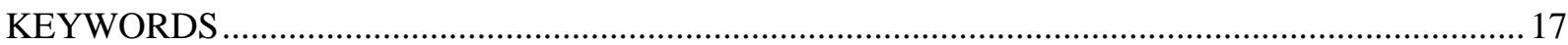

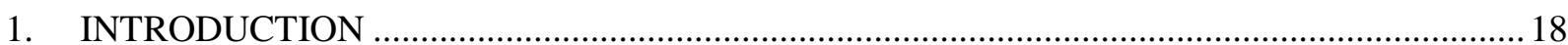

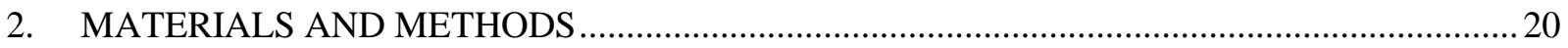

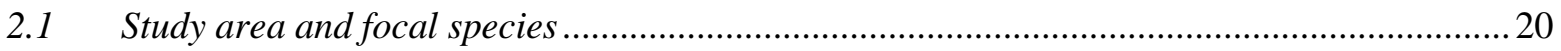

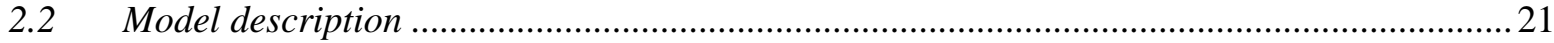

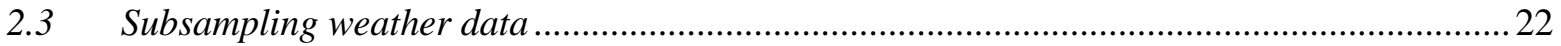

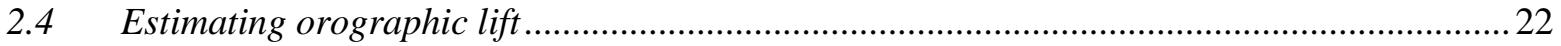

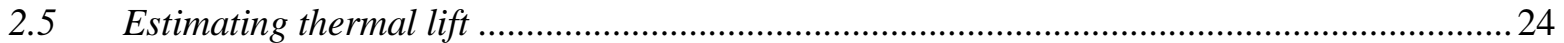

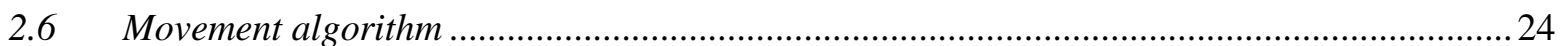

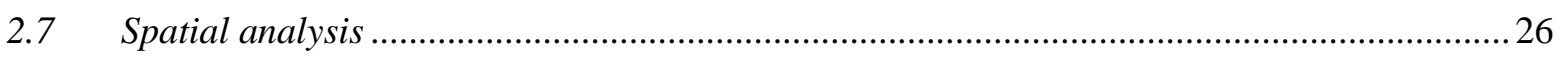

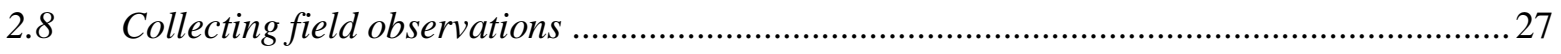

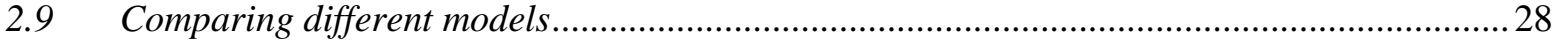

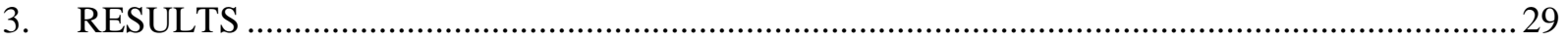

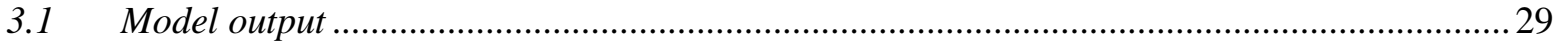

3.2 Spatial analysis: influences of topography and weather ...................................................29

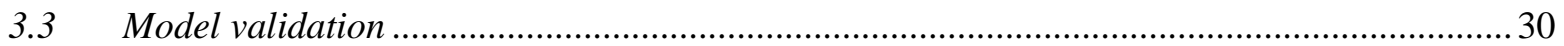

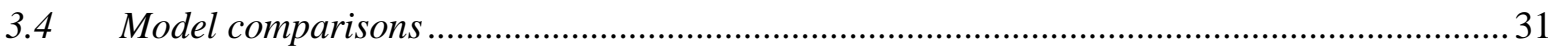

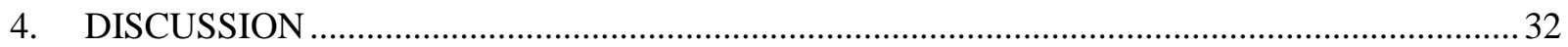

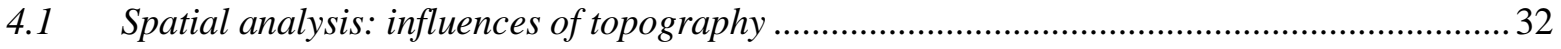


4.2 Spatial analysis: influences of weather .......................................................................... 32

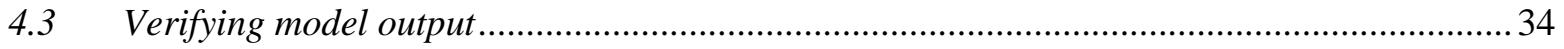

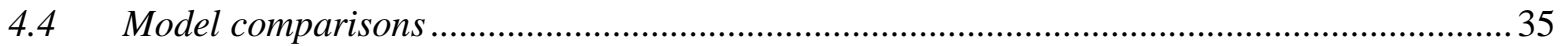

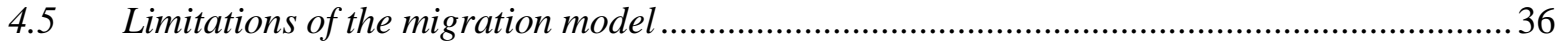

4.6 New opportunities for simulating migration with implications for continued monitoring ......37

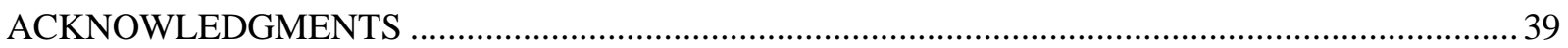

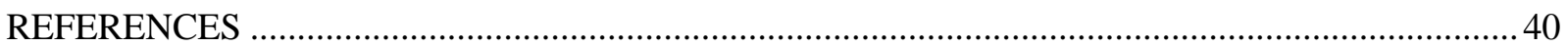

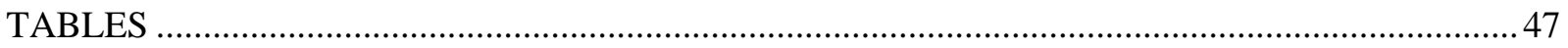

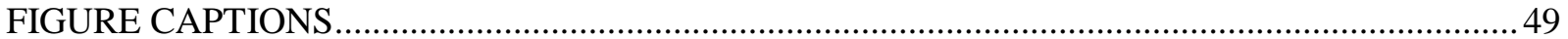

CHAPTER 2: MODELING POPULATION SIZE OF GOLDEN EAGLES WITH CITIZENSCIENCE DATA SUGGESTS THE IMPORTANCE OF MISSED INDIVIDUALS ............... 59

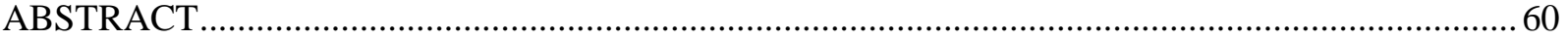

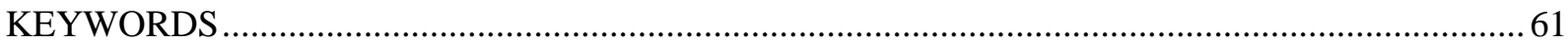

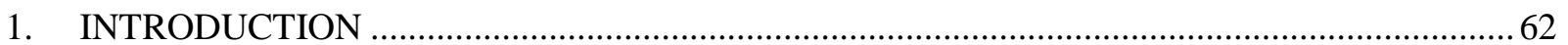

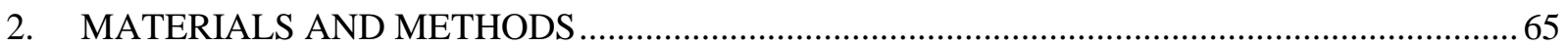

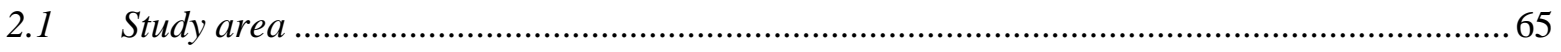

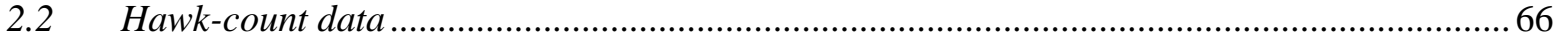

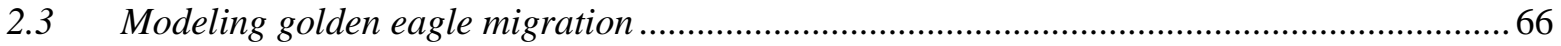

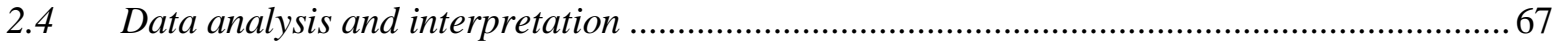

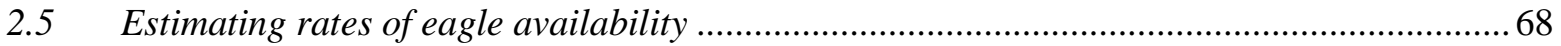

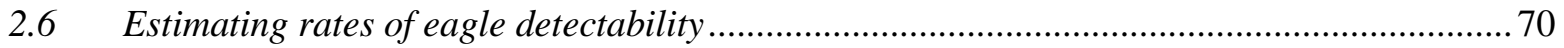

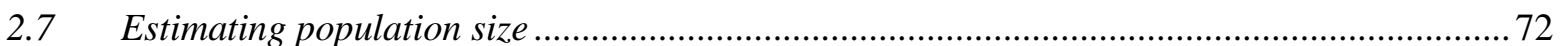

$2.8 \quad$ Estimating population size with detection rates from literature ........................................... 73

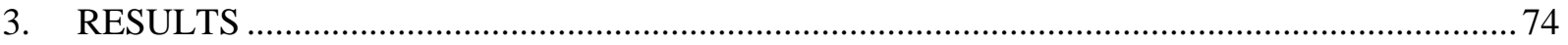

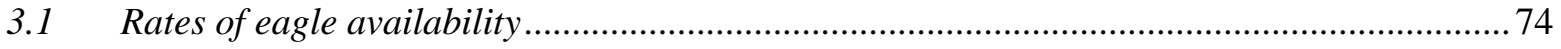

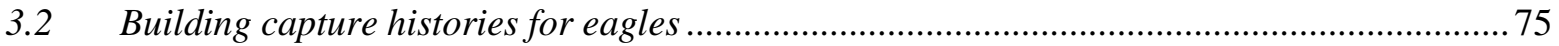

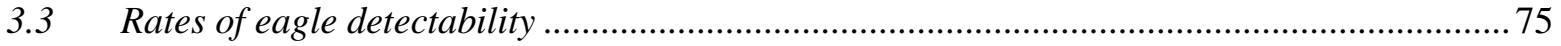

3.4 Number of eagles migrating through the Kittatinny Ridge System ......................................76

3.5 Number of eagles migrating through Pennsylvania ................................................................ 76

3.6 Number of eagles based on detection rates from literature ................................................ 77

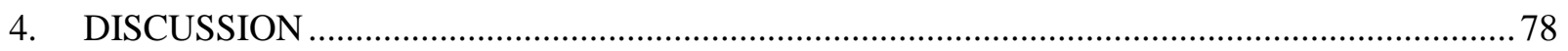

$4.1 \quad$ Evaluating estimates of population size ……....................................................................... 78 
4.2 Golden eagle conservation in eastern North America ...................................................... 80

4.3 A novel approach for estimating population size ................................................................ 81

4.4 Implications: Citizen-science data are useful in population size estimation ...........................83

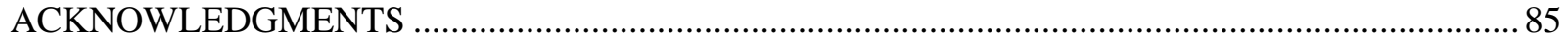

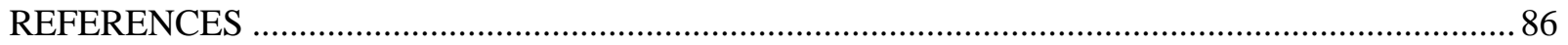

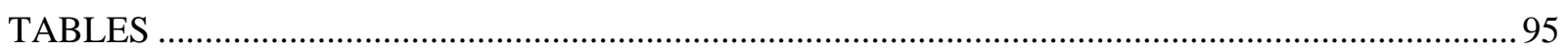

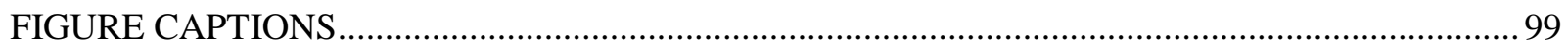

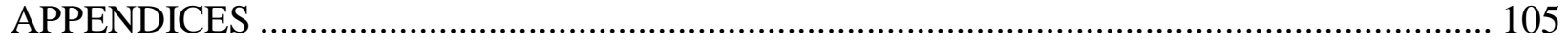

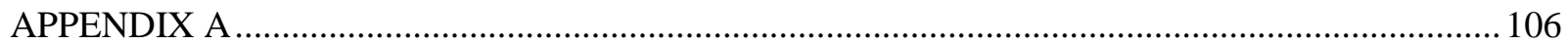

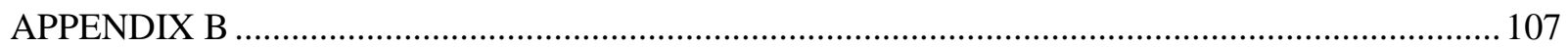

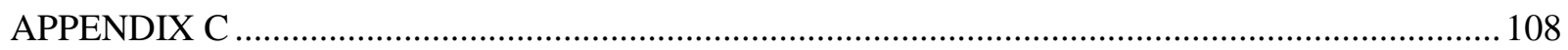




\section{LIST OF TABLES}

Table 1-1. Statistics of estimated uplift to the total number of simulated movements $(n=$ 25,481,796) of golden eagles in Pennsylvania, USA during November 2002-2011. Zero values represent those uplift values $\leq 0 \mathrm{~m} / \mathrm{s}$ and non-zero values represent those $>0 \mathrm{~m} / \mathrm{s}$.

Table 1-2. Proportions of total simulated flight routes $(n=6,094)$ intersecting physiographic provinces and the Kittatinny Ridge System in Pennsylvania, USA.

Table 2-1. Candidate model set, parameter descriptions, and biological interpretations of parameters in POPAN Jolly-Seber mark-recapture.

Table 2-2. Model summaries and ranks for different, POPAN Jolly-Seber model sets. The capture history type corresponds to both how we estimated time windows ("timing criterion," using ridgeline distance and mean flight speed for slope-soaring eagles; Duerr et al., 2012) and whether or not we included age class information ("aging criterion," from historic hawk-count data) to match individual eagles and construct unique capture histories. Parameters in POPAN Jolly-Seber are probability of apparent survival $(\Phi)$, system entry (pent), recapture $(p)$, and estimated superpopulation size $(N)$. We modeled the parameters either constant $($.$) or variable (\mathrm{t})$ with respect to hawk-count site. All candidate models included detection probability $(p)$ varying with site.

Table 2-3. Summary of the real estimates for detectability (mean \pm SE; 95\% CI) per candidate set (Table 2-2). When we exclude the aging criterion, mean detectability increases as the timing criterion increases.

Table 2-4. November estimates of population size (mean ( \pm SE); 95\% CI) per year based on the derived estimates of the top-ranked model in candidate set A and the model-averaged, derived 
estimates in candidate set B (Table 2-2), both with capture histories using the 1 SE timing criterion. 


\section{LIST OF FIGURES}

Figure 1-1. Study area and model system: the central Appalachian Mountain range in Pennsylvania, USA.

Figure 1-2. Conceptual model describing the general steps involved in modeling migration routes across the study area. Eagle movement steps occur in consecutive, $90 \mathrm{~m}$ increments corresponding to the spatial resolution of the NED ( $1 \mathrm{arc} \mathrm{sec})$. When uplift is good (>0 m/s) then the eagle chooses among five (x) grid-points, and moves one grid-point at a time (a). When uplift is bad $(0 \mathrm{~m} / \mathrm{s})$ then the eagle chooses among $36(\mathrm{y})$ grid-points (southwest of the current position), and moves to one grid-point in a group of points containing the highest average lift, compared among four different groups of grid-points (b). Lift is averaged over nine grid-points per group to compare average lift among the four groups. When an eagle reaches the southern boundary of the study area, its flight route completes, and a new flight route is constructed. The process repeats until all flight routes are built.

Figure 1-3. Variation in counts of golden eagles based on classes of migration days. We classified our NARR weather datasets $(n=33$ d) by natural breaks in hawk-count data collected on each type of day in the study area. We used November data from the following hawk-counts: Allegheny Front, Stone Mountain, Waggoner's Gap, Second Mountain, and Hawk Mountain Sanctuary (Hawk Migration Association of North America 2008). We used the three classes as a proxy for weather conditions on a given day.

Figure 1-4. a) Density of the complete sample of simulated flight routes $(n=6,094)$ for golden eagles in Pennsylvania, USA during November 2002-2011. This overall density is juxtaposed with subsets of simulations classified by high-, medium-, and low-migration count days as a 
proxy for weather conditions. b) Regional comparison with flight routes $(n=1,755)$ modeled on high-migration days. c) Regional comparison with flight routes $(n=1,329)$ modeled on medium-migration days. d) Regional comparison with flight routes $(n=3,010)$ modeled on lowmigration days. Size of hot-spot areas varied by migration day class with $5,203.18 \mathrm{~km}^{2}$, $5,386.98 \mathrm{~km}^{2}, 6,152.87 \mathrm{~km}^{2}$ for high-, medium-, and low-migration days, respectively.

Figure 1-5. Regional comparison of density fields between movement simulations of this work ( $n=25,481,796)$ and movement observations ( $n=16,348$ data points for 21 eagles) from telemetry work in Pennsylvania, USA (autumn 2006-2012; Miller 2012).

Figure 1-6. a) Regional comparison of hawk-count data on golden eagles collected on the same days and during similar hours of field data collection. b) Local comparison of the largest golden eagle recordings from our field data with counts conducted on the same days and during similar hours at the Allegheny Front Hawkwatch, near Central City, Pennsylvania, USA. Sites denoted with an * designates that they are a new, potential count site for future monitoring of golden eagles. Of these new sites, the Brush Mountain site (near Skelp Mountain Road) does not allow public access, while the other two areas do support public access.

Figure 1-7. Regional comparison of simulations constructed with different computer models that simulate golden eagle migration: our migration model $(n=90)$ and FlightPath v. $1.1(n=$ 90). We used the average conditions for the input weather dataset. Simulated eagles were started in the northeastern corners of each model's simulation area. Despite mechanistic differences between the two models, there are several areas in the Ridge and Valley physiographic province where simulated eagles' flights overlap and travel in close proximity. 
Simulations from our migration model occur in closer proximity to more hawk-count sites than do simulations from FlightPath.

Figure 2-1. a) Simulation modeling area: the central Appalachian Mountain range in Pennsylvania, USA. b) Mark-recapture modeling area: the Kittatinny Ridge System. Markrecapture sites $(\star)$, from northeast to southwest, are: Little Gap, Bake Oven Knob, Hawk Mountain Sanctuary, Second Mountain, and Waggoner's Gap.

Figure 2-2. Subset of simulated migration routes $(n=3)$ passing an existing hawk-count site to illustrate availability v. detectability. There are three types of eagles in relation to the mean sightability distance (within $3 \mathrm{~km}$ ) for hawk-count observers with respect to eagle availability: an eagle that is both available to be counted and is counted, an eagle that is both available to be counted yet not seen and uncounted, and an eagle that is both unavailable to be counted thus not seen and uncounted. There are two types of eagles in relation to the mean sightability distance for hawk-count observers with respect to eagle detectability: an eagle that is detected (both detectable and counted) and an eagle that is undetected (both detectable yet not seen and uncounted). Detectability does not let us account for eagles that are both undetectable and uncounted beyond the mean sightability distance, so we incorporate availability to do so into our estimation procedure. In this example, for this site, eagle availabilty equals $\sim 67 \%$ ( 2 / 3 available eagles), while eagle detectability equals $50 \%$ ( 1 / 2 detectable eagles).

Figure 2-3. Jolly-Seber (POPAN parameterization) mark-recapture model overlaid on select hawk-count sites in the Kittatinny Ridge System, where: pent $\mathrm{t}_{\mathrm{i}-1}$ is the probability of system entry (an influx of new eagles) before each site $(i), p_{\mathrm{i}}$ is the probability of recapture (detection) at each 
site, $\Phi_{\mathrm{i}}$ is the probability of apparent survival (eagle adherence to the ridgeline) over the interval between sites, and $N$ is the estimated total abundance over the entire study area.

Figure 2-4. Variation in ten-yr sets $(n=122)$ of estimated population size during November 2002-2011 in Pennsylvania. To estimate population size, we used November data from the following hawk-counts: Allegheny Front, Stone Mountain, Waggoner's Gap, Second Mountain, and Hawk Mountain Sanctuary (Hawk Migration Association of North America 2008). We modeled population size with numerous separate assumptions about eagle availability and detectability. Lowest estimates population size involved highest estimates of detectability and site-specific estimates of availability based on classes of high-, medium-, and low-migration days. Highest estimates of population size involved the lowest estimates of detectability and uniform estimates of availability. 


\section{CHAPTER 1}

\section{MODELING AUTUMN MIGRATION IDENTIFIES NEW MOVEMENT CORRIDORS}

OF A RARE, SOARING RAPTOR IN CENTRAL APPALACHIA 
Formatted for submission to Ecological Modelling

\title{
MODELING AUTUMN MIGRATION IDENTIFIES NEW MOVEMENT CORRIDORS OF A RARE, SOARING RAPTOR IN CENTRAL APPALACHIA
}

\author{
ANDREW J. DENNHARDT ${ }^{* 1}$ \\ TODD E. KATZNER ${ }^{12}$
}

ADAM E. DUERR ${ }^{1}$

DAVID C. BRANDES ${ }^{3}$

*Corresponding author; E-mail: ajdennhardt@gmail.com; Phone: 304-293-4412

${ }^{1}$ Division of Forestry and Natural Resources, West Virginia University, Morgantown, WV 26506, USA

${ }^{2}$ U.S. Department of Agriculture, Forest Service, Timber and Watershed Laboratory, Parsons, WV 26287, USA

${ }^{3}$ Department of Civil and Environmental Engineering, Lafayette College, Easton, PA 18042, USA

\begin{abstract}
Understanding animal movements is fundamental to ecology and conservation, yet direct measurement of movements of birds is both challenging and costly. Raptor populations are especially difficult to monitor, but movement models can provide information toward this goal.
\end{abstract}


The golden eagle (Aquila chrysaetos canadensis) in eastern North America is a species of regional conservation concern, and little is known about its population ecology, movements, or behavior. Because of their rarity and role as apex predators, improving monitoring of this small population is of great importance. We simulated autumn migration in Pennsylvania, USA based on regional topography, eagle flight behaviors, estimated uplift, and a principal axis of migration. In total, we modeled 6,094 flight routes, averaging $2,191( \pm 1,281 ; \pm \mathrm{SD} ;$ range: $3-$ $5,373)$ moves. Simulations were spatially comparable to historic, flight route data collected via telemetry. In our model, orographic uplift was stronger and more frequent than thermal uplift (Welch's two-sample $t=-560.13, \mathrm{df}=43,059,702, p<0.0001$ ), and uplift values were not correlated with the number of simulated movements (orographic, Pearson's $r=-0.015$ and thermal, $r=0.003$ ). We used output from our simulations to select sites and collect field data in new areas concentrating golden eagles on migration. This not only verified our modeled predictions, but it also allowed us to locate new, potential monitoring sites for migrant golden eagles. We also compared output from our migration model to that of an existing model that simulates raptor migration, to evaluate the influence of topography, spatial relationships with hawk-count sites, and role of scale in modeling migration. This work contributes to current scientific knowledge through development of a novel, cost-effective method for modeling migration patterns of a rare, low-density raptor species.

\section{KEYWORDS}

Aquila chrysaetos, golden eagle, Hawk Migration Association of North America, movement model, Pennsylvania, raptor migration 


\section{INTRODUCTION}

Movement ecology seeks to explain the intrinsic and extrinsic factors that influence movements and spatial distributions of animals (Nathan et al., 2008). Many bird populations worldwide are characterized, in part, by their migratory behavior (Mandel et al., 2008, Zalles and Bildstein, 2000). Migratory behaviors are often expansive in scale, and such behaviors can have real consequences on population biology. For example, for some species, most mortality occurs during migration (Newton, 2010, Sillett and Holmes, 2002). Consequently, this period is important for study and monitoring of species of conservation concern (Ainslie et al., 2013, Bildstein, 2006, Dunn and Hussell, 1995, Farmer et al., 2010, Sattler and Bart, 1984, Thorup et al., 2006).

Monitoring is difficult when focal populations are composed of secretive, low-density individuals. Birds are highly vagile and change their behaviors in breeding and non-breeding seasons; therefore, analyzing their movements can be challenging. These challenges are compounded when individuals are sensitive to human activity and when conservation efforts are inhibited by logistics and finances (Zalles and Bildstein, 2000). Among birds, raptors present some of the most significant monitoring challenges. Birds of prey are not highly vocal, and they are also elusive, generally staying out of sight of humans. Monitoring their populations can be important to effective conservation management because birds of prey are apex predators that are often indicative of ecosystem health (Bildstein, 2001, Rodríguez-Estrella et al., 1998, Sergio et al., 2005, 2006, 2008).

During migration, raptors are monitored at hawk-count sites, often where the landscape concentrates their flights (Geyer von Schweppenburg, 1963, Kerlinger, 1989, Zalles and Bildstein, 2000). Concentration points allow for more efficient data collection, and in some 
circumstances, hawk-count data can provide demographic estimates for ecological and management applications. For example, hawk-counts are used to estimate trends in raptor populations and to make inference about demographic parameters such as population size (Hawk Migration Association of North America, 2004, Hull et al., 2010, Lewis and Gould, 2000). Because hawk-count data are so readily available, using them in concert with movement models may lead to important insights into where individuals migrate and how populations might best be monitored in time and space.

Golden eagles (Aquila chrysaetos canadensis) are rarely observed in eastern North America and little is known about their population ecology, movements, and behavior (Katzner et al., 2012a, Kochert and Steenhof, 2002). Eastern golden eagles breed in remote areas of northeastern provinces of Canada, and most migrate through the central Appalachian Mountains to overwinter in the eastern United States (Brodeur and Morneau, 1999, Brodeur et al., 1996, Millsap and Vana, 1984, Morneau et al., 1994). Despite reports of continental population declines (Hoffman and Smith, 2003, Smith et al., 2008), there are hints that the size of this eastern subpopulation may be increasing (Farmer and Smith, 2010, Farmer et al., 2008). However, the number of individuals in this population is unknown.

Although eastern golden eagles are rare and difficult to study on their remote breeding grounds, but they are counted in the hundreds at hawk-count sites throughout the Appalachian region. Therefore, hawk-count data may provide a foundation for insight toward conservation management of this species. The main objective of this study was to use simulation models to evaluate southbound golden eagle migration within central Appalachia and to relate spatial patterns in those movements to the locations of existing hawk-count sites. Previous models of golden eagle movements have focused on migration influenced by one form of uplift (Brandes 
and Ombalski, 2004). Due to recent evidence implicating a role for multiple flight modes, we designed our computer model with multiple forms of uplift to simulate eagle migration in the central Appalachians (Duerr et al., 2012, Lanzone et al., 2012). We then used this model to answer the following questions: 1) how does regional topography and weather influence eagle migration routes? and 2) are there gaps in the spatial distribution of hawk-count sites where migrant eagles are concentrating, which could support new hawk-count sites?

\section{MATERIALS AND METHODS}

\subsection{Study area and focal species}

Eastern golden eagles breed in multiple northeastern provinces of Canada (Kochert et al., 2002, Watson, 2010). Each autumn, this migratory population is funneled through the central Appalachian Mountains, and individuals frequently use orographic and thermal uplift in this area to subsidize their long-distance flights (Duerr et al., 2012). We focused our research on an area of the central Appalachians roughly defined by the state of Pennsylvania, USA (Figure 1-1). Topography in Pennsylvania is diverse and includes long-linear ridges, lowland valleys, forested highlands, and mountain foothills spread throughout multiple physiographic provinces (United States Forest Service, 2012). Local, autumn weather is temperate, windy, and overcast. Easterly and westerly winds are most prevalent, and both interact with the steep topography of mountain ridges to generate orographic uplift, which the eagles use in slope-soaring flight (Bohrer et al., 2012). On warmer days with little wind, downward solar radiation heats the land surface and produces thermal uplift, which the eagles use in thermal-soaring and gliding flight (Duerr et al., 2012). Eastern golden eagles move through central Appalachia in large numbers, with peak migration occurring in November (Katzner et al., 2012a, 2012b). 


\subsection{Model description}

We designed a computer model (hereafter, migration model), written in the Visual C\# 4.0 coding language (Microsoft Corporation, 2010), to simulate migratory movements of individual golden eagles in the study area. The majority of flight routes begin along the northern Pennsylvania border. We also simulated a proportion of flight routes on the northeastern boundary of the study area to gain insight into movements along the Kittatinny Ridge System, an important migration corridor in autumn. The proportion of simulated birds starting on the northeastern boundary matched the proportion of real birds counted on the Kittatinny to the total counted within Pennsylvania (Hawk Migration Association of North America, 2008).

The model selected starting positions along this northeastern boundary by drawing a random number from a uniform distribution. Along the northern border, the model randomly selected starting positions from a Gaussian distribution, defined by the easternmost and westernmost telemetry data ( $n=21$ tracked eagles; Miller, 2012). After a starting point was selected, the simulated eagle evaluates uplift in the five surrounding grid-points and selects a destination grid-point based on a random number draw, weighted by the uplift in that grid-point. This process is repeated until the simulated eagle reaches a border of the modeling region (south, east, or west; Figure 1-2).

We established the following rules of motion for the migration model:

1. Eagle movement decisions are based only on topography and weather (i.e., uplift), not on conspecifics, terrestrial habitat, or individual experience.

2. Eagles use slope-soaring and thermal-soaring and gliding while on migration.

3. Eagles migrate across the study area within a 24-hr time period.

4. Eagles do not stop to forage or roost (i.e., flights are continuous and uninterrupted). 
5. Weather conditions (e.g., wind speed, wind direction, thermal activity) shift on the hourly scale (i.e., per $100 \mathrm{~km}$ of modeled flight).

6. Eagle movements are governed by a combination of deterministic patterns (based on available uplift) and stochasticity.

7. The probability of migration for an eagle is equal for all weather days, regardless of the weather conditions.

\subsection{Subsampling weather data}

To create meteorological inputs for the model, we randomly selected 33 weather days from November 2002-2011. We obtained meteorological data from the North American Regional Reanalysis (NARR; Mesinger et al., 2006). We subsampled the weather data from 32 $\mathrm{km}^{2}$ resolution to the scale of a National Elevation Dataset (NED, $90 \mathrm{~m}^{2}$ resolution; United States Geological Survey, 2012) over the study area, using a spatial join of NARR grid-points to NED grid-points in ArcGIS 10 (ESRI Inc., Redlands, CA). On each of our randomly selected days, we chose 3 separate, 3-hr blocks of data (i.e., 1500, 1800, 2100 Greenwich Mean Time, equivalent to 1000, 1300, 1600 Eastern Standard Time) and pulled the following weather for that day: wind, heat flux, boundary layer, and air temperature conditions. Our complete sample comprised 495 weather files (i.e., $33 \mathrm{~d} \times 3 \mathrm{hr} \times 5$ variables), of which 15 (i.e., $1 \mathrm{~d} \times 3 \mathrm{hr} \times 5$ variables) were randomly selected as input for each model run.

\subsection{Estimating orographic lift}

Local topography deflects horizontal surface winds to generate orographic uplift that eagles use to subsidize flight. We estimated orographic uplift $\left(w_{o}\right)$ based on the following relationship of terrain slope and aspect (from the NED) to wind speed and direction (Bohrer et al., 2012, Brandes and Ombalski, 2004): 
$w_{o}=v C_{\alpha}$,

$C_{\alpha}=\operatorname{Sin}(\theta) \operatorname{Cos}(\alpha-\beta)$,

where $v$ is the horizontal wind speed at ground-level $(\mathrm{m} / \mathrm{s}), C_{\alpha}$ is an updraft coefficient with a constant angle of terrain slope, $\theta$ (degrees, level $=0$ ) per grid-point, and terrain aspect, $\beta$ (degrees, North $=0$ ), and horizontal wind direction at ground-level, $\alpha$ (degrees, North $=0) . \mathrm{We}$ did not consider orographic uplift on the leeward side of the terrain, and all negative values of $w_{0}$ were set to 0 (Bohrer et al., 2012, Brandes and Ombalski, 2004). We calculated terrain slope and aspect as follows (Zevenbergen and Thorne, 1987):

$\theta=\arctan \left[(d z / d x)^{2}+(d z / d y)^{2}\right]^{1 / 2}$,

$\beta=\arctan [(d z / d x) /(d z / d y)]$

where $d z / d x$ and $d z / d y$ are the eastward (x) and northward characteristics $(y)$ of the local terrain, respectively.

For every $90 \mathrm{~m}^{2}$ grid-point of the NED within the study area, we estimated a value of $w_{o}$ based on the input NARR wind conditions. We used the $U$-wind and $V$-wind data, measured at $30 \mathrm{~m}$ above the ground surface to identify wind speed and wind direction. We calculated all wind speeds and wind directions from the $U$ - and $V$-wind data as follows:

$v=\sqrt{U_{i}^{2}+V_{i}^{2}}$,

$\alpha=57.29578 \times \arctan 2\left(U_{i}+V_{i}\right)+180$,

where $v$ and $\alpha$ represent the wind speed and wind direction, respectively, $U_{i}$ and $V_{i}$ are the $U$ and $V$-wind components in radians at grid-point $i$, and 57.29578 is a conversion factor from radians to degrees. 


\subsection{Estimating thermal lift}

Downward solar radiation during the daytime heats the ground surface, which can produce strong heat flux for thermals that eagles use to subsidize flight (Bohrer et al., 2012). Values of thermal uplift velocity can be estimated by the convective velocity parameter, $w^{*}$ (Spaar and Bruderer, 2000, Stull, 1988):

$w^{*}=[g z(H / T)]^{1 / 3}$,

where $g$ is the acceleration due to gravity $\left(\mathrm{m} / \mathrm{s}^{2}\right), z$ is the flight altitude $(\mathrm{m}), H$ is the surface sensible heat flux $\left(\mathrm{W} / \mathrm{m}^{2}\right), T$ is the potential air temperature $(\mathrm{K})$, and $w^{*}$ represents the mean uplift velocity $(\mathrm{m} / \mathrm{s})$ at any height within the boundary layer. We set all negative values of $w^{*}$ to 0.

For each $90 \mathrm{~m}^{2}$ pixel of the NED a value of $w^{*}$ was estimated using the height of the planetary boundary layer (HPBL, corresponding to $z$ in 2.1 above), sensible heat flux (SHF, $H$ ), and potential air temperature (POTT, $T$ ) from the NARR data.

\subsection{Movement algorithm}

We modeled individual eagle movements as a response to the amount of uplift available at the grid-points into which they could move (Appendix A; van Loon et al., 2011). At every step in the model, each grid-point has a value of $w_{o}$ and $w^{*}$ whose sum is the total uplift available to a migrating eagle. We chose to simulate movements based on total uplift because high magnitudes of orographic and thermal uplift typically do not co-occur. This is because high winds that favor orographic lift tend to disintegrate thermals (Bohrer et al., 2012, Duerr et al., 2012, Shamoun-Baranes et al., 2010).

We modeled southbound, autumn migration for golden eagles in the study area. For stochasticity in the model, we placed grid-point movement probabilities (i.e., weighted by local 
uplift) around an eagle's current position, so that an eagle could select subsequent positions to move to in simulated flight routes. We weighted the grid-point probabilities to the southwest, and this is based on a southwesterly preferred axis of migration (PAM) because of the nature of regional topography (Brandes and Ombalski, 2004, Kerlinger, 1989). For example, most central Appalachian ridges bear southwest in direction (from an autumn migrant's perspective) in Pennsylvania. An eagle could only move west (W), east (E), southwest (SW), south (S), or southeast (SE) one grid-point at a time, based on each probability. These probabilities were set in the following way, based on cardinal directions from an eagle's position: $\mathrm{W}=0.225, \mathrm{E}=0.05$, $\mathrm{SW}=0.300, \mathrm{~S}=0.225, \mathrm{SE}=0.200$. At any time an eagle moved more than five grid-points in the east or west direction, the movement probabilities were adjusted in equal proportion to each other so that selection of southward movements increased in chance. When an eagle travels too far east or west (more than five moves), both east and west grid-point probabilities are decreased, while the others are increased, forcing greater chances of migrating in any one of the southerly directions (i.e., SW, S, or SE). This helped southward migration progress by restricting excessive east to west movements (and vice versa).

When lift was $\leq 0 \mathrm{~m} / \mathrm{s}$ in the five nearest cells, the simulated eagle would move southwest based on uplift in that direction. To do this, lift was averaged among four groups of nine grid-points between $90-500 \mathrm{~m}$ in the southwesterly direction from the current position. Each time, the group containing the highest average lift was chosen, and an eagle then moved immediately to the furthest (southwest) grid-point in that selected group. This "looking ahead" behavior involving movement from one point to another in a distant group of locations, mimics direct, powered (i.e., flapping) flight between positions (Appendix B; Brandes, 2009). For 
example, an eagle might see a distant ridgeline, perceive current wind conditions as favorable, and fly directly to a point on that ridgeline to use orographic lift.

\subsection{Spatial analysis}

We mapped movement paths in ArcGIS 10 (ESRI Inc., Redlands, CA). We computed the magnitude of flight routes per unit area, to view the spatial distribution of hot- and cold-spots in the simulations. To determine how topography influenced simulated migration, we examined the proportion of modeled flight routes that intersected with regional physiographic provinces (United States Forest Service, 2012) and the Kittatinny Ridge System (Hawk Migration Association of North America, 2008).

Recent research has shown that the probability of a golden eagle migrating increases with specific weather conditions that produce local uplift (Duerr et al., in review). Therefore, to analyze how weather influences our simulations, we used real data from Pennsylvania hawkcount sites on each of our NARR weather days $(n=33)$ to define classes of eagle migration days, as a proxy for the quality of weather conditions on a given day (Figure 1-3). We defined three classes of days (i.e., high-, medium-, and low-migration) by natural breaks in the data. A highmigration day occurred when $\geq 24$ golden eagles were counted at sites in Pennsylvania. On a medium-migration day, between nine and 23 golden eagles were counted. During a lowmigration day, between zero and eight eagles were counted. We selected flight routes by their weather day attributes to define each route by its type of migration day. Again, we computed the density of flight routes with area to view how simulations changed with migration day. Specifically, we extracted the hot-spots (i.e., areas of greatest flight route density) to evaluate any changes between days. To quantify differences between classes of migration days, we 
calculated the area of hot-spots per class. This allowed us to evaluate whether golden eagles migrate on a broad or narrow front during such types of days (Murray Jr., 1964).

We also analyzed the density of routes from actual autumn flights (2006-2012) of golden eagles ( $n=21)$ collected via telemetry (Miller, 2012), and we compared that density field to that of our simulated flights as a preliminary verification of model performance. We compared the distributions of orographic and thermal uplift using Welch's two-sample $t$-test, assuming unequal variance. We also examined the correlation between each uplift form and the number of movements over all simulated paths. We conducted all statistical analyses using R Statistical Software 2.15.2 (R Core Development Team, 2013).

\section{$2.8 \quad$ Collecting field observations}

We used output from the density of simulated flight routes to find potential gaps in the distribution of existing hawk-count sites (Hawk Migration Association of North America, 2008). We extracted migration hot-spots from this density field. We restricted sites to visit by locating those nearest to statistically significant clusters (>95\% confidence) of flight routes using the Hot Spot Analysis Tool (Gettis-Ord Gi test) in the Spatial Statistics package (ESRI Inc., Redlands, CA). Next, we defined the number of potential sites to survey by only including those with open land-cover (Fry et al., 2011) and elevated topography (e.g., preferably on long, linear ridgelines) to aid our ability to sight migrants. We limited sites to visit based on their proximity to public roads (i.e., < $1 \mathrm{~km}$ ) using the Digital Base Map of Pennsylvania County Road dataset (Pennsylvania Department of Conservation and Natural Resources, 2007). We also excluded all sites $<5 \mathrm{~km}$ from an active hawk-count site. Finally, we randomly sampled from this collection of potential sites to collect data on migrant golden eagles. We also mapped our survey data 
alongside data collected at nearby hawk-count sites on the same days, in order to compare recordings of migrant golden eagles. This served as another verification of model performance.

\subsection{Comparing different models}

Lastly, we compared output from our simulation model to that of an existing raptor migration model, FlightPath v. 1.1 (Brandes, 2009). FlightPath uses only modeled estimates of orographic uplift to simulate eagle migration. Our model uses empirically-derived estimates of both orographic and thermal uplift in simulations. The two models are similar in that they both model migration at $90 \mathrm{~m}^{2}$ grid-point resolution, use terrain-based orographic uplift estimation, involve a southwesterly principal axis of migration, apply a look ahead function in areas of low lift, and select from ranges of potential starting positions. The models are different because FlightPath models movement over a smaller area, includes an option for declaring eagle random movements (e.g., in scale and frequency), and uses a minimum uplift threshold to limit eagle movements.

We simulated an identical number of flight routes with each model under the same weather conditions and with similar starting constraints. In each model, simulations started in the northeastern corner of their respective modeling region. We then mapped the output from each model, and compared spatial differences in the simulated flight routes from each model to understand influences of regional topography and similar weather conditions on their simulations. Finally, to evaluate how well each model simulated flight routes near hawk-count sites, we compared the number of simulations per model that passed through $3 \mathrm{~km}$ buffer zones (i.e., mean distance for observers to see and identify migrating raptors; Ainslie et al., 2013, Farmer et al., 2010) around hawk-count sites in Pennsylvania. 


\section{RESULTS}

\subsection{Model output}

Our migration model produced 25,481,796 individual moves, comprising a total of 6,378 simulated flight routes. Of this total, 5,000 routes started along the northernmost boundary of the model system, while 1,378 started along the northeastern boundary ( $\sim 27 \%$ of the preliminary set; Hawk Migration Association of North America, 2008). Some simulations comprised fewer than three moves because they started too close to an edge of the model system, and we excluded these routes $(n=284)$ from spatial analyses. Therefore, our final sample of simulations contained 6,094 complete flight routes. Mean $( \pm \mathrm{SD})$ number of moves per flight route was 2,191 ( $\pm 1,281$; range: $3-5,373$ grid-points).

\subsection{Spatial analysis: influences of topography and weather}

The geographic distribution of modeled eagle flight routes was non-uniform. The majority of eagle flights were concentrated in the Ridge and Valley physiographic province of the central Appalachians (Figure 1-4a). Distributions of modeled orographic and thermal lift were non-normal and right-skewed. Orographic uplift was stronger and occurred more frequently than thermal uplift (Welch's two-sample $t=-560.13, \mathrm{df}=43,059,702, p<0.0001$ ), and uplift values were not correlated with the number of simulated movements (orographic, Pearson's $r=-0.015$ and thermal, $r=0.003$; Table 1-1).

Proportions of flight routes intersecting different physiographic provinces were also nonuniformly distributed across the study area (Table 1-2). The greatest proportion of flight routes intersected the Allegheny Plateaus (0.996) with lower proportions crossing the Allegheny Mountain (0.331), Blue Ridge Mountain (0.101), and Northern Piedmont (0.189) regions. The majority (0.707) of routes crossed the Ridge and Valley province, which contains most of the 
hawk-count sites in Pennsylvania (Hawk Migration Association of North America, 2008). More than $25 \%$ of routes passed within $3 \mathrm{~km}$ (i.e., mean distance for observers to see and identify migrants; Farmer et al., 2010) of the Kittatinny ridgeline, near sites like Hawk Mountain Sanctuary (Table 1-2; Hawk Migration Association of North America, 2008).

We used high-, medium-, and low-migration days at hawk-count sites as a proxy for most-, moderately-, and least-favorable weather. On high-migration days, simulations were most clustered over the central portion of the study area, with the highest density of routes passing through the Ridge and Valley province (Figs. 1-4b). On medium-migration days (Figure 1-4c), the highest density of simulations was less clustered than that of high-migration days. On lowmigration days (Figure 1-4d), the highest density of simulated routes was least concentrated than both high- and medium-migration days. In addition, for both medium- and low-migration days, the majority of routes passed through the Ridge and Valley province. The amount of area for hot-spots decreased with migration day class: $5,203.18 \mathrm{~km}^{2}, 5,386.98 \mathrm{~km}^{2}$, and $6,152.87 \mathrm{~km}^{2}$ for high-, medium-, and low-migration days, respectively. In each subset of simulations, three major areas consistently expressed the highest density of routes. These individual mountains (listed with Pennsylvania counties) are: 1) Bald Eagle (Centre, Clinton, and Lycoming), Tussey (Huntingdon, and Blair), and Allegheny (Bedford); 2) Brush, Canoe, and Evitts (Blair and Bedford); and 3) Endless, Jacks, Stone, and Tuscarora (Susquehanna, Union, Mifflin, Huntingdon, and Fulton). Using information on these mountains, it may be possible to locate previously unknown sites that concentrate migrant golden eagles.

\subsection{Model validation}

Modeled simulations reflect movement patterns observed via telemetry (see Duerr et al., 2012, Katzner et al., 2012b, Lanzone et al., 2012, Miller et al., 2014), as many simulations 
concentrate along prominent Appalachian ridgelines and existing hawk-count sites. Areas of greatest densities were comparable between simulated and actual flight routes of golden eagles (Figure 1-5).

We identified 129 potential hawk-count sites and randomly chose 11 sites for model validation. We counted migrating raptors at these sites for 121 observer hrs, over the span of 13 d (Appendix C), during the peak migration period for golden eagles in 2013 (15 October - 04 December; Figure 1-6). Sites had a mean elevation of $630 \mathrm{~m}$, and the majority $(n=9)$ had an easterly aspect. Overall, we recorded 56 migrating golden eagles at six of the sites. These migrants comprised $72 \%$ of the total number of eagles counted $(n=78 ; 56$ golden eagles +19 bald eagles (Haliaeetus leucocephalus) + 3 unidentified eagles). In addition to recording eagles, we recorded other raptors $(n=330$; e.g., Cathartes aura, Coragyps atratus, and various Falcos, Buteos and Accipiters) at nine test sites. At two sites we did not observe any migrating raptors.

\subsection{Model comparisons}

We simulated 90 flight routes with both our model and FlightPath, using similar starting constraints and weather conditions (Figure 1-7). The majority of simulations from FlightPath passed through the Ridge and Valley province. However, very few FlightPath simulations crossed the Kittatinny Ridge System. In contrast, more routes from our migration model passed sites along that corridor. Many of our routes were closer to other sites not even enclosed in FlightPath's modeling area (e.g., Hawk Mountain Sanctuary). In general, FlightPath simulations more closely followed ridgelines in the Ridge and Valley province. Our simulations do follow some major ridgelines (e.g., Jacks and Stone Mountain), but they also follow more minor ridgelines (e.g., areas north of Second Mountain and Hawk Mountain Sanctuary) than do routes from FlightPath. Finally, for comparison in how well the models simulated routes near 
hawk-count sites, both sets had exactly the same number of simulations $(n=44)$ pass through 3 $\mathrm{km}$ buffer zones around a similar number of hawk-count sites in Pennsylvania. FlightPath simulations passed near seven hawk-count sites, while simulations from the migration model passed near nine. Five of those sites were shared between the models.

\section{DISCUSSION}

\subsection{Spatial analysis: influences of topography}

Our modeling highlights the importance of the Ridge and Valley province of the central Appalachians to golden eagle migration. In fact, an overwhelming majority of our simulated eagle migrations (71\%) intersected the Ridge and Valley. Similarly, the greatest densities of telemetry routes were concentrated in this province. The Ridge and Valley not only is a hot-spot for eagle migration, but it could also support more hawk-count sites (van Fleet, 1997). Furthermore, this region is important for wind energy development (American Wind Energy Association, 2013, Miller et al., 2014) because areas throughout the region produce substantial wind resources. These areas are typically near major ridgelines that eagles use to migrate regionally and travel locally (Brandes et al., 2009, Katzner et al., 2012b). In addition to major ridgelines (> $650 \mathrm{~m}$ in elevation), there also appears to be a role for minor ridgelines $(<650 \mathrm{~m})$ in eagle migration (Miller et al., 2014).

\subsection{Spatial analysis: influences of weather}

In autumn, orographic uplift was stronger and more frequent than thermal uplift, which corroborates evidence that the autumn season is conducive to producing more orographic than thermal uplift (Duerr et al., in review). The area of hot-spots for medium- and low-migration days may implicate the different roles and frequency of use for orographic and thermal uplift in 
eagle migration on days where both uplift forms co-occur at moderate levels. Differences between the three categories could be explained by the real conditions observed on those weather days used in our model. We were unable to confirm whether our modeled weather conditions accurately depicted historic conditions, so we can only speculate about their differences related to eagle migration. For example, on a low-migration day, the weather might be least-favorable for generating orographic uplift (e.g., weak, directed winds; Bohrer et al., 2012, Brandes and Ombalski, 2004) producing a broad-front in eagle migration (Murray Jr., 1964). In contrast, it might be a weather day that favors thermal uplift, where eagles are selecting to use thermals more often (Duerr et al., 2012, Lanzone et al., 2012, Duerr et al., in review), leading them further away from hawk-count sites, out of sight of observers (Ainslie et al., 2013, Farmer et al., 2010). On a medium-migration day, weather conditions might be moderately-favorable for generating orographic uplift (e.g., moderate, directed winds inhibiting weaker thermals), causing some eagles to use the ridgelines and be sighted by hawk-count observers, while more eagles could still be far away using weaker, thermal updrafts.

On a high-migration day, weather conditions might be most-favorable for orographic uplift (e.g., strong, directed winds dissipating thermals; Shamoun-Baranes et al., 2010), bringing larger numbers of eagles toward hawk-count sites at major ridgelines. What is clear from this evaluation of hot-spot area is that, on high-migration days, golden eagle migration may be in a narrow-front as individuals are pushed into a smaller area of Pennsylvania (Murray Jr. 1964), perhaps due to the availability of orographic uplift and limitedness of thermal updrafts. Though they clearly migrate away from ridgelines where orographic uplift is not generated, golden eagles will still use this uplift form in slope-soaring flight for the majority of total migration time in autumn (Miller et al., 2014, Duerr et al., in review). 


\subsection{Verifying model output}

Satellite telemetry confirms that there are several corridors eagles use when entering Pennsylvania, especially in the Endless Mountains (Bradford and Susquehanna counties). Golden eagles enter the Ridge and Valley in large numbers east and northeast of cities like State College, Tyrone, and Altoona, Pennsylvania. This eastern portion of the Ridge and Valley lacks in hawk-count sites, which warrants further investigation. On several occasions in the field, we observed multiple migrating golden eagles at most of our sites in the western Ridge and Valley. For example, we observed migrating golden eagles at $55 \%$ of sites we visited and, on many days, in greater numbers than bald eagles and other raptors. Not only did we observe migrating eagles at sites identified by our model, but data collected at nearby hawk-counts, corresponded to numbers of golden eagles we counted (Figure 1-6a). In some cases, our records were nearly identical to those logged at the Allegheny Front Hawkwatch on the same days. For instance, on 20 November 2013 (at the Buffalo Road site), we counted 12 golden eagles while counters at the Allegheny Front Hawkwatch observed 16 golden eagles ( $23 \mathrm{~km}$ straight-line distance, south of our site; Figure 1-6b). This indicates that there may be connectivity between these sites.

We suspect that connectivity between ridgeline sites is also prevalent elsewhere in Pennsylvania (Teter et al., 2003). However, connectivity between new and existing sites should not be used to portray our new sites as not useful. Rather, this suggests that other sites identified with our model may support migrant eagles elsewhere in the region—sites with potentially greater utility and less connectivity with existing sites. In addition, new evidence suggests that eagle adherence to ridgelines might be lower than previously thought, based on detection rates between spatially connected sites (Dennhardt, 2014). These concepts highlight the relevance of adding new hawk-count sites so that less of the population goes uncounted, perhaps due to eagles 
leaving ridges to forage or advance in the migratory direction between sites. On account of our comparisons with flight routes from telemetry and migration count data collected in the field, we feel confident that our migration model is reliable and useful for simulating autumn migration for golden eagles in Pennsylvania.

\subsection{Model comparisons}

FlightPath simulates eagle flights with a minimum uplift threshold that limits movements in areas of too little lift. Our model does not take into account such a threshold for migrating eagles. The magnitude of uplift might be a potentially important factor that limits movements of large, soaring migrants like golden eagles. The equivalent of a minimum of uplift threshold is the vertical component of velocity (i.e., sink) when a bird is flying at the speed to minimize sink (Pennycuick, 2008). To calculate minimum sink speed, we could assume an adult golden eagle weighs $2.5 \mathrm{~kg}$, has a $1.8 \mathrm{~m}$ wingspan, $0.52 \mathrm{~m}$ wing chord, and $0.936 \mathrm{~m}^{2}$ wing area (i.e., minimum measures for North American golden eagles; Watson, 2010). When an eagle of this size migrates at mean elevation (368.01 m; NED) in Pennsylvania, the estimated minimum sink speed is $0.90 \mathrm{~m} / \mathrm{s}$ (Glide Polar function in Program FLIGHT 1.24; Pennycuick, 2008). Though minimum sink speeds are estimable, we did not include them in our migration model because we lacked necessary morphometric data on eastern golden eagles in order to do so. However, it is especially interesting that our mean simulated estimates for each uplift form were quite close to a minimum sink speed of $0.90 \mathrm{~m} / \mathrm{s}$, especially that of thermal uplift $(0.70$ and $0.89 \mathrm{~m} / \mathrm{s}$ for orographic and thermal, respectively).

Nevertheless, our exclusion of a minimum uplift threshold (or sink speed) could explain why some aberrant simulations occurred west of Laurel Ridge in the Allegheny Mountains. Simulated movements may not truly represent eagle migration in that portion of Pennsylvania. 
Namely, a small proportion of our simulations reached major urban areas near Pittsburgh, Pennsylvania (i.e., devoid of forested, long-linear topography).

\subsection{Limitations of the migration model}

Our migration model does not include some eagle behaviors known to occur in the wild. First, our model does not allow for stopover or roosting episodes. Second, we modeled golden eagle flights in a continuous, day-long manner (i.e., with respect to NARR weather day in November; Mesinger et al., 2006) which may not reflect the true characteristics of migratory flights in Pennsylvania. For example, it might take several days for an eagle to migrate across Pennsylvania, but weather is often temporally correlated, so conditions between consecutive days should be relatively similar (Baigorria and Jones, 2010, Shamoun-Baranes et al., 2010). Third, our model did not incorporate movements related to feeding forays. Nevertheless, on long-distance migration, we know that energy is one limiting factor (Duerr et al., 2012, Shamoun-Baranes et al., 2010). Replenishment of food stores is essential to survival, but it may also be important for sustaining long-distance migration.

The small proportion of simulations ( $27 \%)$ that intersect the Kittatinny Ridge System might be underrepresented in our model. We expected more simulations would pass through this area because it has been a well-known migration corridor for decades where many golden eagles are encountered every autumn (Broun, 1935, Teter et al., 2003, Hawk Migration Association of North America, 2008). Alternatively, what was thought to be a major migration corridor for golden eagles may be, in fact, somewhat minor. To this point, hawk-count sites in this area encounter many immature golden eagles (hatch-year and younger sub-adults) than at other western sites in Pennsylvania. This leads us to believe that our migration model might better represent movements by adult golden eagles. For instance, at Hawk Mountain Sanctuary in 
Novembers $2002-2011,54 \%$ of golden eagles counted were immatures along with $37 \%$ adults and 9\% unaged (Hawk Migration Association of North America, 2008). Further supporting the idea that our model better represents adult migration, adult golden eagles migrate later in the autumn, while younger eagles migrate earlier in the season (Duerr et al., in review).

\subsection{New opportunities for simulating migration with implications for continued monitoring}

Golden eagles are a good model species because their flight behaviors are similar to that of other raptors (i.e., Accipiter and Buteo hawks). Notably, these other species also migrate through the central Appalachians and are observed at multiple hawk-count sites in the region. We counted many individuals of these species migrating at the same time as golden eaglesSharp-shinned hawk, Accipiter striatus, Cooper's hawk, Accipiter cooperii, and Red-tailed hawk, Buteo jamaicensis - sometimes, in the dozens. Moreover, our migration model could be useful for identifying potential spatial conflict between wind energy development and migratory raptor populations (Hunt, 2002, Barrios and Rodríguez, 2004, de Lucas et al., 2008, Miller et al., 2014). This could be accomplished by regionally comparing spatial locations of wind turbines (proposed and constructed) with simulated flight paths.

Eastern golden eagles rely on the Ridge and Valley physiographic province in the central Appalachian Mountains of Pennsylvania when migrating in autumn. We also identified several, key migration corridors for potential new hawk-count sites in Pennsylvania. There are several gaps in the spatial distribution of hawk-count sites, but new sites are locatable in migratory hotspots and corridors of the Allegheny Mountain and Ridge and Valley provinces. We identified a

few sites in the Ridge and Valley province that might sustain new hawk-counts. We also located sites in the Allegheny Mountain province, as a result of our fieldwork. New sites in both provinces would be beneficial to improve current monitoring efforts. Many of the sites we 
describe are accessible to the public by road or short walking distance, which is essential to the persistence of multiple, existing count sites. Ease-of-access is important for attracting volunteers and the public to participate in ongoing research—creating opportunities for increased conservation education (Bildstein, 1998).

It might be useful for new research to incorporate foraging and roosting (i.e., stopover) behaviors into modeling eagle movements. Foraging and stopover behaviors are sometimes ignored or excluded from modern models of migration; though, this could help us understand the relative influence of such behaviors on migration trajectories. Similarly, in another, it would also be informative to analyze the influence of modeled movement probabilities in simulated flights with point-to-point movements from telemetry data. This may help determine movement probabilities that may be more representative of real eagle movements. Additional research should also focus on the factors driving migration in movement hot-spots and corridors, areas guiding golden eagle flights and those of other raptors. It would be especially important to know the role of minimum uplift thresholds (or sink speeds) in migrating raptors and their paths. An in-depth evaluation of the nature and degree of connectivity between hawk-count sites would also be useful. Furthermore, other studies could focus on whether certain magnitudes of orographic uplift keep migratory eagles flying close to ridgelines when thermal activity is weak or absent. With this new information, more comprehensive research projects might focus on making inference to important demographic parameters in populations - a persistent conservation necessity. 


\section{ACKNOWLEDGMENTS}

Funding for this research was provided by the Hawk Migration Association of North America 2012 Research Award, Highlanders for Responsible Development, Inc., Virginia Society for Ornithology, and the Eastern Golden Eagle Working Group. Various hawk-count sites provided their data, which helped make this project a success. We sincerely thank the following individuals and organizations: B. Barnhurst and M. McIntosh (Eagle Crossing, Quebec, CAN), Bird Protection Quebec (Montreal, Quebec, CAN), the Ministere des Ressources naturelles et de la Faune, Gouvernement du Quebec (Quebec, CAN), and Cape May Observatory (New Jersey, USA). We also thank L. Goodrich at Hawk Mountain Sanctuary for her work in getting permissions from all of the hawk-count sites and the actual data to our research team for use. We thank K. Bildstein for his support of this work and for allowing our researchers to stay at the Acopian Center for Conservation Learning at Hawk Mountain Sanctuary during a busy field season. We give much gratitude to the many hawk-count sites in eastern North America recording migratory birds of prey, whose data we used in this research, especially all of the count sites in Pennsylvania, USA. We also thank the devoted observers at Allegheny Front Hawkwatch and Tussey Mountain who lent much of their golden eagle surveying expertise to our researchers. We also thank V. Maskey, S. Lamont, V. Talreja, G. Doretto, D. McLaughlin, M. Strager, and E. Iannello at West Virginia University whose tireless generosity in lending computer coding expertise and technological resources and support is sincerely appreciated. Without their kindness and guidance, this research could not have been completed successfully. We are thankful for generous assistance in the field from H. Clipp, N. Goodman, and L. Moon. We also thank the reviewers of this manuscript, which helped improve this work. 


\section{REFERENCES}

AINSLIE, B., N. ALEXANDER, N. JOHNSTON, J. BRADLEY, A.C. POMEROY, P.L. JACKSON, AND K.A. OTTER. 2013. Predicting spatial patterns of eagle migration using a mesoscale atmospheric model: a case study associated with a mountain-ridge wind development. International Journal of Biometeorology 58: 17-30.

ARCGIS v. 10. ESRI Inc., Redlands, California, USA.

AMERICAN WIND ENERGY ASSOCIATION (AWEA). 2013. State Wind Energy Statistics: Pennsylvania. American Wind Energy Association. Washington, District of Columbia, USA. Online at: <http://awea.rd.net/Resources/state.aspx?ItemNumber=5188> (Last accessed 05 February 2014).

BAIGORRIA, G.A. AND J.W. JONES. 2010. GiST: A Stochastic Model for Generating Spatially and Temporally Correlated Daily Rainfall Data. Journal of Climate 23: 59906008.

BARRIOS, L. AND A. RODRÍGUEZ. 2004. Behavioural and environmental correlates of soaring-bird mortality at on-shore turbines. Journal of Applied Ecology 41: 72-81.

BILDSTEIN, K.L. 1998. Long-Term Counts of Migrating Raptors: A Role for Volunteers in Wildlife Research. Journal of Wildlife Management 62: 435-445.

BILDSTEIN, K.L. 2001. Why migratory birds of prey make great biological indicators. Pages 169-179 in Hawkwatching in the Americas (K.L. Bildstein and D. Klem, Eds.). Hawk Migration Association of North America, North Wales, Pennsylvania, USA.

BILDSTEIN, K.L. 2006. Migrating Raptors of the World: Their Ecology and Conservation. Cornell University Press, Ithaca, New York, USA. 320pp.

BOHRER, G., D. BRANDES, J.T. MANDEL, K.L. BILDSTEIN, T.A. MILLER, M. LANZONE, T. KATZNER, C. MAISONNEUVE, AND J.A. TREMBLAY. 2012. Estimating updraft velocity components over large spatial scales: contrasting migration strategies of golden eagles and turkey vultures. Ecology Letters 15: 96-103.

BRANDES, D. 2009. FlightPath v. 1.1: Terrain-based Raptor Migration Model. Lafayette University Press, Easton, Pennsylvania, USA. 27pp.

BRANDES, D., AND D.W. OMBALSKI. 2004. Modeling raptor migration pathways using a fluid flow analogy. Journal of Raptor Research 38: 195-207.

BRANDES, D., T.M. MILLER AND T. KATZNER. 2009. Wind Power Mortality. Pages 300303 in Avian Ecology and Conservation: A Pennsylvania Focus with National Implications (S.K. Majumdar, T.L. Master, M.C. Brittingham, R.M. Ross, R.S. Mulvihill and J.E. Huffman, Eds.). Pennsylvania Academy of Science, Lafayette College, Easton, Pennsylvania, USA. 
BRODEUR, S., R. DECARIE, D.M. BIRD, AND M. FULLER. 1996. Complete migration cycle of Golden Eagles breeding in northern Québec. Condor 98: 293-299.

BRODEUR, S. AND F. MORNEAU. 1999. Rapport sur la situation de l'aigle royal (Aquila chrysaetos) au Québec. Société de la faune et des parcs du Québec, Direction de la faune et des hábitats. Dépôt légal - Bibliothèque nationale du Québec, Québec, Canada. 75pp.

BROUN, M. 1935. The hawk migration during the fall of 1934, along the Kittatinny Ridge in Pennsylvania. Auk 52: 233-248.

DE LUCAS, M.E., G.F.E. JANSS, D.P. WHITFIELD, AND M. FERRER. 2008. Collision fatality of raptors in wind farm does not depend on raptor abundance. Journal of Applied Ecology 45: 1695-1703.

DENNHARDT, A.J. 2014. Modeling Migration and Citizen-Science Data to Estimate Golden Eagle Abundance in Eastern North America (Thesis). West Virginia University Press, Morgantown, West Virginia, USA.

DUERR, A.E., T.A. MILLER, M. LANZONE, D. BRANDES, J. COOPER, K. O’MALLEY, C. MAISONNEUVE, J. TREMBLAY, AND T. KATZNER. 2012. Testing an Emerging Paradigm in Migration Ecology Shows Surprising Differences in Efficiency between Flight Modes. PLoS ONE 7(4): 1-7.

DUERR, A.E., T. MILlER, M. LANZONE, D. BRANDES, J. COOPER, K. O’MALLEY, C. MAISONNEUVE, J. TREMBLAY, AND T. KATZNER. In review. Stereotyped flight response of slope-soaring birds to seasonal variation in thermal generation. Functional Ecology.

DUNN, E.H. AND D.J.T. HUSSELL. 1995. Using migration counts to monitor landbird populations: Review and evaluation of current status. Pages 43-88 in Current Ornithology, vol. 12 (D.M. Power, Ed.). Plenum Press, New York, New York, USA.

FARMER, C.J. AND J.P. SMITH. 2010. Seasonal differences in migration counts of raptors: utility of spring counts for population monitoring. Journal of Raptor Research 44: 101112.

FARMER, C.J., R.J. BELL, B. DROLET, L.J. GOODRICH, D. GROVE, D.J.T. HUSSELL, D. MIZRAHI, F.J. NICOLETTI, AND J. SODERGREN. 2008. Trends in autumn counts of migratory raptors in eastern North America, 1974-2004. Pages 179-215 in State of North America's Birds of Prey, Series in Ornithology no. 3 (K.L. Bildstein, J.P. Smith, E. Ruelas Inzunza, and R.R. Veit, Eds.). Nuttall Ornithological Club, Cambridge, Massachusetts and American Ornithologists' Union, Washington, District of Columbia, USA. 
FARMER, C.J., K. SAFI, D.R. BARBER, I. NEWTON, M. MARTELL, AND K.L.

BILDSTEIN. 2010. Efficacy of migration counts for monitoring continental populations of raptors: an example using the Osprey (Pandion haliaetus). Auk 127: 863-870.

FRY, J., G. XIAN, S. JIN, J. DEWITZ, C. HOMER, L. YANG, C. BARNES, N. HEROLD, AND J. WICKHAM. 2011. Completion of the 2006 National Land Cover Database for the Conterminous United States. Photogrammetric Engineering \& Remote Sensing 77: 858-864.

GEYER VON SCHWEPPENBURG, H.F. 1963. Zur Terminologie und Theorie der Leitlinie. Journal für Ornithologie 104: 191-204.

HAWK MIGRATION ASSOCIATION OF NORTH AMERICA. 2004. Raptor Population Index Project, Hawk Migration Association of North America, North Wales, Pennsylvania, USA. Online at <http://www.rpi-project.org> (Last accessed 10 November 2012).

HAWK MIGRATION ASSOCIATION OF NORTH AMERICA. 2008. Hawk Migration Association of North America, North Wales, Pennsylvania, USA. Online at <http://www.hmana.org/> or <http://www.hawkcount.org/> (Last accessed 01 January 2014).

HOFFMAN, S.W. AND J.P. SMITH. 2003. Population trends of migratory raptors in western North America, 1977-2001. Condor 105: 397-419.

HULL, J.M., A.M. FISH, J.J. KEANE, S.R. MORI, B.N. SACKS, AND A.C. HULL. 2010. Estimation of Species Identification Error: Implications for Raptor Migration Counts and Trend Estimation. Journal of Wildlife Management 74(6): 1326-1334.

HUNT, G. 2002. Golden Eagles in a Perilous Landscape: Predicting the Effects of Mitigation for Wind Turbine Bladestrike Mortality. California Energy Commission Report P50002-034F. Sacramento, California, USA.

KATZNER, T., B. SMITH, T. MILLER, D. BRANDES, J. COOPER, M. LANZONE, D. BRAUNING, C. FARMER, S. HARDING, D. KRAMAR, C. KOPPIE, C. MAISONNEUVE, AND OTHERS. 2012a. Status, biology, and conservation priorities for North America's eastern Golden Eagle (Aquila chrysaetos) population. Auk 129: 168-176.

KATZNER, T.E., D. BRANDES, T. MILLER, M. LANZONE, C. MAISONNEUVE, J.A. TREMBLAY, R. MULVIHILL, AND G.T. MEROVICH, JR. 2012b. Topography drives migratory flight altitude of golden eagles: implications for on-shore wind energy development. Journal of Applied Ecology 49: 1178-1186.

KERLINGER, P. 1989. Flight Strategies of Migrating Hawks. University of Chicago Press, Chicago, Illinois, USA. 392pp. 
KOCHERT, M.N. AND K. STEENHOF. 2002. Golden Eagles in the U.S. and Canada: status, trends, and conservation challenges. Journal of Raptor Research 36: 32-40.

KOCHERT, M.N., K. STEENHOF, C.L. MCINTYRE, AND E.H. CRAIG. 2002. Golden Eagle (Aquila chrysaetos). In The Birds of North America, no. 684 (A. Poole and F. Gill, Eds.). Academy of Natural Sciences, Philadelphia, and American Ornithologists' Union, Washington, District of Columbia, USA.

LANZONE, M., T. MILLER, P. TURK, D. BRANDES, C. HALVERSON, C. MAISONNEUVE, J. TREMBLAY, J. COOPER, K. O’MALLEY, R. BROOKS AND T. KATZNER. 2012. Flight responses by a migratory soaring raptor to changing meteorological conditions. Biology Letters 8: 710-713.

LEWIS, S.A. AND W.R. GOULD. 2000. Survey Effort Effects on Power to Detect Trends in Raptor Migration Counts. Wildlife Society Bulletin 28: 317-329.

MANDEL, J.T., K.L. BILDSTEIN, G. BOHRER, AND D.W. WINKLER. 2008. Movement ecology of migration in turkey vultures. Proceedings of the National Academy of Sciences 105: 19102-19107.

MESINGER, F., G. DiMEGO, E. KALNAY, K. MITCHELL, P.C. SHAFRAN, W. EBISUZAKI, D. JOVIC, AND OTHERS. 2006. North American Regional Reanalysis: a long-term, consistent, high-resolution climate dataset for the North American domain, as a major improvement upon the earlier global reanalysis datasets in both resolution and accuracy. Bulletin of the American Meteorological Society 87: 343-360.

MICROSOFT CORPORATION. 2010. Visual C\# v. 4.0: .NET Framework Integrated Development Environment, Microsoft Visual Studio 2010. Microsoft Corporation, Redmond, Washington, USA.

MILLER, T.A. 2012. Movement Ecology of Golden Eagles (Aquila chrysaetos) in Eastern North America (Dissertation). The Pennsylvania State University Press, State College, Pennsylvania, USA.

MILLER, T.A., R.P. BROOKS, M. LANZONE, D. BRANDES, J. COOPER, K. O’MALLEY, C. MAISONNEUVE, J. TREMBLAY, A. DUERR, AND T. KATZNER. 2014. Assessing Risk to Birds from Industrial Wind Energy Development via Paired Resource Selection Models. Conservation Biology. doi: 10.1111/cobi.12227.

MILLSAP, B.A. AND S.L. VANA. 1984. Distribution of wintering Golden Eagles in the eastern United States. Wilson Bulletin 94: 692-701.

MORNEAU, F., S. BRODEUR, R. DECARIE, AND D.M. BIRD. 1994. Abundance and distribution of Golden Eagles in Hudson Bay, Québec. Journal of Raptor Research 28: 220-225. 
MURRAY JR., B.G. 1964. A review of sharp-shinned hawk migration along the northeastern coast of the United States. Wilson Bulletin 76: 257-264.

NATHAN, R., W.M. GETZ, E. REVILLA, M. HOLYOAK, R. KADMON, D. SALTZ, AND P.E. SMOUSE. 2008. A movement ecology paradigm for unifying organismal movement research. Proceedings of the National Academy of Sciences 105: 1905219059.

NEWTON, I. 2010. Bird Migration. HarperCollins, London, UK. 400pp.

PENNSYLVANIA DEPARTMENT OF CONSERVATION AND NATURAL RESOURCES. 2007. PAMAP- The Digital Base Map of Pennsylvania. Pennsylvania Department of Conservation and Natural Resources, Harrisburg, Pennsylvania, USA. Online at: <http://www.dcnr.state.pa.us/topogeo/pamap/index.aspx > or $<$ http://www.pamap.dcnr.state.pa.us/> (Last accessed 10 September 2013).

PENNYCUICK, C.J. 2008. Modelling the Flying Bird. Elsevier, Amsterdam, The Netherlands. 496pp.

R CORE DEVELOPMENT TEAM. 2013. R Statistical Software v. 2.15.2. R Foundation for Statistical Computing, Vienna, Austria.

RODRÍGUEZ-ESTRELLA, R., J.A. DONÁZAR, AND F. HIRALDO. 1998. Raptors as Indicators of Environmental Change in the Scrub Habitat of Baja California Sur, Mexico. Conservation Biology 12: 921-925.

SATTLER, G. AND J. BART. 1984. Reliability of counts of migrating raptors: an experimental analysis. Journal of Field Ornithology 55: 415-423.

SERGIO, F., I. NEWTON, AND L. MARCHESI. 2005. Top predators and biodiversity. Nature 436: 192.

SERGIO, F., I. NEWTON, AND L. MARCHESI. 2008. Top predators and biodiversity: much debate, few data. Journal of Applied Ecology 45: 992-999.

SERGIO, F., I. NEWTON, L. MARCHESI, AND P. PEDRINI. 2006. Ecologically justified charisma: preservation of top predators delivers biodiversity conservation. Journal of Applied Ecology 43: 1049-1055.

SHAMOUN-BARANES, J., W. BOUTEN, AND E.E. VAN LOON. 2010. Integrating Meteorology into Research on Migration. Integrative and Comparative Biology 50: 280292.

SILLETT, T.S., AND R.T. HOLMES. 2002. Variation in survivorship of a migratory songbird throughout its annual cycle. Journal of Animal Ecology 71: 296-308. 
SMITH, J.P., C.J. FARMER, S.W. HOFFMAN, G.S. KALTENECKER, K.Z. WOODRUFF, AND P. SHERRINGTON. 2008. Trends in autumn counts of migratory raptors in eastern North America, 1983-2005. Pages 217-252 in State of North America's Birds of Prey, Series in Ornithology no. 3 (K.L. Bildstein, J.P. Smith, E. Ruelas Inzunza, and R.R. Veit, Eds.). Nuttall Ornithological Club, Cambridge, Massachusetts and American Ornithologists' Union, Washington, District of Columbia, USA.

SPAAR, R., O. LIECHTI, AND B. BRUDERER. 2000. Forecasting flight altitudes and soaring performance of migrating raptors by the altitudinal profile of atmospheric conditions. Organisation Scientifique et Technique du Vol à Voile 24: 49-55.

STULL, R.B. 1988. An Introduction to Boundary Layer Meteorology. Kluwer Academic, Dordrecht, The Netherlands. 666pp.

TETER, S., A. KHALILIEH, E. ASHWORTH, AND S. WAMITI. 2003. Ridge Adherence in Golden Eagles Migrating along the Kittatinny Ridge between Bake Oven Knob and Hawk Mountain Sanctuary, Pennsylvania, Autumn 2000-2002. American Hawkwatcher 29: 9-14.

THORUP, K., M. FULLER, T. ALERSTAM, M. HAKE, N. KJELLÉN, AND R. STRANDBERG. 2006. Do migratory flight paths of raptors follow constant geographical or geomagnetic courses? Animal Behavior 72: 875-880.

UNITED STATES FOREST SERVICE. 2012. Ecomap 2007, Physiographic Provinces: Eastern United States. U.S. Forest Service, Washington, District of Columbia, USA. Online at: $<$ http://svinetfc4.fs.fed.us/other_resources/metadata.php> (Last accessed 10 November 2013).

UNITED STATES GEOLOGICAL SURVEY. 2012. National Elevation Dataset. U.S. Geological Survey, Washington, District of Columbia, USA. Online at: <http://nationalmap.gov/viewer.html> (Last accessed 15 May 2013).

VAN FLEET, P.K. 1997. The Geographic Distribution of Diurnal Raptors Migrating Through the Valley and Ridge Province of Central Pennsylvania (Thesis). Shippensburg University Press, Shippensburg, Pennsylvania, USA.

VAN LOON, E.E., J. SHAMOUN-BARANES, W. BOUTEN, AND S.L. DAVIS. 2011. Understanding soaring bird migration through interactions and decisions at the individual level. Journal of Theoretical Biology 270: 112-126.

WATSON, J. 2010. The Golden Eagle. T\&AD Poyser, London, UK. 448pp.

ZALLES, J.I. AND K.L. BILDSTEIN, Eds. 2000. Raptor Watch: A global directory of raptor migration sites. BirdLife International, Conservation Series No. 9, Cambridge, UK and Hawk Mountain Sanctuary, Kempton, Pennsylvania, USA. 419pp. 
ZEVENBERGEN, L.W. AND C.R. THORNE. 1987. Quantitative analysis of land surface topography. Earth Surface Processes and Landforms 12: 47-56. 


\section{TABLES}

Table 1-1. Statistics of estimated uplift to the total number of simulated movements $(n=$ 25,481,796) of golden eagles in Pennsylvania, USA during November 2002-2011. Zero values of each uplift form represent those $\leq 0 \mathrm{~m} / \mathrm{s}$ and non-zero values represent those $>0 \mathrm{~m} / \mathrm{s}$.

\begin{tabular}{|l|rr|}
\hline Statistic & Orographic uplift & Thermal uplift \\
\hline Raw count of zero values & $6,817,057$ & $16,988,977$ \\
Raw count of non-zero values & $18,664,739$ & $8,492,819$ \\
Correlation with no. movements (Pearson's $r$ ) & -0.015 & 0.003 \\
Minimum (m/s) & 0.00 & 0.00 \\
Maximum (m/s) & 9.06 & 7.17 \\
Mean (m/s) & $0.70^{\mathrm{a}}$ & $0.89^{\mathrm{a}}$ \\
Median (m/s) & 0.35 & 0.00 \\
SD $(\mathrm{m} / \mathrm{s})$ & 0.91 & 1.45 \\
\hline
\end{tabular}

${ }^{\mathrm{a}}$ Welch's two-sample $t=-560.13, \mathrm{df}=43,059,702, p<0.0001$ 
Table 1-2. Proportions of total simulated flight routes $(n=6,094)$ intersecting physiographic provinces and the Kittatinny Ridge System in Pennsylvania, USA.

\begin{tabular}{|ccc|}
\hline Physiographic province & Number of flight routes & Proportion of total \\
\hline Allegheny Plateaus & 6,071 & 0.99 \\
Allegheny Mountains & 2,017 & 0.33 \\
Blue Ridge Mountains & 618 & 0.10 \\
Northern Piedmont & 1,150 & 0.19 \\
Ridge and Valley & & 0.71 \\
\hline Migration corridor & 4,310 & 0.27 \\
\hline Kittatinny Ridge System & 1,638 & \\
\hline
\end{tabular}




\section{FIGURE CAPTIONS}

Figure 1-1. Study area and model system: the central Appalachian Mountain range in Pennsylvania, USA.

Figure 1-2. Conceptual model describing the general steps involved in modeling migration routes across the study area. Eagle movement steps occur in consecutive, $90 \mathrm{~m}$ increments corresponding to the spatial resolution of the NED (1 $\mathrm{arc} \mathrm{sec})$. When uplift is good (> $0 \mathrm{~m} / \mathrm{s})$ then the eagle chooses among 5 (x) grid-points, and moves 1 grid-point at a time (a). When uplift is bad $(\leq 0 \mathrm{~m} / \mathrm{s})$ then the eagle chooses among 36 (y) grid-points, and moves to 1 grid-point in a group of points containing the highest average lift, compared among 4 different groups of gridpoints (b). Lift is averaged over 9 grid-points per group to compare average lift among the 4 groups (see Figure 1-4). When an eagle reaches the southern boundary of the study area, its flight route completes, and a new flight route is constructed. The process repeats until all flight routes are built.

Figure 1-3. Variation in counts of golden eagles based on classes of migration days. We classified our NARR weather datasets ( $n=33 \mathrm{~d}$ ) by natural breaks in hawk-count data collected on each type of day in the study area. We used November data from the following hawk-counts: Allegheny Front, Stone Mountain, Waggoner's Gap, Second Mountain, and Hawk Mountain Sanctuary (Hawk Migration Association of North America 2008). We used the three classes as a proxy for the quality of weather conditions on a given day.

Figure 1-4. a) Density of the complete sample of simulated flight routes $(n=6,094)$ for golden eagles in Pennsylvania, USA during November 2002-2011. This overall density is juxtaposed with subsets of simulations classified by high-, medium-, and low-migration count days as a 
proxy for weather conditions. b) Regional comparison with flight routes $(n=1,755)$ modeled on high-migration days. c) Regional comparison with flight routes $(n=1,329)$ modeled on medium-migration days. d) Regional comparison with flight routes $(n=3,010)$ modeled on lowmigration days. Size of hot-spot areas varied by migration day class with $5,203.18 \mathrm{~km}^{2}$, $5,386.98 \mathrm{~km}^{2}, 6,152.87 \mathrm{~km}^{2}$ for high-, medium-, and low-migration days, respectively.

Figure 1-5. Regional comparison of density fields between movement simulations of this work ( $n=25,481,796)$ and movement observations ( $n=16,348$ data points for 21 eagles) from telemetry work in Pennsylvania, USA (autumn 2006-2012; Miller 2012).

Figure 1-6. a) Regional comparison of hawk-count data on golden eagles collected on the same days and during similar hours of field data collection. b) Local comparison of the largest golden eagle recordings from our field data with counts conducted on the same days and during similar hours at the Allegheny Front Hawkwatch, near Central City, Pennsylvania, USA. Sites denoted with an * designates that they are a new, potential count site for future monitoring of golden eagles. Of these new sites, the Brush Mountain site (near Skelp Mountain Road) does not allow public access, while the other two areas do support public access.

Figure 1-7. Regional comparison of simulations constructed with different computer models that simulate golden eagle migration: our migration model $(n=90)$ and FlightPath v. $1.1(n=$ 90). We used the average conditions for the input weather dataset. Simulated eagles were started in the northeastern corners of each model's simulation area. Despite mechanistic differences between the two models, there are several areas in the Ridge and Valley physiographic province where simulated eagles' flights overlap and travel in close proximity. 
Simulations from our migration model occur in closer proximity to more hawk-count sites than do simulations from FlightPath. 


\section{Figure 1-1.}

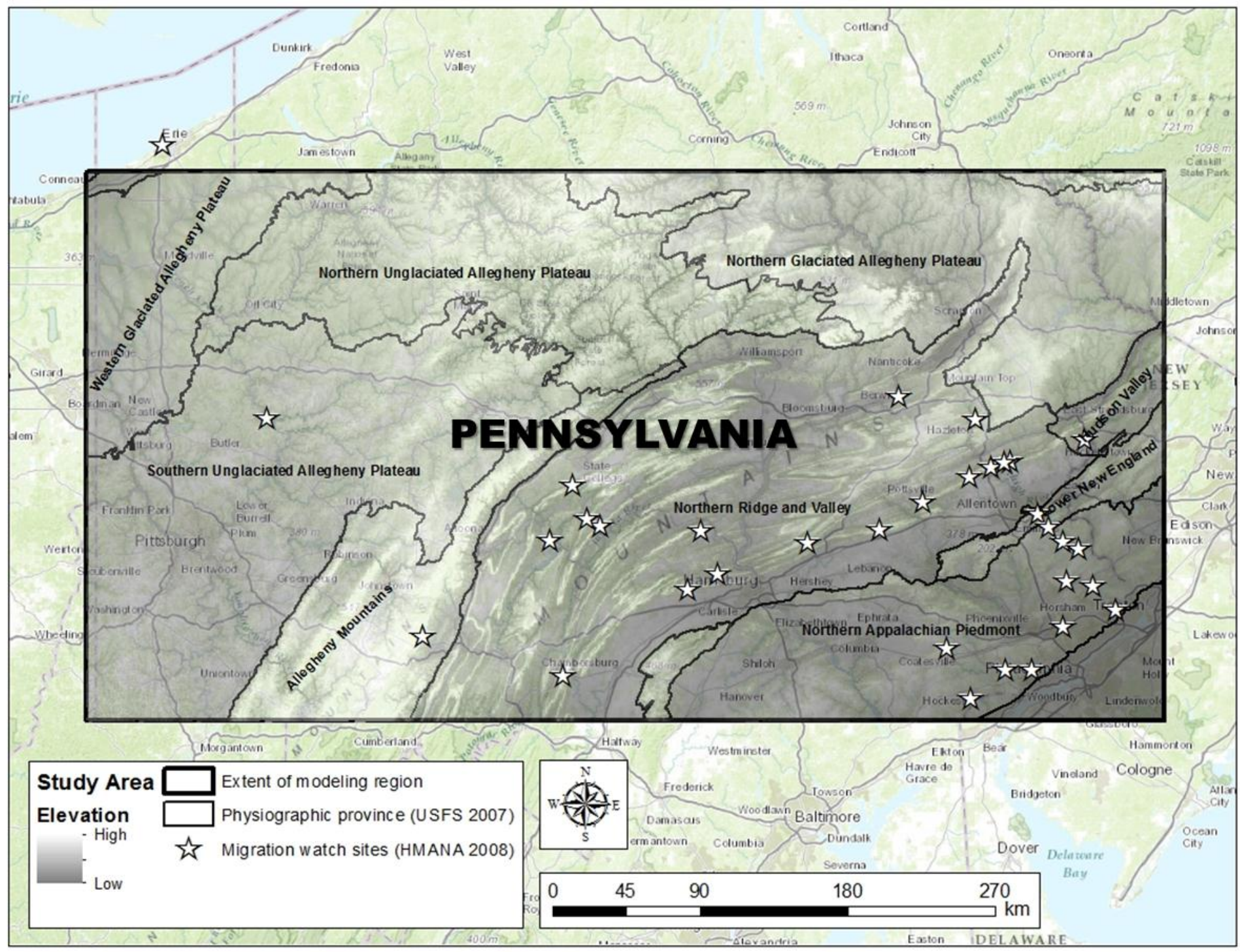




\section{Figure 1-2.}

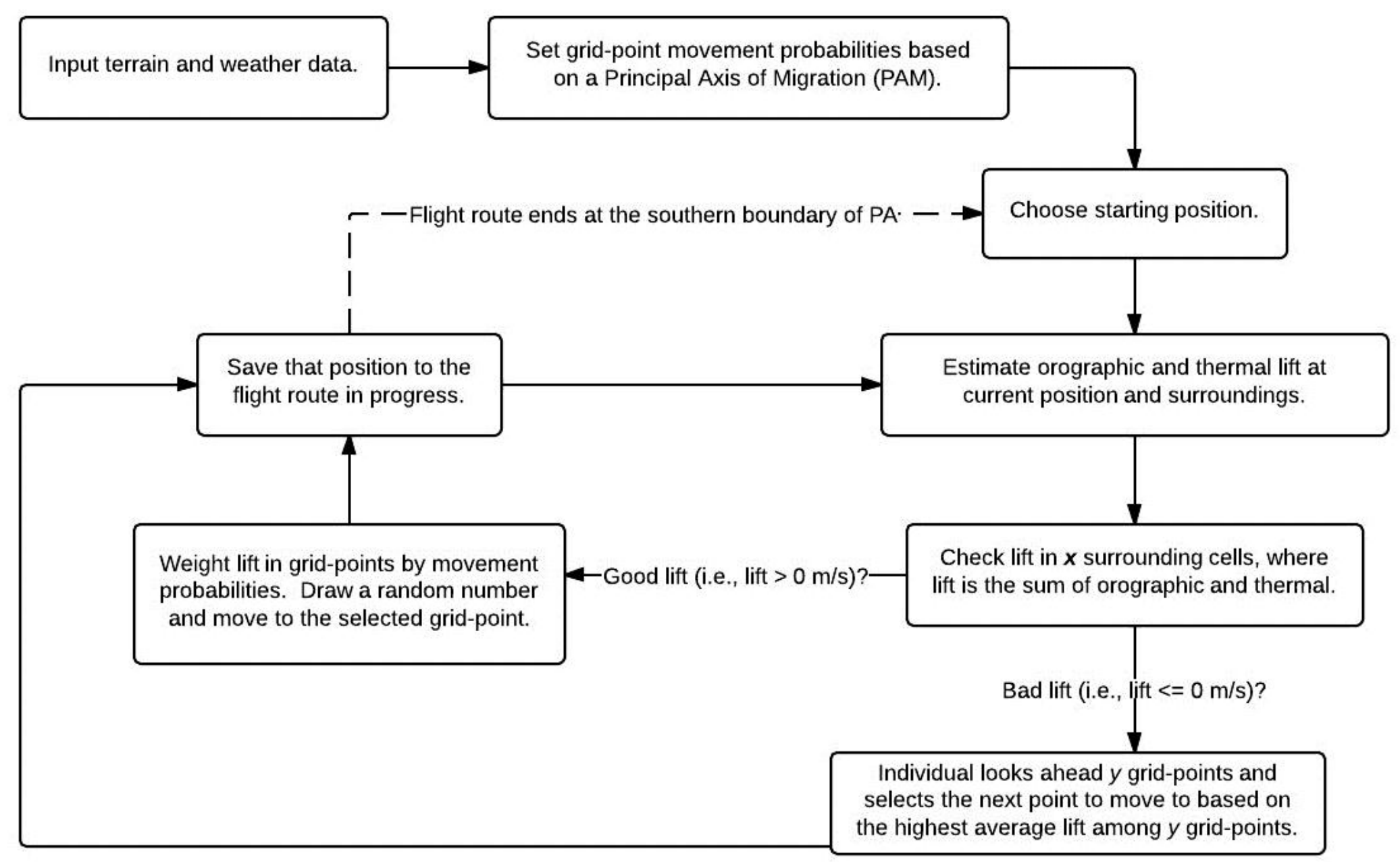


Figure 1-3.

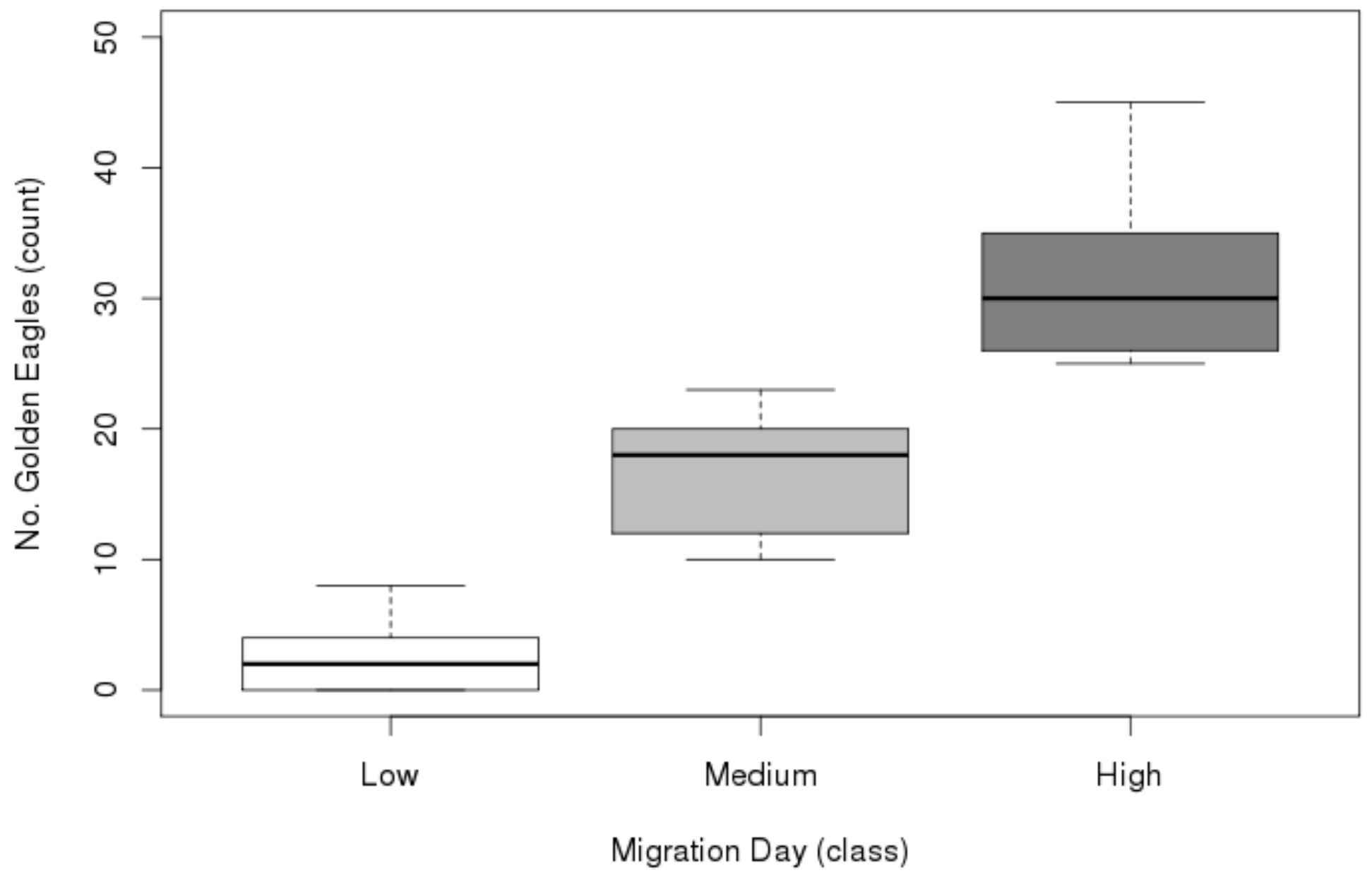




\section{Figure 1-4.}

A

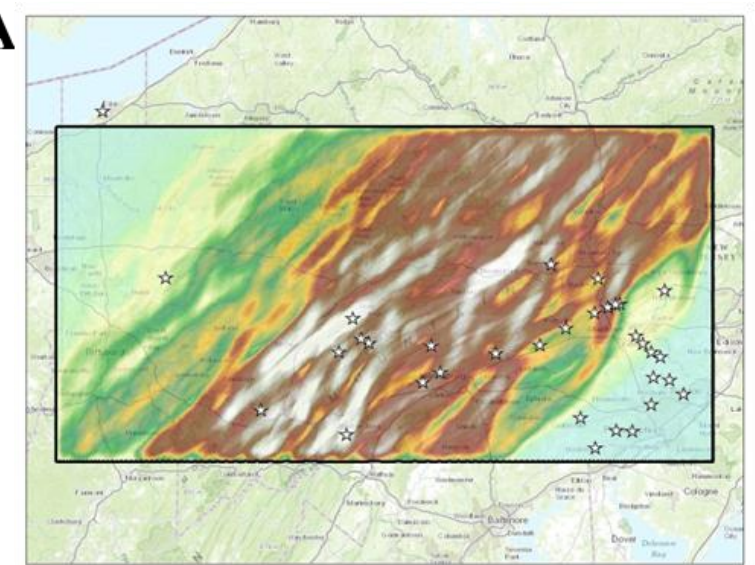

C

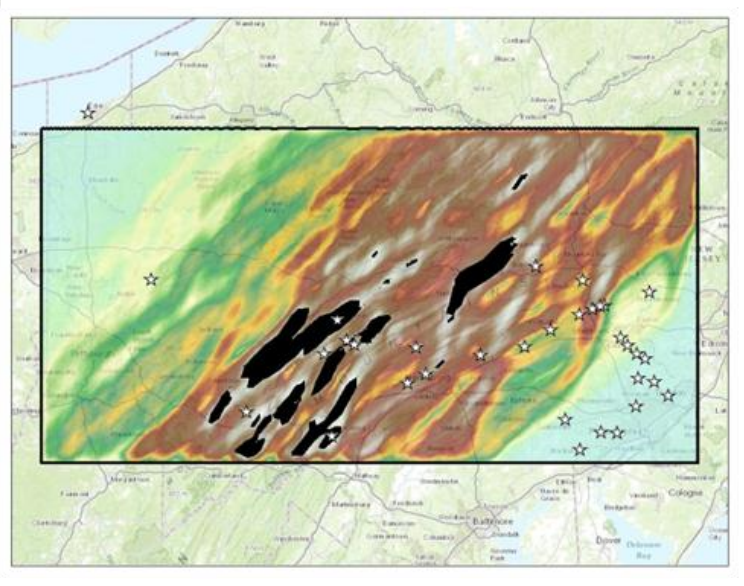

B

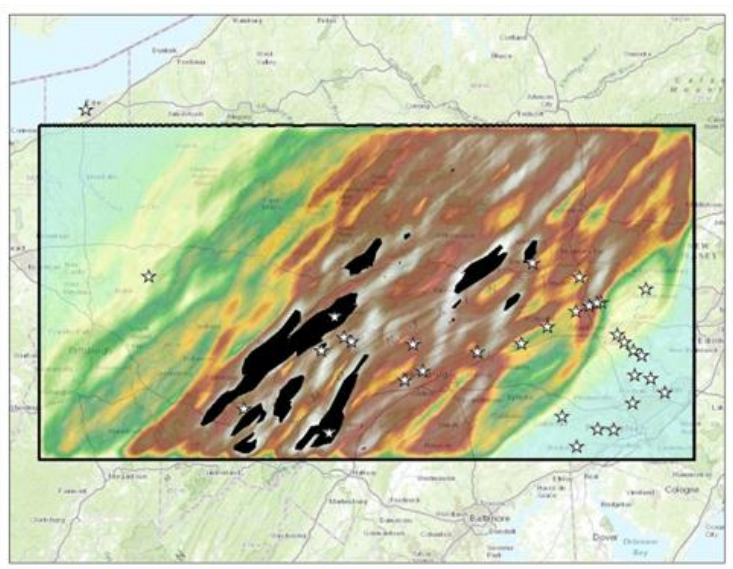

D

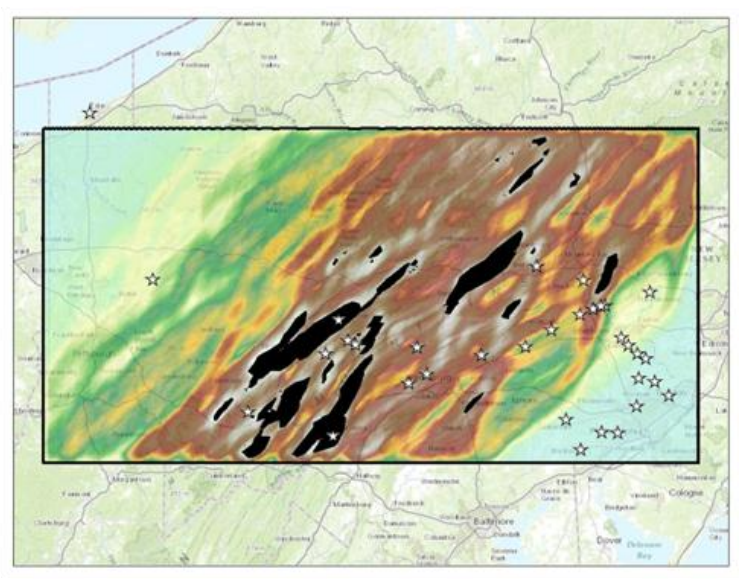

Density of Flight Routes Density of Flight Routes by Migration Day Type Flight routes per unit area $\quad$ Flight routes per unit area

- High $\square$ Extent of the modeling region

- Low is Migration watch sites (HMANA 2008)

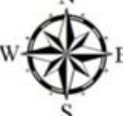

\begin{tabular}{|lrrrr|}
\hline 0 & 50 & 100 & 200 & 300 \\
\hline & & &
\end{tabular}




\section{Figure 1-5.}

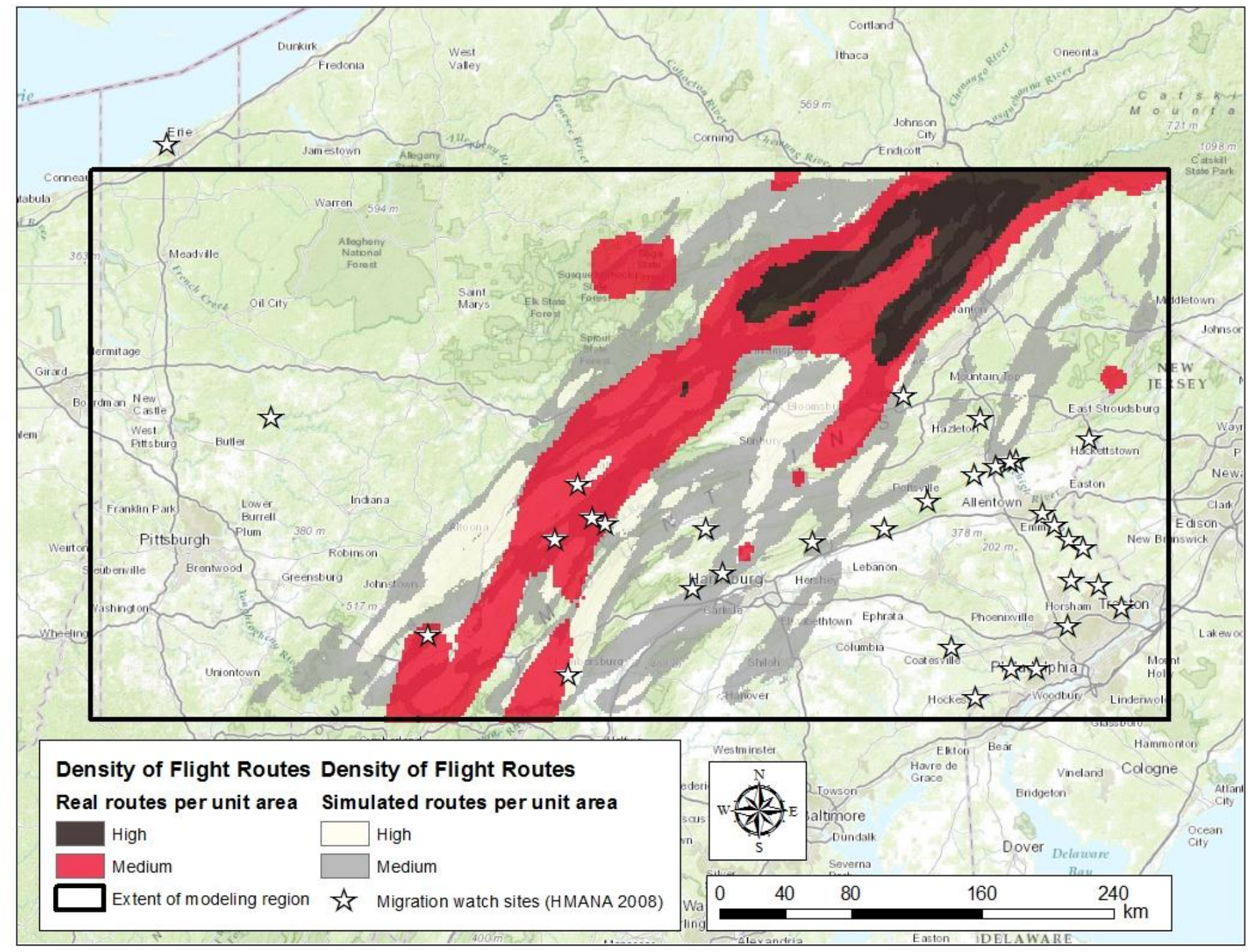


Figure 1-6.

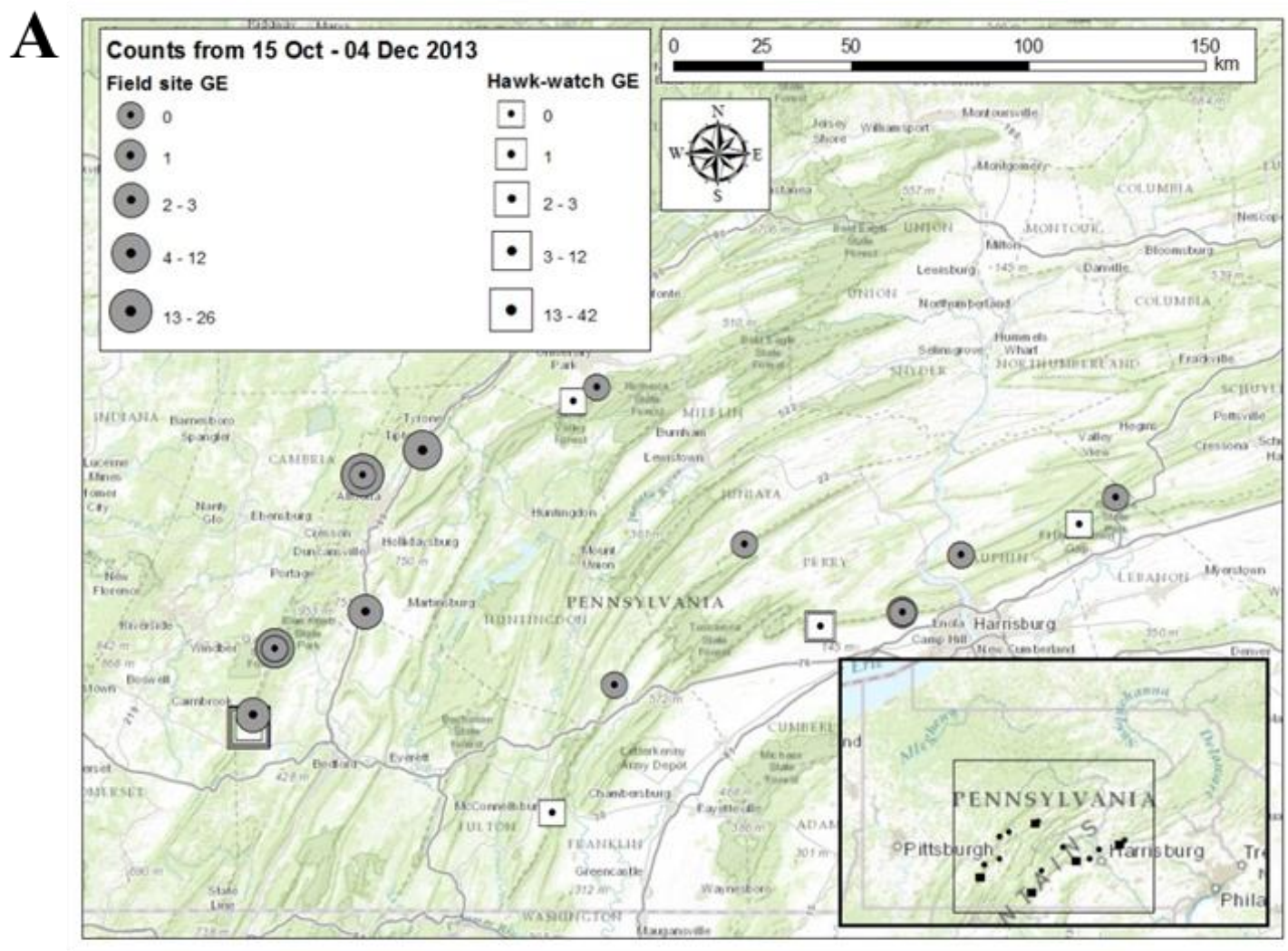

B

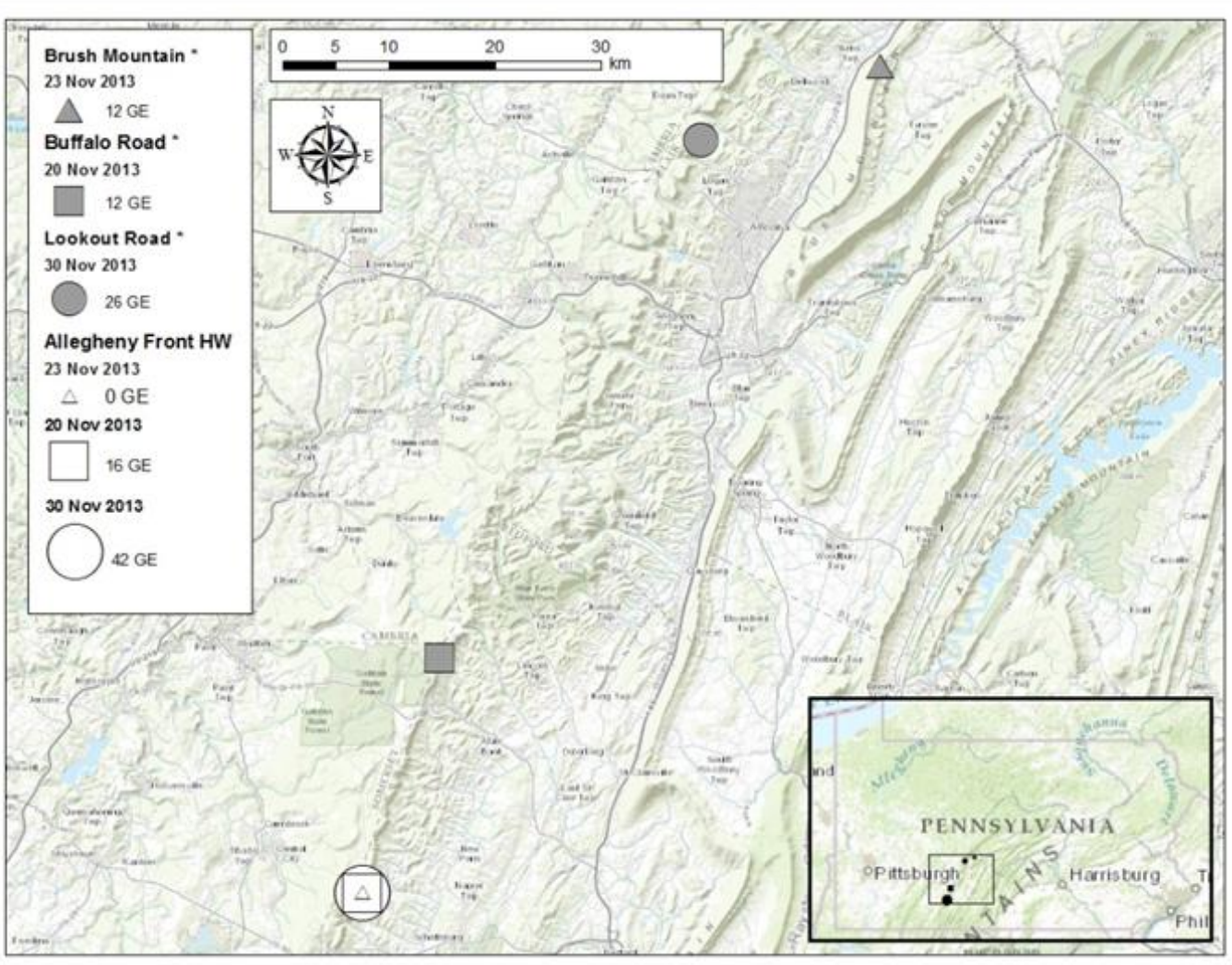




\section{Figure 1-7.}

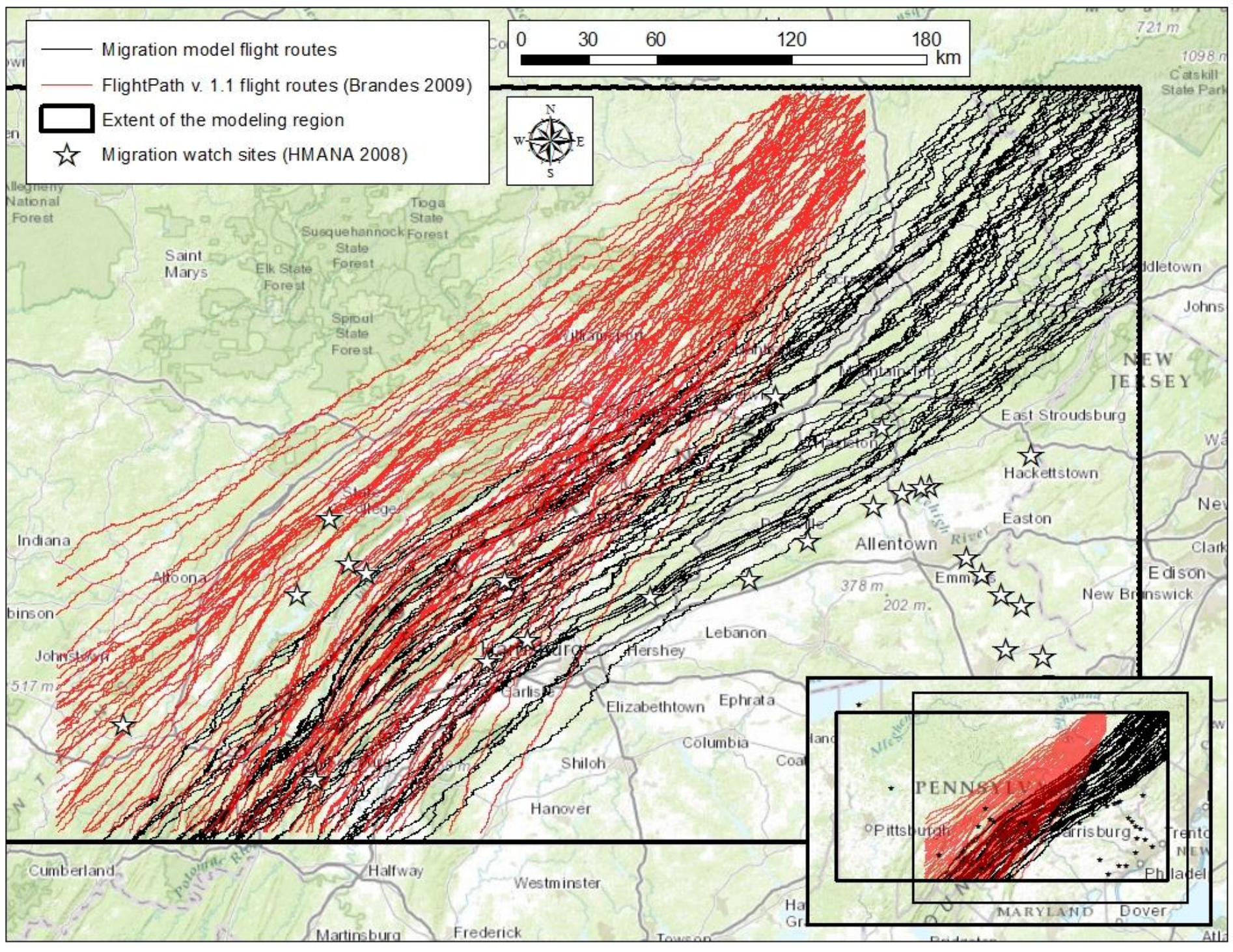


CHAPTER 2

MODELING POPULATION SIZE OF GOLDEN EAGLES WITH CITIZEN-SCIENCE DATA SUGGESTS THE IMPORTANCE OF MISSED INDIVIDUALS 
Formatted for submission to Biological Conservation

MODELING POPULATION SIZE OF GOLDEN EAGLES WITH CITIZEN-SCIENCE

DATA SUGGESTS THE IMPORTANCE OF MISSED INDIVIDUALS

ANDREW J. DENNHARDT ${ }^{* 1}$

TODD E. KATZNER ${ }^{12}$

ADAM E. DUERR ${ }^{1}$

DAVID C. BRANDES ${ }^{3}$

*Corresponding author; E-mail: ajdennhardt@gmail.com; Phone: 304-293-4412

${ }^{1}$ Division of Forestry and Natural Resources, West Virginia University, Morgantown, WV 26506, USA

${ }^{2}$ U.S. Department of Agriculture, Forest Service, Timber and Watershed Laboratory, Parsons, WV 26287, USA

${ }^{3}$ Department of Civil and Environmental Engineering, Lafayette College, Easton, PA 18042, USA

\begin{abstract}
Estimating the size of wildlife populations is fundamental to ecology and conservation. The vagility of many organisms can have significant impacts on population-level monitoring by affecting survey methods and demographic estimates. Demographic analyses, which may require large amounts of data collected over time, are often expensive to collect and maintain.
\end{abstract}


Citizen-science data often involve extensive effort, but possess limited data quality. In the case of hawk-counts in the USA, these data are both standardized and maintained by the Hawk Migration Association of North America. We evaluated the utility of hawk-count data to estimate population size of golden eagles (Aquila chrysaetos canadensis) migrating in eastern North America. We designed a computer model to simulate migratory flights of eagles to assess what proportion of the population is available to be counted at hawk-counts in Pennsylvania, USA. We then conducted a mark-recapture analysis to estimate mean detectability of migrating eagles and mean local abundance along an important migration corridor. Finally, we used estimates of availability and detectability to adjust data from hawk-count sites to derive regional estimates of population size. Mean $( \pm \mathrm{SD})$ availability of golden eagles to hawk-count sites was $0.240( \pm 0.140$; range: $0.040-0.440)$. We estimated mean detectability as $0.073( \pm 0.010$; range: $0.048-0.109$ ). Previous estimates of population size for golden eagles in eastern North America were 1000 - 5000. All of our population estimates far exceeded that of previous approximations. Larger estimates were driven by the low availability and detectability of birds passing by hawk-counts. When using detection rates from recent literature, only then were estimates $<5,000$ individuals. This analysis suggests that (a) detection estimates need to be improved, (b) the majority of migrating golden eagles in eastern North America are not counted at hawk-count sites, and (c) previous population estimates for this species are likely low. This exercise demonstrates the utility of using citizen-science data to address a pressing conservation goal: estimating population size for species of regional concern.

\section{KEYWORDS}

Aquila chrysaetos, golden eagle, hawk-count data, mark-recapture, Pennsylvania, raptor migration 


\section{INTRODUCTION}

Estimating the size of wildlife populations is fundamental to ecology and conservation. The vagility of many organisms can have significant impacts on population-level monitoring, affecting survey methods and demographic estimates (Katzner et al., 2007, Yoccuz et al., 2001). Measurement of demographic parameters is also especially difficult and sometimes inefficient for animals that are widespread (Link and Nichols, 1994, Lewis and Gould, 2000, Margalida et al., 2011). Specifically, secretive and low-density raptors are hard to study, which causes monitoring of their populations to be both expensive and logistically demanding (Dunn and Hussell, 1995, Hussell, 1981, Zalles and Bildstein, 2000). However, because raptors are apex predators indicative of the health of ecosystems, monitoring them is considered critical (Bildstein, 2001, Rodríguez-Estrella et al., 1998, Sergio et al., 2005, 2006, 2008, Zalles and Bildstein, 2000).

For modern conservation of raptors to be successful, monitoring programs must be low in cost and simultaneously gather large amounts of reliable information on populations (Good et al., 2007, Kéry, 2008, Thogmartin et al., 2006, Whitfield et al., 2006). Many monitoring programs reduce costs by using citizen-science volunteers to collect data (Braschler, 2009, Cohn, 2008, Katzner et al., 2005, Silvertown, 2009, Devictor et al., 2010, Mulder et al., 2010). Several such programs focus on sampling bird populations over vast areas. For example, Breeding Bird Surveys (BBS) and Christmas Bird Counts (CBC) occur nationwide during the breeding and non-breeding periods, respectively (Dunn et al., 2005, Gray and Burlew, 2007, Link et al., 1994, Link and Sauer, 1998, Thogmartin et al., 2006). These surveys focus on Passerines because most songbirds are vocal and may be concentrated in high densities. Breeding and winter bird surveys also provide some information on raptor populations (Dunn and Hussell, 1995, Dunn et al., 
2005). Nevertheless, owing to the elusiveness, area-sensitive, and low-density occurrence behaviors of raptors, $\mathrm{BBS}$ and $\mathrm{CBC}$ do not provide adequate information for monitoring their populations (Bildstein, 2006, Zalles and Bildstein, 2000).

Numerous raptors migrate, and counts during migration are useful for monitoring species of conservation concern (Ainslie et al., 2013, Bildstein, 1998, Farmer et al., 2010, Sattler and Bart, 1984). Worldwide, hawk-count data are collected at sites where geography concentrates migrant raptors in large numbers (Zalles and Bildstein, 2000). In North America, these data are collected, stored, and made publicly available by the Hawk Migration Association of North America (HMANA; Hawk Migration Association of North America, 2008). While most sites are staffed by citizen-scientists, a small proportion of sites are maintained by trained researchers. Because volunteers staff many sites, collection costs of hawk-count data are typically minimal to the monitoring organizations and scientific community at large. These data may also prove useful for producing demographic estimates for ecological and management applications (Bednarz et al., 1990, Hawk Migration Association of North America, 2004, Farmer et al., 2007, Farmer et al., 2008a, 2008b, Hull et al., 2010).

The perceived benefits of data collection and potential applications notwithstanding, there can be extensive variation among hawk-count sites caused by poor standardization of counting coverage, different local landscape traits, variable numbers of observers, disparity among observers' proficiencies, weather effects on the counts, and temporal sampling variation (Dunn and Hussell, 1995, Dunn et al., 2008, Heath and Nolte, 2009, Lewis and Gould, 2000, Margalida et al., 2011). In spite of this variation, a great deal of effort has gone into evaluating trends in hawk-count data (Bednarz et al., 1990, Berthiaume et al., 2009, Broun, 1935, Hoffman and Smith, 2003, Hull et al., 2010, Sattler and Bart, 1984), or to use them as an index for 
population trends over time (Bednarz et al., 1990, Hoffman and Smith, 2003, Farmer, 2006, Farmer et al., 2008b, Farmer and Smith, 2010, Nagy, 1977). Several studies also have assessed observer ability to detect raptors (i.e., detectability) at hawk-count sites, and results showed that poor detection rates can negatively impact daily count totals (Allen et al., 1996, Berthiaume et al., 2009, Farmer et al., 2007, Farmer et al., 2010, Heath and Nolte, 2009, Nolte, 2012).

Golden eagles (Aquila chrysaetos canadensis) are rare in eastern North America and little is known about their population demography, movements, and behavior (Katzner et al., 2012a, Kochert and Steenhof, 2002). These birds breed throughout northeastern Canada, and the majority of the population migrates through the central Appalachian Mountains to overwinter in the eastern United States (Brodeur and Morneau, 1999, Brodeur et al., 1996, Millsap and Vana, 1984, Morneau et al., 1994). In states east of the Mississippi River, their wintering distribution is much larger than previously thought (T. Katzner et al., unpublished data). Though continental populations are in decline (Hoffman and Smith, 2003, Smith et al., 2008), this eastern subpopulation may, in fact, be increasing or nearing stability (Farmer et al., 2008a, Farmer and Smith, 2010, Hawk Migration Association of North America, 2004, Ombalski and Brandes, 2010). Other research suggests that there are between 50,000-80,000 golden eagles in North America, around half of the minimum global population (i.e., 120,000 individuals; Farmer et al., 2008a, Global Raptor Information Network, 2014, Hawk Mountain Sanctuary, 2014). Estimates for the eastern subpopulation range between 1,000-5,000 individuals (Katzner et al., 2012a, Ombalski and Brandes, 2010), less than a quarter of that estimated for golden eagles in western North America-19,000-35,000 (Good et al., 2007, Nielson et al., 2011).

Although little is known about this population, eastern golden eagles are counted in the hundreds at hawk-count sites throughout the central Appalachians. This makes them a good 
candidate for use of citizen-science data to better understand their demography. The main objective of this study was to evaluate past and present estimates of golden eagle population size in eastern North America. Specifically, we asked: 1) what proportion of golden eagles that migrate near hawk-count sites are available to be counted by observers, 2) how often are available golden eagles detected at hawk-counts, and 3) how reasonable are existing estimates of eastern golden eagle population size? To answer these research questions, (a) we simulated golden eagle migration to estimate availability to hawk-counters, (b) we applied a markrecapture analysis to citizen-science data, to estimate detectability by hawk-counters, and (c) we compare our modeled population sizes based on hawk-count data and availability and detectability to existing natural-history based estimates. Finally, we interpret both past and present estimates of population size based on hawk-count data in the context of golden eagle conservation in eastern North America.

\section{MATERIALS AND METHODS}

\section{$2.1 \quad$ Study area}

We focused our research on an area of the central Appalachian Mountains roughly defined by the state of Pennsylvania, USA (Figure 2-1a). Topography in Pennsylvania includes many long-linear ridges, lowland valleys, forested highlands, and mountain foothills. Local autumn weather is often temperate, windy, and overcast, with easterly and westerly winds dominate and interact with the steep topography of the ridge and valley regions to generate uplift. Eastern golden eagles move through this area in large numbers, with a peak in migration in the month of November (Katzner et al., 2012a). To collect data on these and other migrants, there are approximately 32 regularly staffed hawk-count sites in Pennsylvania. 


\subsection{Hawk-count data}

HMANA volunteers and employees collected, organized, and posted (on the internet) hawk-count data on golden eagles throughout eastern North America (Hawk Migration Association of North America, 2008). In addition, for a subset of sites, HMANA organizations provided data (not posted online) on age and timing of movements of individual eagles. We considered data only from hawk-count sites located east of the Mississippi River Valley during November 2002-2011. We used data from a subset of sites to estimate eagle availability, detectability, and population size.

\subsection{Modeling golden eagle migration}

To understand what proportion of migrant eagles are available to be counted at hawkcount sites, we designed a computer simulation model (hereafter, migration model), written in the Visual C\# 4.0 coding language (Microsoft Corporation 2010), to simulate migratory movements of golden eagles in the central Appalachian Mountains. The model reflects movement patterns of telemetered, migrant eagles $(n=21$ tracked eagles; Duerr et al., 2012, Katzner et al., 2012b, Lanzone et al., 2012, Miller et al., 2014). Within the model, each simulated flight route begins at a randomly selected starting position on the northeastern Pennsylvania border between the easternmost and westernmost routes used by telemetered eagles. Subsequently, the simulated eagle evaluates uplift in the five surrounding grid-points (i.e., east, west, southeast, southwest, and south at $90 \mathrm{~m}^{2}$ resolution) and selects a destination grid-point based on a directed, random walk. This process is repeated until the simulated eagle

reaches the southernmost border of the modeling region to complete a route. The weather conditions under which we modeled eagle flight were based on a random sample of 33 
November days between 2002 and 2011. These meteorological data were acquired from the North American Regional Reanalysis (NARR) dataset (Mesinger et al., 2006). The following rules govern movements in this migration model:

1. Eagle movement decisions are based only on topography and weather (i.e., uplift), not on conspecifics, terrestrial habitat, or individual experience.

2. Eagles use slope-soaring and thermal-soaring and gliding while on migration.

3. Eagles migrate across the study area within a 24-hr time period.

4. Eagles do not stop to forage or roost (i.e., flights are continuous and uninterrupted).

5. Weather conditions (e.g., wind speed, wind direction, thermal activity) shift on the hourly scale (i.e., per $100 \mathrm{~km}$ of modeled flight).

6. Eagle movements are governed by a combination of deterministic patterns (based on available uplift) and stochasticity.

7. The probability of migration for an eagle is equal for all weather days, regardless of the weather conditions.

The movement model and its decision steps are described in greater detail elsewhere (Dennhardt, 2014).

\subsection{Data analysis and interpretation}

From the perspective of hawk-count observers, there are three different types of migrant eagles. There are those eagles that are potentially available to be counted by observers and detectable to observers (i.e., fly within some known distance around a hawk-count site and are seen), available and undetectable (i.e., fly close enough to a site, but are not seen), and those that are unavailable and undetectable (i.e., fly too far away from a site and are not seen; Figure 2-2). Hawk count data characterize the first of these (available and detected). Our first research 
question aims to identify both the second (available and undetected) and third (unavailable and undetectable) types of eagles at hawk-count sites. Our second research question seeks to estimate detectability at hawk-counts. Our third research question uses hawk-count data and estimates of availability and detectability to calculate population sizes of eastern golden eagles. To address our first research question, we used the migration model to estimate the rate at which eagles are available to be counted at hawk-count sites in Pennsylvania. We could not use flight routes from existing telemetry data on golden eagles because of very few routes passing hawkcount sites in the region. To address our second question, we used historic hawk-count data in a mark-recapture analysis to evaluate the rate at which eagles are detectable at hawk-counts. Finally, we combined hawk-count data from five sites with empirical estimates of availability and modeled estimates of detectability to approximate the size of the total population migrating through Pennsylvania.

\subsection{Estimating rates of eagle availability}

The availability rate is the ratio of the total number of eagles available to be counted $\left(\widehat{N}_{\text {available }}\right)$ to the total eagles present (i.e., sum of available and unavailable, $\left.\widehat{N}_{\text {unavailable }}\right)$ at a given site, as follows:

Availability rate $=\widehat{N}_{\text {available }} /\left(\widehat{N}_{\text {available }}+\widehat{N}_{\text {unavailable }}\right)$

We assumed that observers can see and identify raptors up to $3 \mathrm{~km}$ from an observation point (Ainslie et al., 2013, Farmer et al., 2010). Simulated flight routes that passed within $3 \mathrm{~km}$ of a count site were classified as available (i.e., near enough to be counted), while those outside of this zone were classified as unavailable (i.e., too far away to be counted).

We estimated availability at five hawk-count sites: Allegheny Front (AF), Stone Mountain (ST), Waggoner's Gap (WG), Second Mountain (SM), and Hawk Mountain Sanctuary 
(HM; Hawk Migration Association of North America, 2008). We selected these five sites because of their counting coverage (i.e., greatest number of observers and hours counting) in November, their relative distance from each other $(\geq 25 \mathrm{~km})$, and the many records they had of migrating golden eagles $(\geq 20)$ each autumn. We limited the availability estimates to these five sites to reduce the likelihood that a simulated or real eagle could be counted at more than one hawk-count site.

We estimated the proportion of the migrant population that is available at our five hawkcount sites in two different ways. First, we estimated availability at these sites assuming a uniform distribution of eagle passage. In such a scenario, the number of available and unavailable eagles would be equal (uniform) among sites in space. Second, we used availability rates at these sites estimated from numbers of modeled eagles passing within a set distance from each site (32 km; i.e., based on the average distance between the sites). Availability is the ratio of the number of simulated flight routes passing through zones with a $3 \mathrm{~km}$ radius to the number passing through zones with a $32 \mathrm{~km}$ diameter.

To investigate the impact of weather on potential availability of eagles to observers, we evaluated actual hawk-count data on the 33 randomly chosen days on which we modeled eagle migration (Dennhardt, 2014). We classified three categories of migration days (i.e., high, medium, and low) by natural breaks in the hawk-count data (i.e., $\geq 24,9$, and 0 eagles counted on high-, medium-, and low-migration days, respectively) using ArcGIS 10 (ESRI Inc., Redlands, CA). We then estimated availability rates using uniform and site-specific methods for each of the three classes of days. This is reasonable because changes in weather conditions affect uplift generation, which affects eagle migration (Duerr et al., in review). Migrating golden eagles using orographic uplift are expected to be closer to hawk-counts and thus more available, 
while eagles using thermal uplift are expected to be further away and less available to be counted.

\subsection{Estimating rates of eagle detectability}

We conducted a mark-recapture analysis on hawk-count data to estimate detection rates - the proportion of eagles available to be counted that were actually seen by hawk-count observers. We focused this analysis on the Kittatinny Ridge System (hereafter, Kittatinny; Figure 2-1b) because it contains multiple hawk-count sites. Thus, the Kittatinny presents opportunities for birds to be repeatedly observed (e.g., marked and recaptured). In our formulation, a mark-and-recapture series represents a unique golden eagle that is counted at more than one hawk-count site on the Kittatinny.

To estimate detection rates, we used the Population Analysis (POPAN) parameterization of Jolly-Seber mark-recapture (Jolly, 1965, Schwarz and Arnason, 2013, Schwarz and Seber, 1999, Seber, 1965, Seber, 1986) in Program MARK (White and Burnham, 1999). Specifically, Jolly-Seber gives an estimate of the number of birds migrating along the Kittatinny — a local population size. Jolly-Seber models assume that animals retain their tags throughout study, tags are read properly, sampling is instantaneous, survival is homogenous for marked and unmarked individuals, catchability is homogenous for marked and unmarked individuals, and the study area is constant. Furthermore, POPAN Jolly-Seber provides, for $t$ capture occasions, $t-1$ estimates of probability of apparent survival $(\Phi), t$ estimates of probability of capture, given the individual is both alive and available for capture $(p), t-1$ estimates of probability of system entry into the population per occasion (pent), and super-population size $(N)$ per group (Figure 2-3). Apparent survival $(\Phi)$ is an estimate of the probability of an eagle adhering to the ridgeline, while $1-\Phi$ is the probability of leaving the ridgeline in this analysis (Teter et al., 2003). System entry (pent) is 
the probability of eagle entry into the ridge system between capture occasions. Superpopulation abundance $(N)$ is an estimate of the total number of golden eagles migrating along the Kittatinny. Finally, capture probability $(p)$ is the rate at which hawk-count observers detect golden eagles.

Candidate model sets we constructed were designed to replicate relationships between hawk-counts and golden eagles migrating nearby (Table 2-1). Models were fitted using the logit-link function for $\widehat{\Phi}$ and $\hat{p}$, identity link function for $\widehat{N}$, and multinomial logit-link function to constrain the $\widehat{p e n t}$ parameters to $\leq 1$ (White and Burnham, 1999). Because final capture probability $\left(\widehat{p_{5}}\right)$ is confounded with final apparent survival $\left(\widehat{\Phi}_{4}\right)$, we only considered detection estimates from $\widehat{p_{1}}$ to $\widehat{p_{4}}$. We used Akaike's Information Criterion corrected for small sample sizes $(\mathrm{AIC} c)$ to compare our models and identify models that required model-averaging of parameter estimates (Burnham and Anderson, 2002).

We built virtual capture histories based on golden eagle data, recorded at hawk-counts during all days in Novembers 2002-2011. We defined passage past each of the five markrecapture sites along the Kittatinny as separate capture occasions (Figure 2-1b). For each site, the day an eagle was counted, the time an eagle was counted, and the age of each eagle were the primary inputs to the computer model. To build capture histories unique to each individual, we established three rules for matching eagle records to one another. These rules, described below, were implemented in the Visual C\# coding environment (Microsoft Corporation, 2010).

Our first rule was that recaptures had to be on the same day as captures. Our second rule was that a recapture could only occur when an eagle passed a subsequent site within a time window that allowed the eagle to continuously soar between sites. We measured ridgeline distance between sites and assumed that eagles travelled $10.90 \pm 0.875 \mathrm{~m} / \mathrm{s}$ (mean $\pm \mathrm{SE}$ ) using orographic (ridge) lift (Duerr et al., 2012). To evaluate potential variability in flight times, we 
repeated the analysis for time windows defined by one, two, four, and six SEs. Our third rule was that eagles that passed subsequent sites within the appropriate time window must also match in age class. Using the four sets of capture histories (i.e., those with one, two, four, and six SEs), we built two types of each set-one set of capture histories built with the age class rule included and another set without it. Finally, for every set, we grouped each eagle capture history by the year each eagle was counted (i.e., 2002-2011). Therefore, we estimated our models in Program MARK based on capture histories with a group for each of the 10 years.

We defined a set of four candidate mark-recapture models, a priori, based on eagle biology and the nature of hawk-counts (Table 2-1). Hawk-count data contain no information on distance from observer to raptor, so we assumed detection rates were homogenous with regard to distance (Buckland et al., 2001). We also assumed that detection rates varied between sites. We modeled capture probability $(p)$ with respect to site $(t)$ in all of our candidate models due to evidence of differences in detecting migrants among hawk-count sites (Farmer et al., 2010, Heath and Nolte, 2009, Nolte, 2012).

\section{7 $\quad$ Estimating population size}

We modeled population estimates for comparison with existing natural-history based estimates. We used raw hawk-count data (i.e., from AF, ST, WG, SM, and HM) in conjunction with empirically-derived availability and modeled detection rates, as follows:

$\widehat{N}_{\text {detectable }}=N_{i} / \hat{p}, \quad 2$

$\widehat{N}_{\text {available }}=\widehat{N}_{\text {detectable }} /$ Availability rate ,

$\widehat{N}_{\text {total }}=\sum_{i=1}^{n} \widehat{N}_{\text {available }}, \quad 4$

where, in Eq. 2, $N_{i}$ is the raw count of golden eagles in November at site $i, \hat{p}$ is the estimated detection probability from the mark-recapture analysis, and $\widehat{N}_{\text {detectable }}$ is the estimated number 
of eagles that were detectable at site $i$. In Eq. 3, Availability rate is the estimate of eagle availability at site $i$ (Eq. 1), and $\widehat{N}_{\text {available }}$ is the number of eagles available to be counted at site

i. Finally, in Eq. 4, we sum all local abundances to calculate $\widehat{N}_{\text {total }}$, the size of the total migrant population in Pennsylvania.

We further adjusted our availability rates by the number of eagles that are potentially counted at more than one of our five sites (hereafter, double-count). Without accounting for double-count rates, we would violate our assumption that eagles encountered at a particular hawk-count site are unique to that site. We classified potentially double-counted eagles as those that were available to be counted at multiple sites. We estimated double-count rates by estimating the proportion of simulated flight routes that passed between pairs of hawk-count sites. Simulated eagles unique to a particular hawk-count were those that only passed one site, while others that additionally passed nearby sites would be considered double-counted eagles. To account for double-counting, we adjusted all availability rates by the number of unavailable eagles unique to each hawk-count site, before estimating population size.

Here, we generated ten-yr sets $(n=122)$ of population size estimates using our eight detection rates based on capture histories built with either a one-, two-, four-, or six-SE estimated time window and with (or without) eagle age information. Estimates we present include the following availability features: $3 \mathrm{~km}$ radial buffer (to classify available eagles), $32 \mathrm{~km}$ diameter buffer (to classify unavailable eagles), and the conditions of high-, medium-, and low-migration days (as a proxy for changing weather conditions) in Pennsylvania.

\subsection{Estimating population size with detection rates from literature}

Due to low detection rates estimated from our POPAN Jolly-Seber models, we collected detection rates from recent literature to estimate population size in Pennsylvania and compared 
our original estimates with those estimates. Studies on golden eagle detectability at hawk-count sites are scarce so, in some cases, we had to use detection rates for other raptors as a comparable substitute (i.e., species either similar in size or migratory flight behavior as golden eagles). Sattler and Bart (1984) used a double-observer approach to estimate the proportion of raptors detected at the Derby Hill hawk-count in Ontario, Canada. They estimated detection (mean \pm SE) as $0.78 \pm 0.04$ for red-tailed hawks (Buteo jamaicensis), which, of the species they evaluated, we expected was the most similar in migratory flight as the golden eagle. Berthiaume et al. (2009) used a Huggins closed-capture experiment (White and Burnham 1999) with a double-observer approach and estimated detection as $0.41 \pm 0.09$ for the pooled counts of bald eagles (Haliaeetus leucocephalus) and golden eagles at the Tadoussac hawk-count in Quebec, Canada. Farmer et al. (2010) conducted a Brownian-Bridge movement analysis (Horne et al., 2007) to estimate detection (mean \pm SD) as $0.338 \pm 0.288$ for telemetered osprey (Pandion haliaetus) on migration in eastern North America. Nolte (2012) also used a Huggins closedcapture experiment (White and Burnham 1999) with double-observer count data to estimate detection rates for migrating raptors at the Lucky Peak hawk-count in Boise, Idaho, USA. He estimated detection as $0.875 \pm 0.075$ for golden eagles.

\section{RESULTS}

\subsection{Rates of eagle availability}

We simulated 6,094 eagle flight routes through Pennsylvania. Forty percent of these passed within $3 \mathrm{~km}$ of a hawk-count site. Based on uniform eagle distribution across all sites, mean $( \pm \mathrm{SD})$ availability from the five hawk-count sites was $0.110( \pm 0.050$; range: $0.030-$ 0.150). When eagle distribution was based on proportions of simulated paths within $32 \mathrm{~km}$ of hawk-counts mean availability doubled to $0.240( \pm 0.140$; range: $0.040-0.440)$. 


\subsection{Building capture histories for eagles}

We constructed capture histories from a data set of 3,069 migrant golden eagle observations along the Kittatinny during November from 2002-2011. Of these, 224 were counted at Little Gap, 543 at Bake Oven Knob, 650 at Hawk Mountain Sanctuary, 407 at Second Mountain, and 1,245 at Waggoner's Gap. Mean $( \pm$ SD) number of unique individuals (i.e., capture histories) was 2705 ( \pm 87 ; range: $2775-2592)$ for histories built using the aging criterion and the four sets of timing criteria (i.e., one, two, four, and six SEs). Mean number of unique individuals was 2491 ( \pm 116 ; range: $2347-2586)$ for those built without using the aging criterion and using the four timing criteria.

\subsection{Rates of eagle detectability}

In our mark-recapture analysis, the top-ranked model that carried all of the $\mathrm{AIC} c$ weight (Table 2-2a) included apparent survival $(\Phi)$ varying with site, local abundance $(N)$ varying with site, and kept system entry (pent) constant. This particular model set involved capture histories where we assumed eagle aging would be consistent and that eagles would travel between hawkcounts within one SE's estimated time. Models including constant apparent survival and system entry were never supported. For other model sets where we included the aging criterion, three of four top-ranked models were fully time-dependent, whereas one included system entry as constant and all other parameters varying by site. AIC $c$ weights varied among several models in sets where input capture histories excluded the aging criterion, but included any one of the variations in timing (i.e., one, two, four, or six SEs). No one model carried all of the AIC $c$ weight in these examples (Table 2-2b-e). Instead, variation was distributed throughout the first three models in each set, so we model-averaged detection estimates in those sets (Burnham and Anderson 2002). In capture histories for each of these sets, we assumed that eagle aging would 
not be consistent (i.e., excluded the aging criterion) and that eagles would travel between sites within the respective SE's estimated time. Here, each of the top-ranked models included constant apparent survival, while all else varied with site (Table 2-2b-e).

In the model where we included age classifications and $1 \mathrm{SE}$ time windows, mean $( \pm \mathrm{SE}$; $95 \%$ CI) detection rate was $0.048( \pm 0.006$; Table $2-3 a)$. Detection rates increased to $0.062( \pm$ 0.010), when we increased the SE of the interval for time windows. Our highest estimates of detection did not rely on age classifications. Mean detection was estimated at $0.072( \pm 0.006)$, $0.073( \pm 0.006), 0.092( \pm 0.005)$, and $0.110( \pm 0.006)$ for one, two, four, and six SEs, respectively (Table $2-3 b-e)$.

\subsection{Number of eagles migrating through the Kittatinny Ridge System}

Estimated numbers of migrants along the Kittatinny Ridge varied annually. Mean $( \pm \mathrm{SE}$; $95 \% \mathrm{CI})$ local abundance ranged from $673( \pm 102)$ to $1,493( \pm 178)$ migrating golden eagles, when the aging criterion was included (top-ranked model; Table 2-4a). Mean abundance ranged from $421( \pm 61)-936( \pm 107)$, when the aging criterion was excluded (model-averaged; Table 24b). Each of these sets of local abundance was modeled assuming that eagles would travel between hawk-counts within one SE's estimated time.

\subsection{Number of eagles migrating through Pennsylvania}

We estimated population size based on hawk-count data from five prominent sites in Pennsylvania adjusted by rates of double-counting between sites. Double-count rates varied between sites and were: 0.80 (i.e., $80 \%$ of birds counted at HM were also counted at SM), 0.60 (SM to $\mathrm{WG}), 0.38$ (HM to $\mathrm{WG}$ ), and 0.59 (ST to AF).

Under the scenario where eagle migration (and availability) was uniform across all sites, mean ( \pm SE) annual abundance across all years was 60,973 ( $\pm 15,742$; range: $36,242-95,868)$ 
individuals. Our lowest population estimates were modeled assuming that availability differed between hawk-counts. When availability was specific to site and based on the classes of migration days (high-, medium-, and low-migration, respectively), we obtained three ten-yr (2002-2011) sets of estimated population size. Over these three sets, mean annual population size was $24,794( \pm 6,656$; range: $16,675-49,195)$ golden eagles migrating through Pennsylvania. In our complete collection of population size estimates ( $n=122$ ten-yr sets), mean annual abundance was 55,366 ( $\pm 27,699$; range: 16,675 - 220,932) individuals (Figure 24). Lowest estimates occurred when we modeled population size with site-specific availability and migration day classes, accounting for double-counts of eagles, and detection rates without eagle ages and with six SE's flight time (Table 2-3e). Highest population estimates occurred when we modeled population size without accounting for double-counts of eagles for all availability and detection rates.

\subsection{Number of eagles based on detection rates from literature}

To compare our estimates of population size with those based on typical detection rates, we estimated population size using our availability rates and detection rates for migrating raptors from recent literature (Berthiaume et al., 2009, Farmer et al., 2010, Nolte, 2012, Sattler and Bart, 1984). Due to the inflated SE (i.e., \pm 0.288) for detection rates from Farmer et al. (2010), we include population size estimates with their rates and without them. With detection estimates from their work, mean population size (mean \pm SE) was 9,516 $\pm 8,767$ golden eagles migrating in Pennsylvania during November 2002-2011. Without detectability from Farmer et al. (2010), mean population size was $4,784 \pm 1,940$ individuals. 


\section{DISCUSSION}

\subsection{Evaluating estimates of population size}

Our models suggest that there are more eastern golden eagles than previously recognized. It is difficult to choose which set of our modeled estimates are most reasonable, and it would be inappropriate to assume that model output suggesting smallest population size is most accurate simply because it is closest to previous estimates. At the same time, many of the modeled estimates are implausibly large, and therefore, unlikely to be accurate.

Of the 122 ten-yr sets of estimated population size, we focus our discussion only on those based on the highest detectability and availability rates because those produced the lowest population size estimates. There are an estimated 50,000-80,000 golden eagles in North America (Farmer et al., 2008a, Global Raptor Information Network, 2014, Hawk Mountain Sanctuary, 2014). Of these, an estimated $18,948-29,541$ golden eagles reside in the western contiguous United States (Nielson et al., 2011). These estimates used data collected in late summer (August-September), so they likely exclude migrants from Alaska and western Canada (McCaffery and McIntyre, 2005).

The eastern subpopulation of golden eagles is presumed to be much smaller that the western population (1,000 - 5,000; Katzner et al., 2012a, Ombalski and Brandes, 2010). This is substantially less than our smallest estimates, all of which were $>15,000$ individuals. In fact, with modeled availability rates, population estimates would be $<10,000$ only when detection rates were $>30 \%$. Using detection rates from recent literature, we were able to estimate population size close to the previous maximum approximation of 5,000 - that is, 4,784 $\pm 1,940$ (mean $\pm \mathrm{SE}$ ) individuals. This suggests that our detection estimates may, in fact, be implausible and that our mark-recapture analysis may require some modifications. If we forced detection to 
$42 \%$ and included our mean estimate of availability ( $24 \%)$, only then were population estimates $<5,000$ individuals. Likewise, for the highest detection rate we estimated $(\sim 11 \%)$, availability would have to be $80 \%$ for the total population size to be $<5,000$ individuals.

All calculations with our detectability and availability estimates strongly suggest that the true size of the population of golden eagles in eastern North America is larger than currently recognized. This is especially true because $100-500$ additional migrant golden eagles are observed outside of the area we modeled with more likely not detected and unavailable to be counted—at Cape May Observatory (New Jersey), Detroit River Hawkwatch-Lake Erie Metropark (Michigan), and Hawk Ridge (Minnesota; Hawk Migration Association of North America, 2008, Mehus and Martell, 2010).

It is clear that our low estimates for availability and detectability are driving our high population estimates. It is certainly the case that many eagles are missed by counters, and that is perhaps why hawk-count data are so rarely used to estimate population size. Actual detection rates for golden eagles are likely similar to (if not, slightly greater than) that estimated for telemetered osprey on migration in eastern North America (33.8 $\pm 28.8 \%$, mean \pm SD; Farmer et al., 2010). Higher detection rates might be possible on weekends at prominent sites like Hawk Mountain, when more public observers are present also spotting migrants. However, on weekdays, when public observers are absent, detection might drop dramatically if only few counters are present.

Real availability rates for golden eagles are difficult to estimate but are probably $<50 \%$ at hawk-count sites in Pennsylvania. While it is entirely possible to estimate availability rates based on the telemetered eagles passing close enough to hawk-counts in autumn, current rates are very low (i.e., $<5 \%$ of paths; Miller, 2012). It is unlikely that topography around a single 
hawk-count concentrates $25 \%$ or more of the migrant population, but for some sites, true availability may be closer to that. For example, in our mark-recapture and migration models, it is evident that the Waggoner's Gap (WG) hawk-count encounters large numbers of golden eagles compared to other sites. Across all years, in our mark-recapture experiment, WG counted 1,245 golden eagles, nearly two times that of the well-staffed HM site. Further evidenced in our migration model, a continuous migration corridor (i.e., hot-spot of simulated paths) converges on WG and not on HM. This indicates that higher availability rates might occur where mesoscale environmental factors (e.g., local topography and weather) produce smaller, unbroken migration corridors around some hawk-counts in Pennsylvania. It is possible that minor ridgelines $(<650$ $\mathrm{m}$ in elevation), immediately north of the southernmost sites, may collect and funnel more migrants toward sites like WG. This could produce higher eagle availability rates at similar sites, yet this is not known at present.

\subsection{Golden eagle conservation in eastern North America}

The eastern subpopulation of golden eagles may be increasing (Farmer and Smith, 2010). During the period 1974 - 2004 numbers of golden eagles counted increased consistently in eastern North America (Farmer et al., 2008b); although this trend has not continued since 2004 (Hawk Migration Association of North America, 2008). Despite these trends, our migration model indicates that a large proportion of the total population may fly less frequently near hawkcount sites than is expected in Pennsylvania, especially in areas outside of the Ridge and Valley physiographic province. Away from prominent ridgelines, thermal uplift might be available more often for individuals to thermal-soar and glide, which we know is a faster and more direct mode of transportation than slope-soaring (Duerr et al., 2012). It is clear that this flight behavior could have a negative influence on eagle availability and detectability. Further support that more 
migrants are missed than previously thought, the probability of a golden eagle migrating on a given day increases with presence of weather conditions associated with generating thermal uplift (Duerr et al., in review).

Though they clearly migrate away from ridgelines where orographic uplift is not generated, golden eagles will still use this uplift form in slope-soaring flight for the majority of total migration time in autumn (Duerr et al., in review, Miller et al., 2014). Moreover, eagle slope-soaring behavior has implications for rapidly increasing wind energy development in eastern North America and Pennsylvania in particular (American Wind Energy Association, 2013). With increased development, collision with active wind turbines may become an increasing threat to eastern golden eagles, especially because individuals use slope-soaring more often when thermals are diminished in autumn (Brandes et al., 2009, Miller et al., 2014, United States Fish and Wildlife Service, 2013, Watson, 2010). Eagle fatalities from collisions with turbines are well documented worldwide, which may warrant conservation action with respect to protecting (regionally moving) autumn migrants and (locally moving) winter residents from potential conflicts (Fielding et al., 2006, Hunt, 2002, Katzner et al., 2012b, Madders and Whitfield, 2006, Miller et al., 2014, Pagel et al., 2013, Smallwood and Thelander, 2008). In order to develop conservation action plans, managers require increased knowledge of demography for species of concern, including eastern golden eagles (United States Department of Interior, 2013, United States Fish and Wildlife Service, 2013). Our research highlights one potential mechanism to get at this information.

\subsection{A novel approach for estimating population size}

Though monitoring raptor populations is challenging, our study demonstrates the feasibility of using hawk-count data to inform estimates of population size. However, we 
caution that the technique needs further refining before its results are used in conservation planning. Our migration model clearly illustrates that many more eagles may be missed than previously recognized. At the same time, although our estimates of detectability and availability were exceptionally low, comparisons with recent telemetry data suggest that the general movement patterns produced with our migration model are reasonable and that the availability and detectability rates we estimated are similar to those expected for these birds. Despite this fact, we believe that our approach would likely benefit from improved estimation of availability and detectability rates. Estimation of rates might improve through identification of currently unknown relationships between golden eagles and the intrinsic and extrinsic factors that influence their migratory movements (Nathan et al., 2008). It could be possible that there are smaller areas in the region where golden eagles migrate more frequently along prominent ridgelines - perhaps, due to some unidentified internal navigation, external topographic, or weather factors (Thorup et al., 2006). One example of an unknown relationship might involve differences in eagle migration at scales smaller or larger than $90 \mathrm{~m}^{2}$ grid resolution (i.e., based on zonal landscape features and ambient uplift on eagle movements). Specifically, a hawk-count site in the Ridge and Valley province might be surrounded by long-linear ridgelines in very close proximity $(<1 \mathrm{~km})$. In this type of area, migrants might be brought closer together in greater numbers than at a site positioned many $\mathrm{km}$ away from other prominent, topographic features. In addition, individuals flying at lower altitudes (associated with slope-soaring) may also be missed more often due to being difficult to see on adjacent ridges.

There are also some limitations in how we modeled detection rates, which warrant further investigation. First, we could not assess variation in detection with distance, vegetation (landcover), or topography; though these covariates are important factors that could affect detection at 
hawk-counts (Buckland et al., 2001). Second, our virtually-constructed capture histories may misrepresent migrant eagles along the Kittatinny. Although we manually confirmed numerous "captures" and "recaptures" based on our matching criteria, there could be problems with our virtual framework for building capture histories. For example, if hawk-counters truly were not consistent in eagle age classifications, then our capture histories may violate the tag loss assumption in Jolly-Seber modeling (Schwarz and Arnason, 2013). Any mismatched eagle (e.g., incorrect count date, encounter time mistakes, and/or misclassified ages) constitutes tag loss in our design and would bias our detection estimates and reduce precision in our estimates (Arnason and Mills, 1981, Margalida et al., 2011). When we excluded age classifications in building eagle capture histories, detection rates increased, and this may indicate violation of the no tag-loss assumption.

\subsection{Implications: Citizen-science data are useful in population size estimation}

This exercise demonstrates the utility of using citizen-science data to address a pressing conservation goal: estimating population size for a species of regional concern. Both the migration and mark-recapture models suggest that a large proportion of migrant golden eagles are likely being missed by hawk-count observers in Pennsylvania. This is important because sampling to estimate population size depends on understanding the relationship between the size of the sample and the size of the population. Nonetheless, hawk-count data are useful because of their standardized collection and relatively low cost to research (Bildstein et al., 2008, Dunn et al., 2008, Hawk Migration Association of North America, 2006), while the monetary investment involved with collection and analysis of other data types can be much greater. The accessibility of such large, historic datasets allowed us to assess demography of a species of regional conservation concern. Future work with citizen-science data might focus on further 
standardization of their collection, increased counting coverage in terms of number of observers and time, applications with other migrant raptor species, and investigations into better estimating availability and detectability for estimates of population size. 


\section{ACKNOWLEDGMENTS}

Funding for this research was provided by the Hawk Migration Association of North America 2012 Research Award, Highlanders for Responsible Development, Inc., Virginia Society for Ornithology, and the Eastern Golden Eagle Working Group. Various hawk-count sites provided their data, which helped make this project a success. We sincerely thank the following individuals and organizations: B. Barnhurst and M. McIntosh (Eagle Crossing, Quebec, CAN), Bird Protection Quebec (Montreal, Quebec, CAN), the Ministere des Ressources naturelles et de la Faune, Gouvernement du Quebec (Quebec, CAN), and Cape May Observatory (New Jersey, USA). We also thank L. Goodrich at Hawk Mountain Sanctuary for her work in getting permissions from all of the hawk-count sites and the actual data to our research team for use. We thank K. Bildstein for his support of this work and for allowing our researchers to stay at the Acopian Center for Conservation Learning at Hawk Mountain Sanctuary during a busy field season. We give much gratitude to the many hawk-count sites in eastern North America recording migratory birds of prey, whose data we used in this research, especially all of the count sites in Pennsylvania, USA. We also thank the devoted observers at Allegheny Front Hawkwatch and Tussey Mountain who lent much of their golden eagle surveying expertise to our researchers. We also thank V. Maskey, S. Lamont, V. Talreja, G. Doretto, D. McLaughlin, M. Strager, and E. Iannello at West Virginia University whose tireless generosity in lending computer coding expertise and technological resources and support is sincerely appreciated. Without their kindness and guidance, this research could not have been completed successfully. We are thankful for generous assistance in the field from H. Clipp, N. Goodman, and L. Moon. We also thank the reviewers of this manuscript, which helped improve this work. 


\section{REFERENCES}

AINSLIE, B., N. ALEXANDER, N. JOHNSTON, J. BRADLEY, A.C. POMEROY, P.L. JACKSON, AND K.A. OTTER. 2013. Predicting spatial patterns of eagle migration using a mesoscale atmospheric model: a case study associated with a mountain-ridge wind development. International Journal of Biometeorology 58: 17-30.

ALLEN, P.E., L.J. GOODRICH, AND K.L. BILDSTEIN. 1996. Within- and among-year effects of cold fronts on migrating raptors at Hawk Mountain, Pennsylvania, 1934-1991. Auk 113: 329-338.

ARCGIS v. 10. ESRI Inc., Redlands, California, USA.

ARNASON, A.N AND K.H. MILLS. 1981. Bias and Loss of Precision Due to Tag Loss in Jolly-Seber Estimates for Mark-Recapture Experiments. Journal of Fisheries and Aquatic Sciences 38: 1077-1095.

AMERICAN WIND ENERGY ASSOCIATION (AWEA). 2013. State Wind Energy Statistics: Pennsylvania. American Wind Energy Association. Washington, District of Columbia, USA. Online at: <http://awea.rd.net/Resources/state.aspx?ItemNumber=5188> (Last accessed 05 February 2014).

BEDNARZ, J.C., D. KLEM, JR., L.J. GOODRICH, AND S.E. SENNER. 1990. Migration counts of raptors at Hawk Mountain, Pennsylvania, as indicators of population trends, 1934-1986. Auk 107: 96-109.

BERTHIAUME, E., M. BÉLISLE, AND J.P. SAVARD. 2009. Incorporating Detectability into Analyses of Population Trends Based on Hawk Counts: A Double-Observer Approach. Condor 111: 43-58.

BILDSTEIN, K.L. 1998. Long-Term Counts of Migrating Raptors: A Role for Volunteers in Wildlife Research. Journal of Wildlife Management 62: 435-445.

BILDSTEIN, K.L. 2001. Why migratory birds of prey make great biological indicators. Pages 169-179 in Hawkwatching in the Americas (K.L. Bildstein and D. Klem, Eds.). Hawk Migration Association of North America, North Wales, Pennsylvania, USA.

BILDSTEIN, K.L. 2006. Migrating Raptors of the World: Their Ecology and Conservation. Cornell University Press, Ithaca, New York, USA. 320pp.

BILDSTEIN, K.L., J.P. SMITH, AND E. RUELAS INZUNZA. 2008. The future of raptormigration monitoring. Pages 435-446 in State of North America's Birds of Prey, Series in Ornithology no. 3 (K.L. Bildstein, J.P. Smith, E. Ruelas Inzunza, and R.R. Veit, Eds.). Nuttall Ornithological Club, Cambridge, Massachusetts, and American Ornithologists' Union, Washington, District of Columbia, USA. 
BRANDES, D., T.M. MILLER AND T. KATZNER. 2009. Wind Power Mortality. Pages 300303 in Avian Ecology and Conservation: A Pennsylvania Focus with National Implications (S.K. Majumdar, T.L. Master, M.C. Brittingham, R.M. Ross, R.S. Mulvihill and J.E. Huffman, Eds.). Pennsylvania Academy of Science, Lafayette College, Easton, Pennsylvania, USA.

BRASCHLER, B. 2009. Successfully Implementing a Citizen-Scientist Approach to Insect Monitoring in a Resource-poor Country. BioScience 59: 103-104.

BRODEUR, S., R. DECARIE, D.M. BIRD, AND M. FULLER. 1996. Complete migration cycle of Golden Eagles breeding in northern Québec. Condor 98: 293-299.

BRODEUR, S. AND F. MORNEAU. 1999. Rapport sur la situation de l'aigle royal (Aquila chrysaetos) au Québec. Société de la faune et des parcs du Québec, Direction de la faune et des hábitats. Dépôt légal - Bibliothèque nationale du Québec, Québec, Canada. 75pp.

BROUN, M. 1935. The hawk migration during the fall of 1934, along the Kittatinny Ridge in Pennsylvania. Auk 52: 233-248.

BUCKLAND, S.T., D.R. ANDERSON, K.P. BURNHAM, J.L. LAAKE, D.L. BORCHERS, AND L. THOMAS. 2001. Introduction to Distance Sampling: Estimating Abundance of Biological Populations. Oxford University Press, Oxford, UK. 432pp.

BURNHAM, K. AND D. ANDERSON. 2002. Model Selection and Multi-Model Inference (2nd Edition). Springer-Verlag, New York, New York, USA. 496 pp.

COHN, J.P. 2008. Citizen Science: Can Volunteers Do Real Research? BioScience 58: 192197.

DENNHARDT, A.J. 2014. Modeling Migration and Citizen-Science Data to Estimate Golden Eagle Abundance in Eastern North America (Thesis). West Virginia University Press, Morgantown, West Virginia, USA.

DEVICTOR, V., R.J. WHITTAKER, AND C. BELTRAME. 2010. Beyond scarcity: citizen science programmes as useful tools for conservation biogeography. Diversity and Distributions 16: 354-362.

DUERR, A.E., T.A. MILLER, M. LANZONE, D. BRANDES, J. COOPER, K. O'MALLEY, C. MAISONNEUVE, J. TREMBLAY, AND T. KATZNER. 2012. Testing an Emerging Paradigm in Migration Ecology Shows Surprising Differences in Efficiency between Flight Modes. PLoS ONE 7(4): 1-7.

DUERR, A.E., T. MILLER, M. LANZONE, D. BRANDES, J. COOPER, K. O'MALLEY, C. MAISONNEUVE, J. TREMBLAY, AND T. KATZNER. In review. Stereotyped flight response of slope-soaring birds to seasonal variation in thermal generation. Functional Ecology. 
DUNN, E.H. AND D.J.T. HUSSELL. 1995. Using migration counts to monitor landbird populations: Review and evaluation of current status. Pages 43-88 in Current Ornithology, vol. 12 (D.M. Power, Ed.). Plenum Press, New York, New York, USA.

DUNN, E.H., B.L. ALTMAN, J. BART, C.J. BEARDMORE, H. BERLANGA, P.J. BLANCHER, G.S. BUTCHER, D.W. DEMAREST, R. DETTMERS, W.C. HUNTER, AND OTHERS. 2005. High priority needs for range-wide monitoring of North American landbirds. Partners in Flight Technical Series, no. 2. Online at <http://www.partnersinflight.org/pubs/ts/02-MonitoringNeeds.pdf> (Last accessed 15 November 2011).

DUNN, E., D.J.T. HUSSEL, AND E. RUELAS I. 2008. Recommended Methods for Population Monitoring at Raptor-migration Watchsites. Pages 447-460 in State of North America's Birds of Prey, Series in Ornithology no. 3 (K.L. Bildstein, J.P. Smith, E. Ruelas Inzunza, and R.R. Veit, Eds.). Nuttall Ornithological Club, Cambridge, Massachusetts and American Ornithologists' Union, Washington, District of Columbia, USA.

FARMER, C.J. AND J.P. SMITH. 2010. Seasonal differences in migration counts of raptors: utility of spring counts for population monitoring. Journal of Raptor Research 44: 101112.

FARMER, C.J., D.J.T. HUSSELL, AND D. MIZRAHI. 2007. Detecting population trends in migratory birds of prey. Auk 124: 1047-1062.

FARMER, C.J., K. SAFI, D.R. BARBER, I. NEWTON, M. MARTELL, AND K.L. BILDSTEIN. 2010. Efficacy of migration counts for monitoring continental populations of raptors: an example using the Osprey (Pandion haliaetus). Auk 127: 863-870.

FARMER, C.J., L.J. GOODRICH, E. RUELAS I., AND J.P. SMITH. 2008a. Conservation Status of North America's Birds of Prey. Pages 303-420 in State of North America's Birds of Prey, Series in Ornithology no. 3 (K.L. Bildstein, J.P. Smith, E. Ruelas Inzunza, and R.R. Veit, Eds.). Nuttall Ornithological Club, Cambridge, Massachusetts and American Ornithologists' Union, Washington, District of Columbia, USA.

FARMER, C.J., R.J. BELL, B. DROLET, L.J. GOODRICH, D. GROVE, D.J.T. HUSSELL, D. MIZRAHI, F.J. NICOLETTI, AND J. SODERGREN. 2008b. Trends in autumn counts of migratory raptors in eastern North America, 1974-2004. Pages 179-215 in State of North America's Birds of Prey, Series in Ornithology no. 3 (K.L. Bildstein, J.P. Smith, E. Ruelas Inzunza, and R.R. Veit, Eds.). Nuttall Ornithological Club, Cambridge, Massachusetts and American Ornithologists' Union, Washington, District of Columbia, USA.

FIELDING, A.H., D.P. WHITFIELD, AND D.R.A. MCLEOD. 2006. Spatial association as an indicator of the potential for future interactions between wind energy developments and golden eagles Aquila chrysaetos in Scotland. Biological Conservation 131: 359-369. 
GLOBAL RAPTOR INFORMATION NETWORK. 2014. Species account: Golden Eagle Aquila chrysaetos. The Peregrine Fund, Boise, Idaho, USA. Online at: <http://www.globalraptors.org> (Last accessed 15 February 2014).

GRAY, B.R. AND M.M. BURLEW. 2007. Estimating Trend Precision and Power to Detect Trends across Grouped Count Data. Ecology 88: 2364-2372.

GOOD, R.E., R.M. NIELSON, H. SAWYER, AND L.L. MCDONALD. 2007. A population estimate for golden eagles in the western United States. Journal of Wildlife Management 71: 395-402.

HEATH, J.A. AND E.G. NOLTE. 2009. Detectability of Migrating Raptors at Lucky Peak, Idaho. Hawk Migration Studies 34: 16-17.

HAWK MIGRATION ASSOCIATION OF NORTH AMERICA. 2004. Raptor Population Index Project. Hawk Migration Association of North America, North Wales, Pennsylvania, USA. Online at <http://www.rpi-project.org > (Last accessed 10 November 2012).

HAWK MIGRATION ASSOCIATION OF NORTH AMERICA. 2006. Data collection protocol. Hawk Migration Association of North America, North Wales, Pennsylvania, USA. Online at: <http://www.hmana.org/forms.php> (Last accessed 10 January 2014)).

HAWK MIGRATION ASSOCIATION OF NORTH AMERICA. 2008. Hawk Migration Association of North America, North Wales, Pennsylvania, USA. Online at <http://www.hmana.org/> or <http://www.hawkcount.org/> (Last accessed 01 January 2014).

HAWK MOUNTAIN SANCTUARY. 2014. RaptorPedia, Hawk species at Hawk Mountain: Golden eagles. Hawk Mountain Sanctuary, Kempton, Pennsylvania, USA. Online at: <http://www.hawkmountain.org/raptorpedia/hawks-at-hawk-mountain> (Last accessed 15 February 2014).

HOFFMAN, S.W. AND J.P. SMITH. 2003. Population trends of migratory raptors in western North America, 1977-2001. Condor 105: 397-419.

HORNE, J.S., E.O. GARTON, S.M. KRONE, AND J.S. LEWIS. 2007. Analyzing animal movements using Brownian bridges. Ecology 88: 2354-2363.

HULL, J.M., A.M. FISH, J.J. KEANE, S.R. MORI, B.N. SACKS, AND A.C. HULL. 2010. Estimation of Species Identification Error: Implications for Raptor Migration Counts and Trend Estimation. Journal of Wildlife Management 74: 1326-1334.

HUNT, G. 2002. Golden Eagles in a Perilous Landscape: Predicting the Effects of Mitigation for Wind Turbine Bladestrike Mortality. California Energy Commission Report P50002-034F. Sacramento, California, USA. 
HUSSELL, D.J.T. 1981. The use of migration counts for monitoring bird population levels. Pages 92-102 in Estimating Numbers of Terrestrial Birds (C.J. Ralph and J.M. Scott, Eds.). Blackburn Press, Caldwell, New Jersey, USA.

JOLLY, G.M. 1965. Explicit estimates from capture-recapture data with both death and immigration-Stochastic model. Biometrika 50: 113-128.

KATZNER, T., B. SMITH, T. MILLER, D. BRANDES, J. COOPER, M. LANZONE, D. BRAUNING, C. FARMER, S. HARDING, D. KRAMAR, C. KOPPIE, C. MAISONNEUVE, AND OTHERS. 2012a. Status, biology, and conservation priorities for North America's eastern Golden Eagle (Aquila chrysaetos) population. Auk 129: 168-176.

KATZNER, T.E., D. BRANDES, T. MILLER, M. LANZONE, C. MAISONNEUVE, J.A. TREMBLAY, R. MULVIHILL, AND G.T. MEROVICH, JR. 2012b. Topography drives migratory flight altitude of golden eagles: implications for on-shore wind energy development. Journal of Applied Ecology 49: 1178-1186.

KATZNER, T., E.J. MILLNER-GULLAND, AND E. BRAGIN. 2007. Using Modeling to Improve Monitoring of Structured Populations: Are We Collecting the Right Data? Conservation Biology 21: 241-252.

KATZNER, T., S. ROBERTSON, B. ROBERTSON, J. KLUCSARITS, K. MCCARTY, AND K.L. BILDSTEIN. 2005. Results from a long-term nest-box program for American Kestrels: implications for improved population monitoring and conservation. Journal of Field Ornithology 76: 217-226.

KÉRY, M. 2008. Estimating Abundance From Bird Counts: Binomial Mixture Models Uncover Complex Covariate Relationships. Auk 125: 336-345.

KOCHERT, M.N. AND K. STEENHOF. 2002. Golden Eagles in the U.S. and Canada: status, trends, and conservation challenges. Journal of Raptor Research 36: 32-40.

LANZONE, M., T. MILLER, P. TURK, D. BRANDES, C. HALVERSON, C. MAISONNEUVE, J. TREMBLAY, J. COOPER, K. O'MALLEY, R. BROOKS AND T. KATZNER. 2012. Flight responses by a migratory soaring raptor to changing meteorological conditions. Biology Letters 8: 710-713.

LEWIS, S.A. AND W.R. GOULD. 2000. Survey Effort Effects on Power to Detect Trends in Raptor Migration Counts. Wildlife Society Bulletin 28: 317-329.

LINK, W.A. AND J.D. NICHOLS. 1994. On the Importance of Sampling Variation to Investigations of Temporal Variation in Animal Population Size. Oikos 69: 539-544.

LINK, W.A. AND J.R. SAUER. 1998. Estimating Population Change from Count Data: Application to the North American Breeding Bird Survey. Ecological Applications 8: 258-268. 
LINK, W.A., R.J. BARKER, J.R. SAUER, AND S. DROEGE. 1994. Within-Site Variability in Surveys of Wildlife Populations. Ecology 75: 1097-1108.

MADDERS, M. AND D.P. WHITFIELD. 2006. Upland raptors and the assessment of wind farm impacts. Ibis 148: 43-56.

MARGALIDA, A., D. ORO, A. CORTÉS-AVIZANDA, R. HEREDIA, AND J.A. DONÁZAR. 2011. Misleading Population Estimates: Biases and Consistency of Visual Surveys and Matrix Modeling in the Endangered Bearded Vulture. PLOS ONE 6: 1-5.

MCCAFFERY, B.J. AND C. MCINTYRE. 2005. Disparities between Results and Conclusions: Do Golden Eagles Warrant Special Concern Based on Migration Counts in the Western United States? Condor 107: 469-473.

MEHUS, S. AND M. MARTELL. 2010. A Wintering Population of Golden Eagles in Southwestern Wisconsin and Southeastern Minnesota. Passenger Pigeon 72: 135-141.

MESINGER, F., G. DIMEGO, E. KALNAY, K. MITCHELL, P.C. SHAFRAN, W. EBISUZAKI, D. JOVIC, AND OTHERS. 2006. North American Regional Reanalysis: a long-term, consistent, high-resolution climate dataset for the North American domain, as a major improvement upon the earlier global reanalysis datasets in both resolution and accuracy. Bulletin of the American Meteorological Society 87: 343-360.

MICROSOFT CORPORATION. 2010. Visual C\# v. 4.0: .NET Framework Integrated Development Environment, Microsoft Visual Studio 2010. Microsoft Corporation, Redmond, Washington, USA.

MILLER, T.A. 2012. Movement Ecology of Golden Eagles (Aquila chrysaetos) in Eastern North America (Dissertation). The Pennsylvania State University Press, State College, Pennsylvania, USA.

MILLER, T.A., R.P. BROOKS, M. LANZONE, D. BRANDES, J. COOPER, K. O'MALLEY, C. MAISONNEUVE, J. TREMBLAY, A. DUERR, AND T. KATZNER. 2014. Assessing Risk to Birds from Industrial Wind Energy Development via Paired Resource Selection Models. Conservation Biology. doi: 10.1111/cobi.12227.

MILLSAP, B.A. AND S.L. VANA. 1984. Distribution of wintering Golden Eagles in the eastern United States. Wilson Bulletin 94: 692-701.

MORNEAU, F., S. BRODEUR, R. DECARIE, AND D.M. BIRD. 1994. Abundance and distribution of Golden Eagles in Hudson Bay, Québec. Journal of Raptor Research 28: 220-225.

MULDER, R.A., P. GUAY, M. WILSON, AND G. COULSON. 2010. Citizen science: recruiting residents for studies of tagged urban wildlife. Wildlife Research 37: 440-446. 
NAGY, A.C. 1977. Population trend indices based on 40 years of autumn counts at Hawk Mountain Sanctuary in northeastern Pennsylvania. Pages 243-253 in World Conference on Birds of Prey (R.D. Chancellor, Ed.). International Council for Bird Preservation, Cambridge, UK.

NATHAN, R., W.M. GETZ, E. REVILLA, M. HOLYOAK, R. KADMON, D. SALTZ, AND P.E. SMOUSE. 2008. A movement ecology paradigm for unifying organismal movement research. Proceedings of the National Academy of Sciences 105: 1905219059.

NIELSON, R.M., T. RINTZ, L.L. MCDONALD, AND T.L. MCDONALD. 2011. Results of the 2010 survey of Golden Eagles (Aquila chrysaetos) in the Western United States. Western EcoSystems Technology, Inc., Cheyenne, Wyoming, USA.

NOLTE, E. 2012. Raptors Present but Unobserved: Detectability at a Western Migration Watch-Site and its Effect on Trend Analysis (Thesis). Boise State University Press, Boise, Idaho, USA.

OMBALSKI, D., AND D. BRANDES. 2010. Golden Eagle (Aquila chrysaetos). In Terrestrial Vertebrates of Concern in Pennsylvania: A Guide to Conservation, Management, and Research, (M. A. Steele, M.C. Brittingham, T.J. Maret, J.F. Merritt, Eds.). Johns Hopkins University Press, Baltimore, Maryland, USA. 528pp.

PAGEL, J.E., K.J. KRITZ, B.A. MILLSAP, R.K. MURPHY, E.L. KERSHNER, AND S. COVINGTON. 2013. Bald Eagle and Golden Eagle Mortalities at Wind Energy Facilities in the Contiguous United States. Journal of Raptor Research 47: 311-315.

RODRÍGUEZ-ESTRELLA, R., J.A. DONÁZAR, AND F. HIRALDO. 1998. Raptors as Indicators of Environmental Change in the Scrub Habitat of Baja California Sur, Mexico. Conservation Biology 12: 921-925.

SATTLER, G. AND J. BART. 1984. Reliability of counts of migrating raptors: an experimental analysis. Journal of Field Ornithology 55: 415-423.

SCHWARZ, C.J. AND A.N. ARNASON. 2013. Jolly-Seber models in MARK. Pages 12.112.52 in Program MARK: A Gentle Introduction no. 12 (E.G. Cooch and G.C. White, Eds.). Online at: <http://www.phidot.org/software/mark/docs/book/> (Last accessed 15 February 2014).

SCHWARZ, C.J. AND G.A.F. SEBER. 1999. Estimating Animal Abundance: Review III. Statistical Science 14: 427-456.

SEBER, G.A.F. 1965. A note on the multiple recapture census. Biometrika 52: 249-259.

SEBER, G.A.F. 1986. A Review of Estimating Animal Abundance. Biometrics 42: 267-292. 
SERGIO, F., I. NEWTON, AND L. MARCHESI. 2005. Top predators and biodiversity. Nature 436: 192.

SERGIO, F., I. NEWTON, AND L. MARCHESI. 2008. Top predators and biodiversity: much debate, few data. Journal of Applied Ecology 45: 992-999.

SERGIO, F., I. NEWTON, L. MARCHESI, AND P. PEDRINI. 2006. Ecologically justified charisma: preservation of top predators delivers biodiversity conservation. Journal of Applied Ecology 43: 1049-1055.

SILVERTOWN, J. 2009. A new dawn for citizen science. Trends in Ecology and Evolution 24: 467-471.

SMALLWOOD, K.S. AND C. THELANDER. 2008. Bird mortality in the Altamont Pass Wind Resource Area, California. Journal of Wildlife Management 72: 215-223.

SMITH, J.P., C.J. FARMER, S.W. HOFFMAN, G.S. KALTENECKER, K.Z. WOODRUFF, AND P. SHERRINGTON. 2008. Trends in autumn counts of migratory raptors in eastern North America, 1983-2005. Pages 217-252 in State of North America's Birds of Prey, Series in Ornithology no. 3 (K.L. Bildstein, J.P. Smith, E. Ruelas Inzunza, and R.R. Veit, Eds.). Nuttall Ornithological Club, Cambridge, Massachusetts and American Ornithologists' Union, Washington, District of Columbia, USA.

TETER, S., A. KHALILIEH, E. ASHWORTH, AND S. WAMITI. 2003. Ridge Adherence in Golden Eagles Migrating along the Kittatinny Ridge between Bake Oven Knob and Hawk Mountain Sanctuary, Pennsylvania, Autumn 2000-2002. American Hawkwatcher 29: 9-14.

THOGMARTIN, W.E., F.P. HOWE, F.C. JAMES, D.H. JOHNSON, E.T. REED, J.R. SAUER, AND F.R. THOMPSON, III. 2006. A Review of the Population Estimation Approach of the North American Landbird Conservation Plan. Auk 123: 892-904.

THORUP, K., M. FULLER, T. ALERSTAM, M. HAKE, N. KJELLÉN, AND R. STRANDBERG. 2006. Do migratory flight paths of raptors follow constant geographical or geomagnetic courses? Animal Behavior 72: 875-880.

UNITED STATES DEPARTMENT OF INTERIOR. 2013. Eagle Permits: Changes in the Regulations Governing Eagle Permitting. Federal Register 78(236): 73704-73725. Docket no. FWS-R9-MB-2011-0054; FF09M21200-134-FXMB1231099BPP0.

UNITED STATES FISH AND WILDLIFE SERVICE. 2013. Eagle Conservation Plan Guidance: Module 1- Land-based Wind Energy, Version 2. U.S. Fish and Wildlife Service, Washington, District of Columbia, USA. 118pp.

WATSON, J. 2010. The Golden Eagle. T\&AD Poyser, London, UK. 448pp. 
WHITE, G.C. AND K.P. BURNHAM. 1999. Program MARK: survival estimation from populations of marked animals. Bird Study 46: 1-138.

WHITFIELD, D.P., A.H. FIELDING, D.R.A. MCLEOD, P.F. HAWORTH, AND J. WATSON. 2006. A conservation framework for the golden eagle in Scotland: Refining condition targets and assessment of constraint influences. Biological Conservation 130: 465-480.

YOCCUZ, N.G., J. D. NICHOLS, AND T. BOULINIER. 2001. Monitoring of biological diversity in space and time. Trends in Ecology and Evolution 16: 446-453.

ZALLES, J.I. AND K.L. BILDSTEIN, Eds. 2000. Raptor Watch: A global directory of raptor migration sites. BirdLife International, Conservation Series No. 9, Cambridge, UK and Hawk Mountain Sanctuary, Kempton, Pennsylvania, USA. 419pp. 


\section{TABLES}

Table 2-1. Candidate model set, parameter descriptions, and biological interpretations of parameters in POPAN Jolly-Seber markrecapture.

\begin{tabular}{|c|c|c|c|c|}
\hline Model Description & Apparent Survival, $\Phi$ & Detection Rate, $p$ & System Entry, pent & Local Population Size, $N$ \\
\hline Fully time-dependent & Site-dependent & Site-dependent & Site-dependent & Site-dependent \\
\hline$\Phi(\mathrm{t}) p(\mathrm{t}) \operatorname{pent}(\mathrm{t}) N(\mathrm{t})$ & $\begin{array}{l}\text { Eagles do not adhere to } \\
\text { ridgeline }\end{array}$ & $\begin{array}{l}\text { Detection rate } \\
\text { varies among sites }\end{array}$ & $\begin{array}{l}\text { Entry into system } \\
\text { differs between sites }\end{array}$ & $\begin{array}{l}\text { Local abundance varies } \\
\text { by site }\end{array}$ \\
\hline Constant apparent survival & Constant & Site-dependent & Site-dependent & Site-dependent \\
\hline$\Phi() p.(\mathrm{t}) \operatorname{pent}(\mathrm{t}) N(\mathrm{t})$ & $\begin{array}{l}\text { Eagles adhere to the } \\
\text { ridgeline }\end{array}$ & $\begin{array}{l}\text { Detection rate } \\
\text { varies among sites }\end{array}$ & $\begin{array}{l}\text { Entry into system } \\
\text { differs between sites }\end{array}$ & $\begin{array}{l}\text { Local abundance varies } \\
\text { by site }\end{array}$ \\
\hline Constant system entry & Site-dependent & Site-dependent & Constant & Site-dependent \\
\hline$\Phi(\mathrm{t}) p(\mathrm{t}) \operatorname{pent}() N.(\mathrm{t})$ & $\begin{array}{l}\text { Eagles do not adhere to } \\
\text { ridgeline }\end{array}$ & $\begin{array}{l}\text { Detection rate } \\
\text { varies among sites }\end{array}$ & $\begin{array}{l}\text { Entry into system is } \\
\text { the same between sites }\end{array}$ & $\begin{array}{l}\text { Local abundance varies } \\
\text { by site }\end{array}$ \\
\hline Constant survival, entry, and & Constant & Site-dependent & Constant & Constant \\
\hline$\Phi() p.(\mathrm{t}) \operatorname{pent}() N.()$. & $\begin{array}{l}\text { Eagles adhere to the } \\
\text { ridgeline }\end{array}$ & $\begin{array}{l}\text { Detection rate } \\
\text { varies among sites }\end{array}$ & $\begin{array}{l}\text { Entry into system is } \\
\text { the same between sites }\end{array}$ & $\begin{array}{l}\text { Local abundance does } \\
\text { not vary by site }\end{array}$ \\
\hline
\end{tabular}


Table 2-2. Model summaries and ranks for different, POPAN Jolly-Seber model sets. The capture history type corresponds to both how we estimated time windows ("timing criterion," using ridgeline distance and mean flight speed for slope-soaring eagles; Duerr et al., 2012) and whether or not we included age class information ("aging criterion," from historic hawk-count data) to match individual eagles and construct unique capture histories. Parameters in POPAN Jolly-Seber are probability of apparent survival $(\Phi)$, system entry (pent), recapture $(p)$, and estimated superpopulation size $(N)$. We modeled the parameters either constant (.) or variable (t) with respect to hawk-count site. All candidate models included detection probability $(p)$ varying with site.

\begin{tabular}{|c|c|c|c|c|c|}
\hline Capture History Type & Model Description & Delta AIC $c$ & AIC $c$ Weight & Model Likelihood & No. Parameters \\
\hline A) $1 \mathrm{SE}$ timing criterion & $\Phi(\mathrm{t}) \operatorname{pent}() N.(\mathrm{t})$ & 0.0 & 0.996 & 1.000 & 19 \\
\hline \multirow[t]{3}{*}{ With aging criterion } & $\Phi(.) \operatorname{pent}(\mathrm{t}) N(\mathrm{t})$ & 11.1 & 0.004 & 0.004 & 18 \\
\hline & $\Phi(\mathrm{t}) \operatorname{pent}(\mathrm{t}) N(\mathrm{t})$ & 17.3 & 0.000 & 0.000 & 20 \\
\hline & $\Phi(.) \operatorname{pent}() N.()$. & 113.1 & 0.000 & 0.000 & 8 \\
\hline B) $1 \mathrm{SE}$ timing criterion & $\Phi(.) \operatorname{pent}(\mathrm{t}) N(\mathrm{t})$ & 0.0 & 0.542 & 1.000 & 18 \\
\hline \multirow[t]{3}{*}{ Without aging criterion } & $\Phi(\mathrm{t}) \operatorname{pent}() N.(\mathrm{t})$ & 0.7 & 0.387 & 0.714 & 19 \\
\hline & $\Phi(\mathrm{t}) \operatorname{pent}(\mathrm{t}) N(\mathrm{t})$ & 4.1 & 0.071 & 0.132 & 20 \\
\hline & $\Phi(.) \operatorname{pent}() N.()$. & 589.5 & 0.000 & 0.000 & 8 \\
\hline C) $2 \mathrm{SE}$ timing criterion & $\Phi(.) \operatorname{pent}(\mathrm{t}) N(\mathrm{t})$ & 0.0 & 0.551 & 1.000 & 18 \\
\hline \multirow[t]{3}{*}{ Without aging criterion } & $\Phi(\mathrm{t}) \operatorname{pent}() N.(\mathrm{t})$ & 0.8 & 0.377 & 0.684 & 19 \\
\hline & $\Phi(\mathrm{t}) \operatorname{pent}(\mathrm{t}) N(\mathrm{t})$ & 4.1 & 0.073 & 0.132 & 20 \\
\hline & $\Phi(.) \operatorname{pent}() N.()$. & 527.3 & 0.000 & 0.000 & 8 \\
\hline D) $4 \mathrm{SE}$ timing criterion & $\Phi(.) \operatorname{pent}(\mathrm{t}) N(\mathrm{t})$ & 0.0 & 0.669 & 1.000 & 18 \\
\hline \multirow[t]{3}{*}{ Without aging criterion } & $\Phi(\mathrm{t}) \operatorname{pent}() N.(\mathrm{t})$ & 2.0 & 0.243 & 0.363 & 19 \\
\hline & $\Phi(\mathrm{t}) \operatorname{pent}(\mathrm{t}) N(\mathrm{t})$ & 4.1 & 0.088 & 0.132 & 20 \\
\hline & $\Phi(.) \operatorname{pent}() N.()$. & 48.7 & 0.000 & 0.000 & 8 \\
\hline E) $6 \mathrm{SE}$ timing criterion & $\Phi(.) \operatorname{pent}(\mathrm{t}) N(\mathrm{t})$ & 0.0 & 0.840 & 1.000 & 18 \\
\hline \multirow[t]{3}{*}{ Without aging criterion } & $\Phi(\mathrm{t}) \operatorname{pent}(\mathrm{t}) N(\mathrm{t})$ & 4.1 & 0.110 & 0.132 & 20 \\
\hline & $\Phi(\mathrm{t}) \operatorname{pent}() N.(\mathrm{t})$ & 5.7 & 0.049 & 0.058 & 19 \\
\hline & $\Phi(.) \operatorname{pent}() N.()$. & 285.3 & 0.000 & 0.000 & 8 \\
\hline
\end{tabular}


Table 2-3. Summary of the real estimates for detectability (mean \pm SE; 95\% CI) per candidate set (Table 2-2). When we exclude the aging criterion, mean detectability increases as the timing criterion increases.

\begin{tabular}{|llll|}
\hline Capture History Type & Low Detection & Mean Detection & High Detection \\
\hline $\begin{array}{l}\text { A) 1 SE timing criterion } \\
\text { With aging criterion }\end{array}$ & 0.0422 & 0.0483 & 0.0543 \\
$\begin{array}{l}\text { B) 1 SE timing criterion } \\
\text { Without aging criterion }\end{array}$ & 0.0620 & 0.0720 & 0.0780 \\
$\begin{array}{l}\text { C) 2 SE timing criterion } \\
\text { Without aging criterion }\end{array}$ & 0.0614 & 0.0728 & 0.0842 \\
$\begin{array}{l}\text { D) } 4 \text { SE timing criterion } \\
\text { Without aging criterion }\end{array}$ & 0.0821 & 0.0920 & 0.1020 \\
$\begin{array}{l}\text { E) 6 SE timing criterion } \\
\text { Without aging criterion }\end{array}$ & 0.0984 & & 0.1208 \\
\hline
\end{tabular}

${ }^{\mathrm{a}}$ Detection rates based on model-averaging the real estimates of $p$ per candidate set. 
Table 2-4. November estimates of population size (mean ( $\pm \mathrm{SE})$; 95\% CI) per year based on the derived estimates of the top-ranked model in candidate set A and the model-averaged, derived estimates in candidate set B (Table 2-2), both with capture histories using the $1 \mathrm{SE}$ timing criterion.

\begin{tabular}{|lllllllllll|}
\hline Year & 2002 & 2003 & 2004 & 2005 & 2006 & 2007 & 2008 & 2009 & 2010 & 2011 \\
\hline Estimate & 823 & 1,469 & 872 & 1,082 & 1,244 & 913 & 1,493 & 673 & 1,086 & 774 \\
With aging criterion & $(116)$ & $(176)$ & $(121)$ & $(141)$ & $(156)$ & $(125)$ & $(178)$ & $(102)$ & $(141)$ & $(112)$ \\
& & & & & & & & & & \\
Estimate & 545 & 919 & 545 & 665 & 756 & 576 & 936 & 421 & 682 & 515 \\
Without aging criterion & $(72)$ & $(105)$ & $(72)$ & $(83)$ & $(91)$ & $(75)$ & $(107)$ & $(61)$ & $(85)$ & $(70)$ \\
\hline
\end{tabular}




\section{FIGURE CAPTIONS}

Figure 2-1. a) Simulation modeling area: the central Appalachian Mountain range in Pennsylvania, USA. b) Mark-recapture modeling area: the Kittatinny Ridge System. Markrecapture sites $(\star)$, from northeast to southwest, are: Little Gap, Bake Oven Knob, Hawk Mountain Sanctuary, Second Mountain, and Waggoner's Gap.

Figure 2-2. Subset of simulated migration routes $(n=3)$ passing an existing hawk-count site to illustrate availability v. detectability. There are three types of eagles in relation to the mean sightability distance (within $3 \mathrm{~km}$ ) for hawk-count observers with respect to eagle availability: an eagle that is both available to be counted and is counted, an eagle that is both available to be counted yet not seen and uncounted, and an eagle that is both unavailable to be counted thus not seen and uncounted. There are two types of eagles in relation to the mean sightability distance for hawk-count observers with respect to eagle detectability: an eagle that is detected (both detectable and counted) and an eagle that is undetected (both detectable yet not seen and uncounted). Detectability does not let us account for eagles that are both undetectable and uncounted beyond the mean sightability distance, so we incorporate availability to do so into our estimation procedure. In this example, for this site, eagle availabilty equals $\sim 67 \%$ (2 / 3 available eagles), while eagle detectability equals 50\% (1 / 2 detectable eagles).

Figure 2-3. Jolly-Seber (POPAN parameterization) mark-recapture model overlaid on select hawk-count sites in the Kittatinny Ridge System, where: pent $\mathrm{i}_{\mathrm{i}-1}$ is the probability of system entry (an influx of new eagles) before each site $(i), p_{\mathrm{i}}$ is the probability of recapture (detection) at each site, $\Phi_{\mathrm{i}}$ is the probability of apparent survival (eagle adherence to the ridgeline) over the interval between sites, and $N$ is the estimated total abundance over the entire study area. 
Figure 2-4. Variation in ten-yr sets $(n=122)$ of estimated population size during November 2002-2011 in Pennsylvania. To estimate population size, we used November data from the following hawk-counts: Allegheny Front, Stone Mountain, Waggoner's Gap, Second Mountain, and Hawk Mountain Sanctuary (Hawk Migration Association of North America 2008). We modeled population size with numerous separate assumptions about eagle availability and detectability. Lowest estimates population size involved highest estimates of detectability and site-specific estimates of availability based on classes of high-, medium-, and low-migration days. Highest estimates of population size involved the lowest estimates of detectability and uniform estimates of availability. 
Figure 2-1.

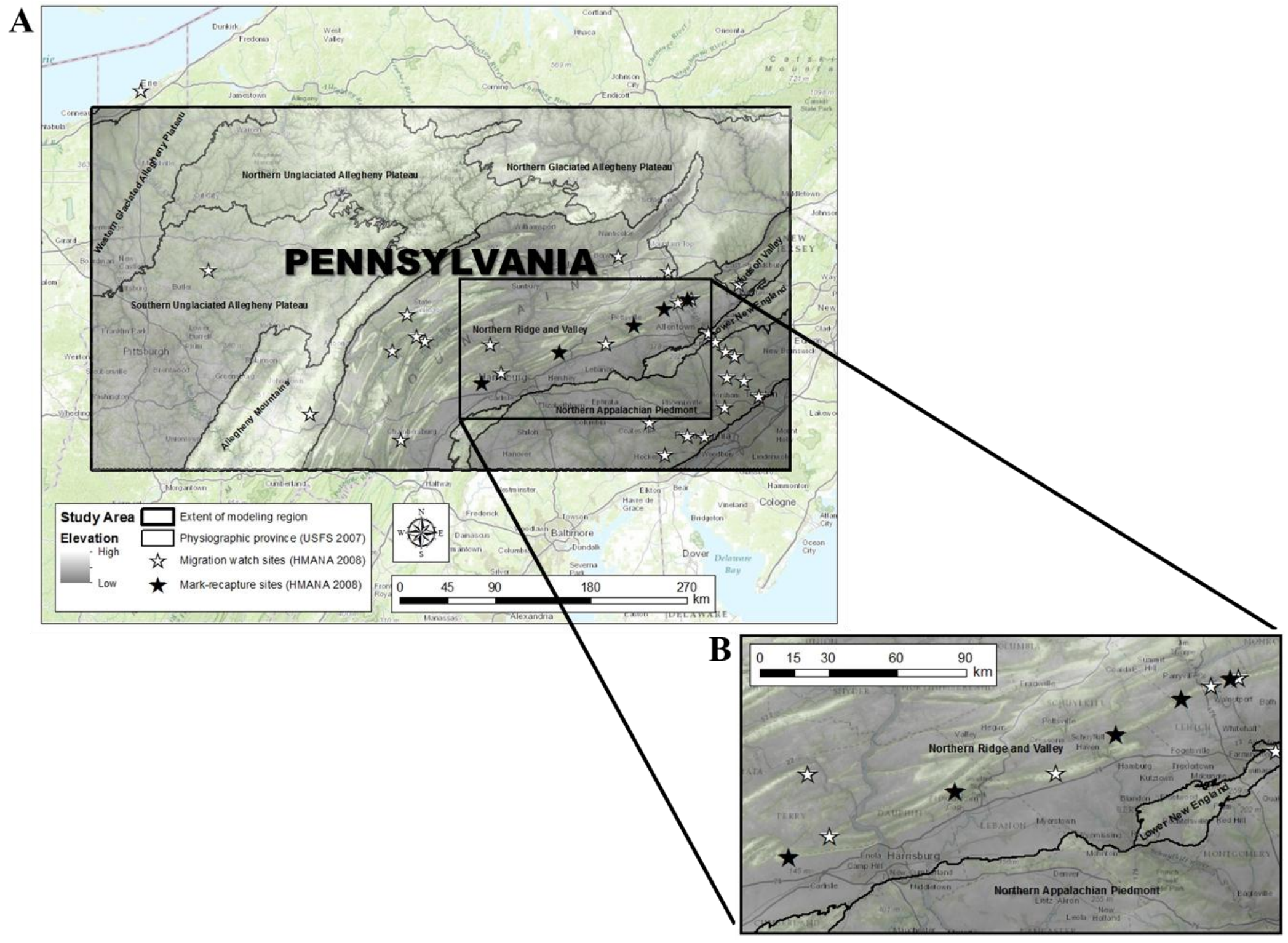


Figure 2-2.

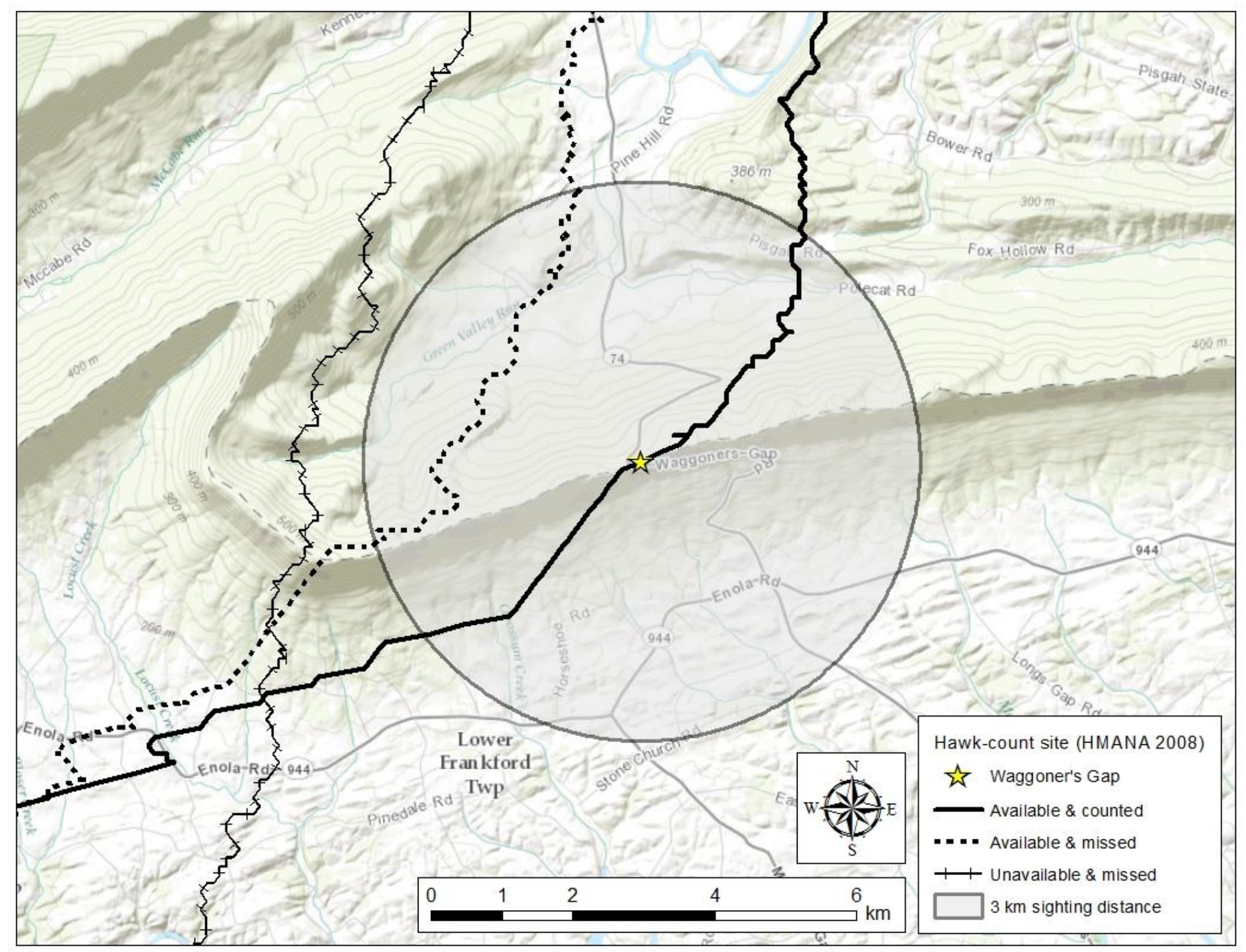


Figure 2-3.

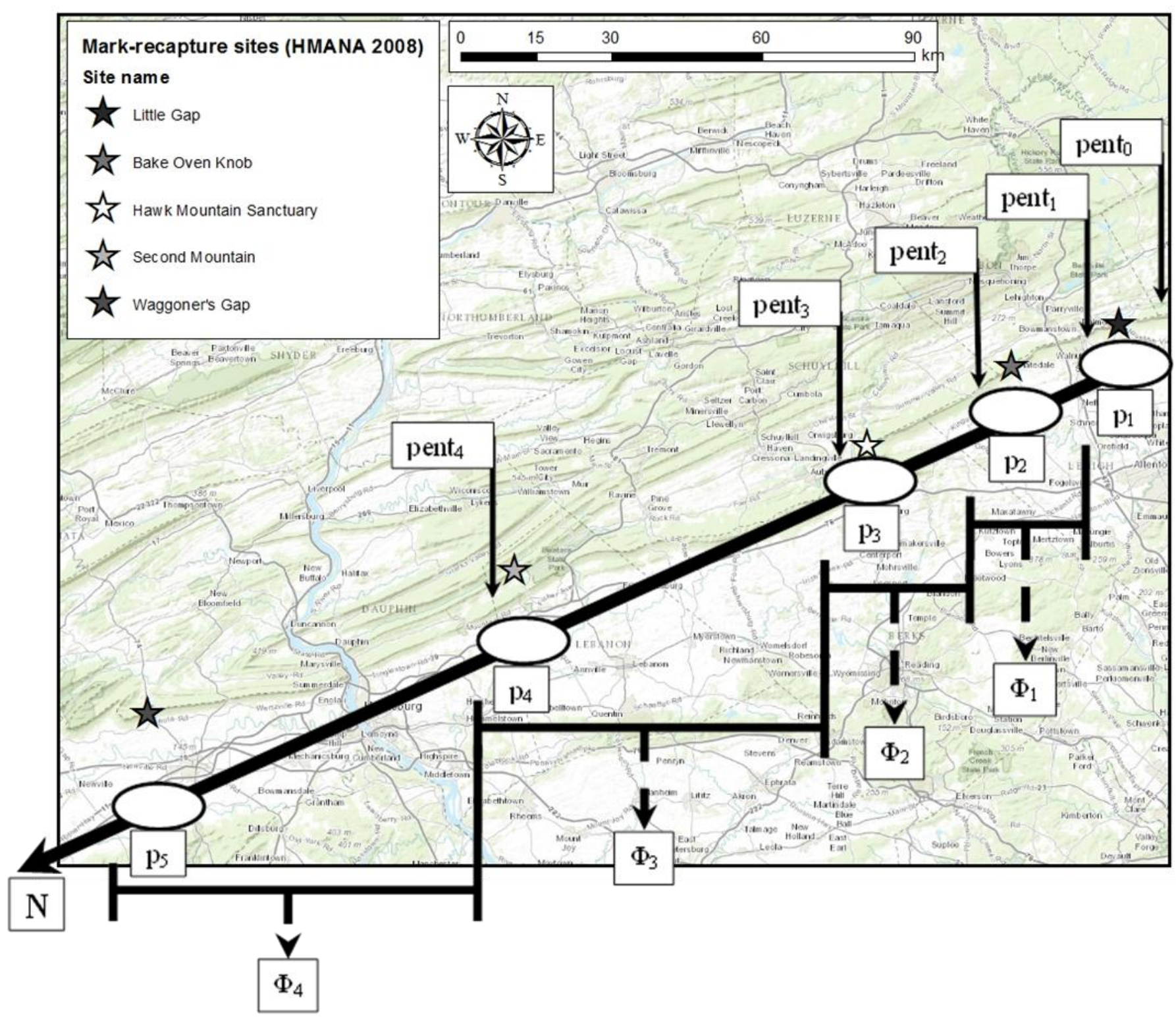




\section{Figure 2-4.}

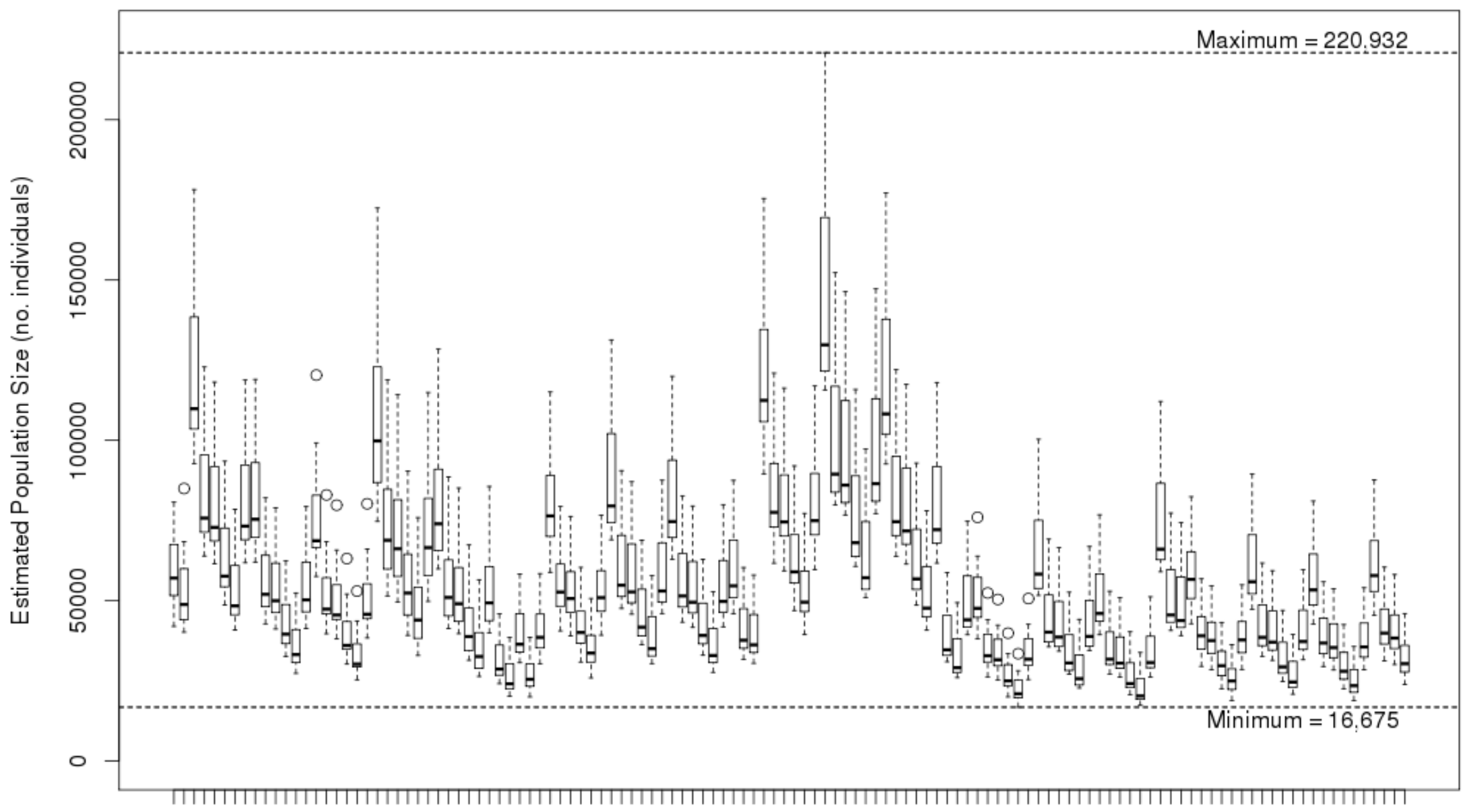

$\begin{array}{lllllllllllllllllllllllll}1 & 5 & 9 & 13 & 18 & 23 & 28 & 33 & 38 & 43 & 48 & 53 & 58 & 63 & 68 & 73 & 78 & 83 & 88 & 93 & 98 & 104 & 110 & 116 & 122\end{array}$

Set of 10-yr Estimates (set no.) 
APPENDICES 


\section{APPENDIX A}

Algorithm steps for the migration model, which simulates flight routes of golden eagles in

Pennsylvania, USA.

\begin{tabular}{|c|c|c|c|c|}
\hline Step 1 & \multicolumn{4}{|c|}{ BASE PROBABILITY GRID } \\
\hline & $\overline{0,0}$ & 0,1 & 0,2 & 0,3 \\
\hline & 1,0 & 0.225 & POSITION & 0.05 \\
\hline & 2,0 & 0.3 & 0.225 & 0.2 \\
\hline & \multicolumn{4}{|c|}{ LIFT GRID: TOTAL LIFT AVAILABLE } \\
\hline & 0,0 & 0,1 & 0,2 & 0,3 \\
\hline & 1,0 & 1 & POSITION & 1 \\
\hline & 2,0 & 1.5 & 3 & 1.5 \\
\hline & Average lift & & & \\
\hline & 1.6 & & & \\
\hline Step 2 & \multicolumn{4}{|c|}{ LIFT DIVIDED BY AVERAGE LIFT } \\
\hline & 0,0 & 0,1 & 0,2 & 0,3 \\
\hline & 1,0 & 0.625 & POSITION & 0.625 \\
\hline & 2,0 & 0.9375 & 1.875 & 0.9375 \\
\hline Step 3 & \multicolumn{4}{|c|}{ MULTIPLY CELLS FROM STEPS $1 \& 2$} \\
\hline & 0,0 & 0,1 & 0,2 & 0,3 \\
\hline & 1,0 & 0.140625 & POSITION & 0.03125 \\
\hline & 2,0 & 0.28125 & 0.421875 & 0.1875 \\
\hline & Sum for step 4 & & & \\
\hline & 1.0625 & & & \\
\hline Step 4 & \multicolumn{4}{|c|}{ NORMALIZATION: TRUE PROBABILITY GRID } \\
\hline & 0,0 & 0,1 & 0,2 & 0,3 \\
\hline & 1,0 & 0.132352941 & POSITION & 0.029411765 \\
\hline & 2,0 & 0.264705882 & 0.397058824 & 0.176470588 \\
\hline Step 5 & \multicolumn{4}{|c|}{ RANGES TO SELECT \# FROM $(0,1)$} \\
\hline & 0,0 & 0,1 & 0,2 & 0,3 \\
\hline & 1,0 & $<=0.1323$ & POSITION & $>0.1323,<=0.1617$ \\
\hline & 2,0 & $>0.1617,<=0.4264$ & $>0.6028,<=1.0000$ & $>0.4264,<=0.6028$ \\
\hline Step 6 & \multicolumn{4}{|c|}{ CHOOSE RANDOM NUMBER $(0,1)$ WHICH DICTATES MOVEMENT TO NEXT CELL } \\
\hline
\end{tabular}




\section{APPENDIX B}

Structure of the "looking ahead" function where, only in areas of low uplift ( $\leq 0 \mathrm{~m} / \mathrm{s}$ ), a simulated eagle can choose a location to move to, from one of four groups (1- orange, 2- red, 3- blue, 4- green) of grid-points, in the southwesterly direction of its current position $(n)$. When this function is applied, the furthest a simulated eagle can move from its current position is $\sim 0.5 \mathrm{~km}$ (yellow arrow). This model behavior mimics eagle flapping flight where an individual uses its visual acuity and perceptability of local uplift to choose an area (ahead) to fly to directly.

\begin{tabular}{|c|c|c|c|c|}
\hline$n-4$ & $n-3$ & $n-2$ & $n-1$ & POSITION $(\boldsymbol{n})$ \\
\hline$n+((1 *$ row $)-4)$ & $n+((1 *$ row $)-3)$ & $n+((1 *$ row $)-2)$ & $n+((1 *$ row $)-1)$ & $n+(1 *$ row $)$ \\
\hline$n+((2 *$ row $)-4)$ & $n+((2 *$ row $)-3)$ & $n+((2 *$ row $)-2)$ & $n+((2 *$ row $)-1)$ & $n+(2 *$ row $)$ \\
\hline$n+((3 *$ row $)-4)$ & $n+((3 *$ row $)-3)$ & $n+((3 *$ row $)-2)$ & $n+((3 *$ row $)-1)$ & $n+(3 *$ row $)$ \\
\hline & $n+((4 *$ row $)-3)$ & $n+((4 *$ row $)-2)$ & $n+((4 *$ row $)-1)$ & $n+(4 *$ row $)$ \\
\hline$n+((4 *$ row $)-4)$ & $n+10$ & \\
\hline
\end{tabular}




\section{APPENDIX C}

Field data collected at sites spread throughout the study area during autumn, peak migration for golden eagles in 2013.

\begin{tabular}{|c|c|c|c|c|c|c|c|c|c|c|c|}
\hline Site name & Site status & Count date & No. observers & Observer hrs & Latitude & Longitude & Elevation $(\mathrm{m})$ & Golden eagles & Bald eagles & Unidentified eagles & Other raptors \\
\hline $\begin{array}{l}\text { Buffalo Road Vista, } \\
\text { Gallitizin State Park }\end{array}$ & Public access & 15 Oct 2013 & 1 & 0.75 & 40.23329 & -78.66141 & 839 & 0 & 0 & 0 & 0 \\
\hline $\begin{array}{l}\text { Shaffer Road, Allegheny } \\
\text { Mountains }\end{array}$ & No public access & 15 Oct 2013 & 1 & 6.033 & 40.10366 & -78.71805 & 807 & 2 & 4 & 0 & 218 \\
\hline Tussey Mountain East & Public access & 16 Oct 2013 & 1 & 2.5 & 40.73666 & -77.84365 & 626 & 0 & 0 & 0 & 0 \\
\hline $\begin{array}{l}\text { Millers Gap Road Tower } \\
\text { Pad }\end{array}$ & Public access & 03 Nov 2013 & 3 & 21 & 40.30250 & -77.06960 & 392 & 1 & 2 & 1 & 19 \\
\hline $\begin{array}{l}\text { Appalachian Trail, Peters } \\
\text { Mountain Road }\end{array}$ & Public access & 08 Nov 2013 & 2 & 10 & 40.41446 & -76.91922 & 402 & 0 & 1 & 1 & 4 \\
\hline $\begin{array}{l}\text { Millers Gap Road Tower } \\
\text { Pad }\end{array}$ & Public access & 08 Nov 2013 & 2 & 2 & 40.30250 & -77.06960 & 392 & 0 & 0 & 0 & 0 \\
\hline $\begin{array}{l}\text { Claysburg Line Lane, } \\
\text { Dunning Mountain }\end{array}$ & Public access & 09 Nov 2013 & 2 & 12 & 40.30397 & -78.43174 & 625 & 3 & 0 & 0 & 15 \\
\hline Swatara State Park Helipad & Public access & 15 Nov 2013 & 1 & 1.5 & 40.52546 & -76.52752 & 364 & 0 & 0 & 0 & 1 \\
\hline Tuscarora Mountain Road & Public access & 16 Nov 2013 & 1 & 4 & 40.43591 & -77.47016 & 587 & 0 & 0 & 0 & 0 \\
\hline $\begin{array}{l}\text { Path Valley Road and } \\
\text { Spring Run Road }\end{array}$ & Public access & 16 Nov 2013 & 1 & 3.5 & 40.16316 & -77.79863 & 586 & 0 & 0 & 0 & 14 \\
\hline $\begin{array}{l}\text { Appalachian Trail, Peters } \\
\text { Mountain Road }\end{array}$ & Public access & 19 Nov 2013 & 1 & 6 & 40.41446 & -76.91922 & 402 & 0 & 2 & 1 & 20 \\
\hline $\begin{array}{l}\text { Buffalo Road Vista, } \\
\text { Gallitizin State Park }\end{array}$ & Public access & 20 Nov 2013 & 1 & 7 & 40.23329 & -78.66141 & 839 & 12 & 1 & 0 & 13 \\
\hline $\begin{array}{l}\text { Buffalo Road Vista, } \\
\text { Gallitizin State Park }\end{array}$ & Public access & 21 Nov 2013 & 2 & 16 & 40.23329 & -78.66141 & 839 & 0 & 0 & 0 & 2 \\
\hline $\begin{array}{l}\text { Skelp Mountain Road, } \\
\text { Brush Mountain }\end{array}$ & No public access & 23 Nov 2013 & 2 & 14.5 & 40.61485 & -78.28840 & 608 & 12 & 2 & 0 & 14 \\
\hline $\begin{array}{l}\text { Lookout Road, Allegheny } \\
\text { Mountains }\end{array}$ & Public access & 30 Nov 2013 & 1 & 9 & 40.56713 & -78.44014 & 781 & 26 & 6 & 0 & 8 \\
\hline $\begin{array}{l}\text { Lookout Road, Allegheny } \\
\text { Mountains }\end{array}$ & Public access & 04 Dec 2013 & 1 & 3 & 40.56713 & -78.44014 & 781 & 0 & 1 & 0 & 1 \\
\hline $\begin{array}{l}\text { Buffalo Road Vista, } \\
\text { Gallitizin State Park }\end{array}$ & Public access & 04 Dec 2013 & 1 & 2 & 40.23329 & -78.66141 & 839 & 0 & 0 & 0 & 1 \\
\hline
\end{tabular}

